\title{
A novel, potent, and drug-like tetrahydroquinazoline inhibitor that is highly selective for human topoisomerase II $\alpha$ over $\beta$
}

Jose Antonio Ortega, ${ }^{\#[a]}$ Jose M. Arencibia, ${ }^{\#[a]}$ Elirosa Minniti, ${ }^{[a, b]}$ Jo Ann W. Byl, ${ }^{[c]}$ Sebastian Franco

Ulloa, ${ }^{[\mathrm{ad}]}$ Marco Borgogno, ${ }^{[\mathrm{a}]}$ Vito Genna, ${ }^{[\mathrm{ad}}$ Maria Summa, ${ }^{[\mathrm{d}]}$ Sine Mandrup Bertozzi, ${ }^{[\mathrm{d}]}$ Rosalia Bertorelli, ${ }^{[\mathrm{d}]}$ Andrea Armirotti, ${ }^{[\mathrm{d}]}$ Anna Minarini, ${ }^{[\mathrm{b}]}$ Claudia Sissi, ${ }^{*[\mathrm{e}]}$ Neil Osheroff, ${ }^{[[\mathrm{c}, \mathrm{f}, \mathrm{g}]}$ Marco De Vivo*[a]

[a] Laboratory of Molecular Modelling and Drug Discovery. Istitutoltaliano di Tecnologia, Via Morego 30, 16163 Genoa, Italy. Dr. Marco De Vivo. E-mail: marco.devivo@iit.it

[b] Department of Pharmacy and Biotechnology. Alma Mater Studiorum-University of Bologna, Via Belmeloro 6, 40126 Bologna, Italy

[c] Department of Biochemistry, Vanderbilt University School of Medicine, Nashville, TN 37232-0146, USA. Prof. Neil Osheroff. E-mail: neil.osheroff@vanderbilt.edu

[d] Analytical Chemistry and Translational Pharmacology, Istitutoltaliano di Tecnologia, Via Morego 30, 16163 Genoa, Italy.

[e] Department of Pharmaceutical and Pharmacological Sciences. University of Padova, Via Marzolo 5, 35131 Padova, Italy

[f] Department of Medicine (Hematology/Oncology), Vanderbilt University School of Medicine, Nashville, TN 37232-6307, USA

[g] VA Tennessee Valley Healthcare System, Nashville, TN 37212, USA,

${ }^{[\#]}$ These authors equally contributed to this work.

${ }^{*}$ Corresponding Author(s) 


\section{Table of Contents}

S1. Main compounds

S2. NMR spectra, UPLC-MS analysis and mass spectrometry of main compounds

S3. Cell Assays
A. Cell lines
B. Cell Viability Assay
C. Immunodetection of $\mathrm{H} 2 \mathrm{AX}$ phosphorylation

S4. Additional Molecular Biology
A. Topoisomerase inhibition
B. Topoll inhibition mechanism characterization of compound 14
Materials
DNA Relaxation
DNA Cleavage
DNA Intercalation
ATP hydrolysis

S5. Virtual screening

S6. Docking calculations

S7. In vitro physicochemical and metabolic stability assay
A. Aqueous kinetic solubility assay.
B. In vitro mouse plasma stability study.
C. In vitro mouse microsomal stability study.

S8. Off target Activity performed at Eurofin (Safety47TM Panel)

S9. Pharmacokinetic studies
A. Plasma profile
B. Brain profile 


\section{S1. Main compounds}

Table S1. Main compounds

\begin{tabular}{|c|c|c|c|c|c|}
\hline Compound & Structure & Compound & Structure & Compound & Structure \\
\hline 1 & & 6 & & 11 & \\
\hline 2 & & 7 & & 12 & \\
\hline 3 & & 8 & & 13 & \\
\hline 4 & & 9 & & 14 & \\
\hline 5 & & 10 & & & \\
\hline
\end{tabular}




\section{S2. NMR spectra of tested compounds}

\section{${ }^{1} \mathrm{H}-\mathrm{NMR}$ Compound 1}

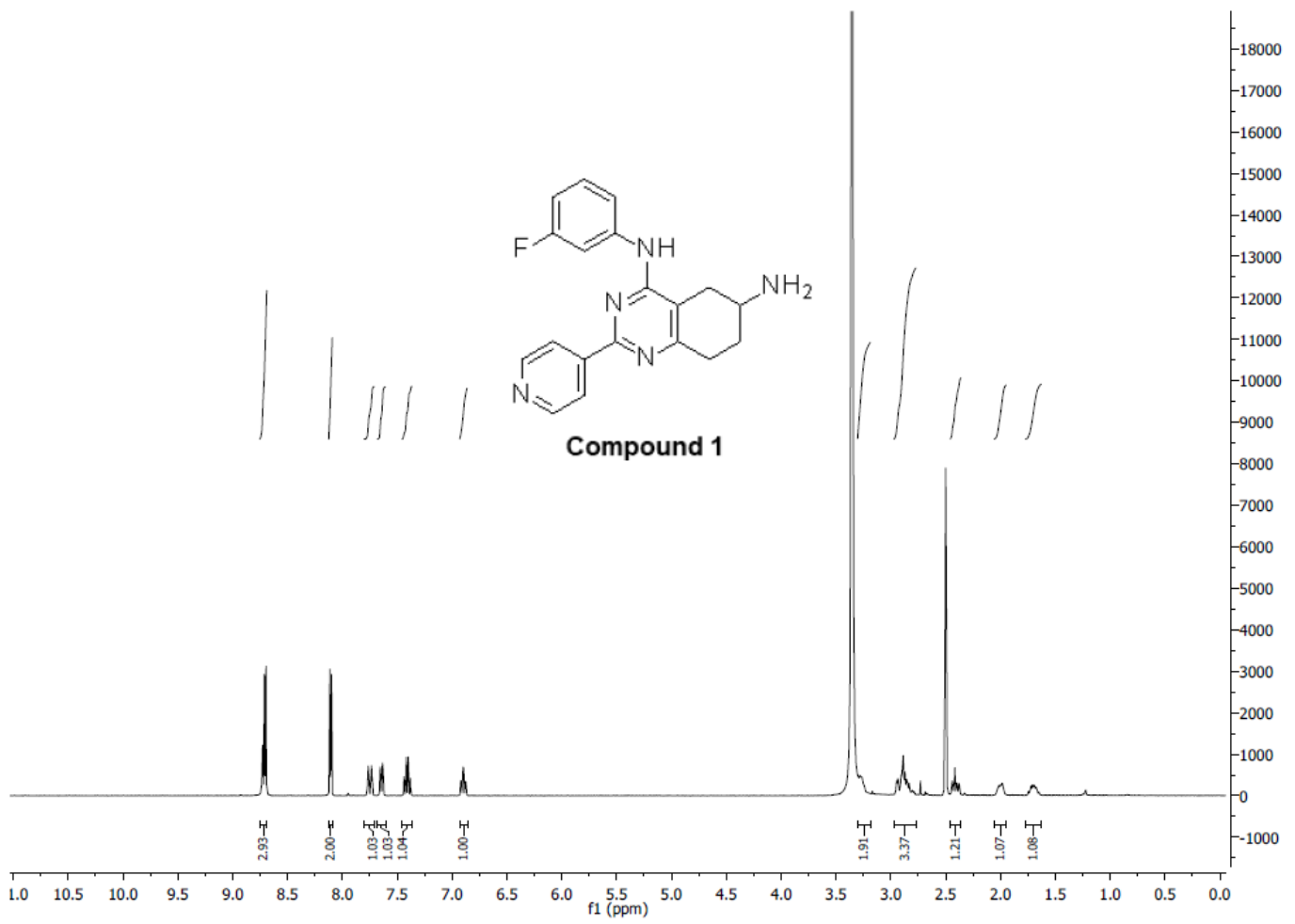

${ }^{13}$ C-NMR Compound 1

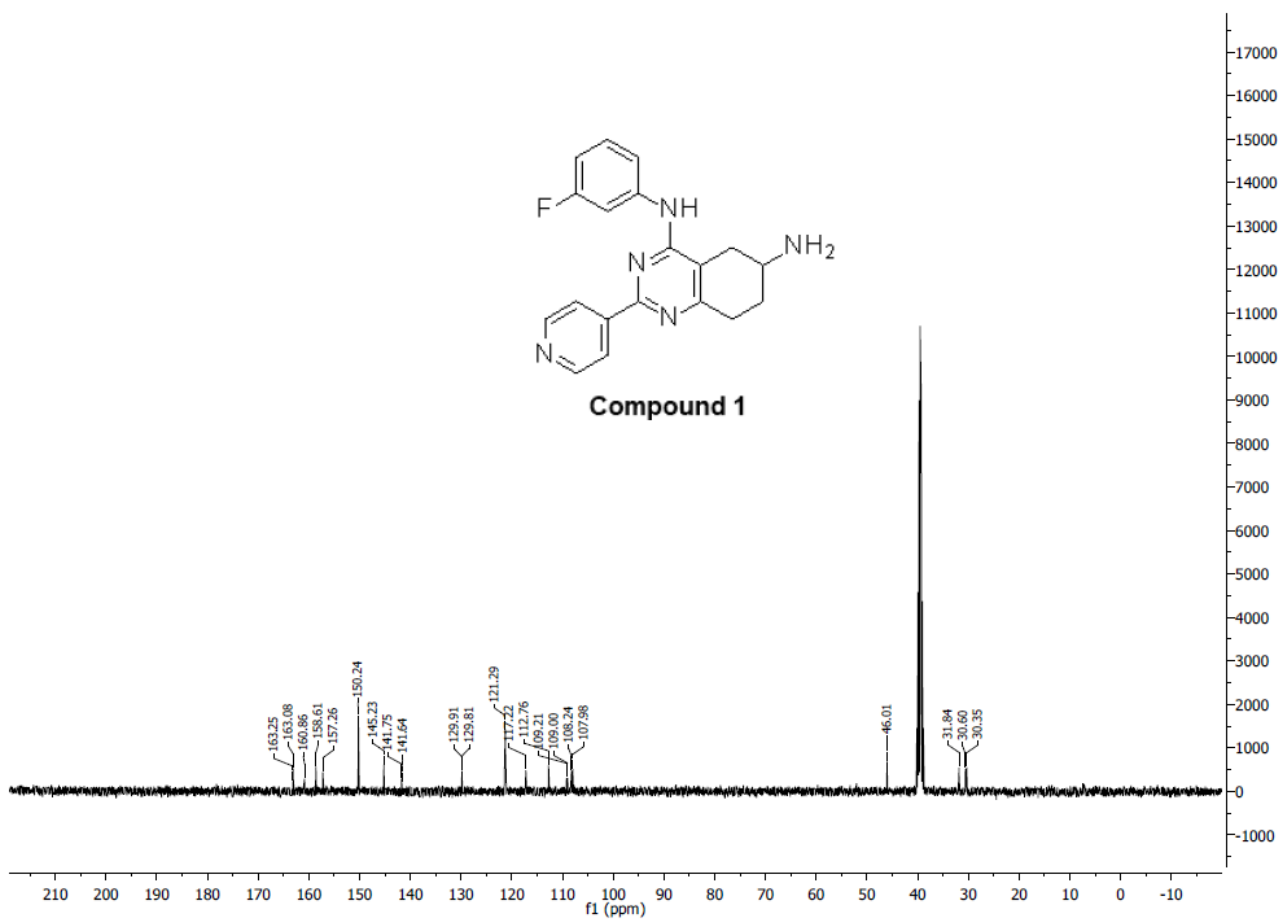




\section{UPLC-MS analysis Compound 1}

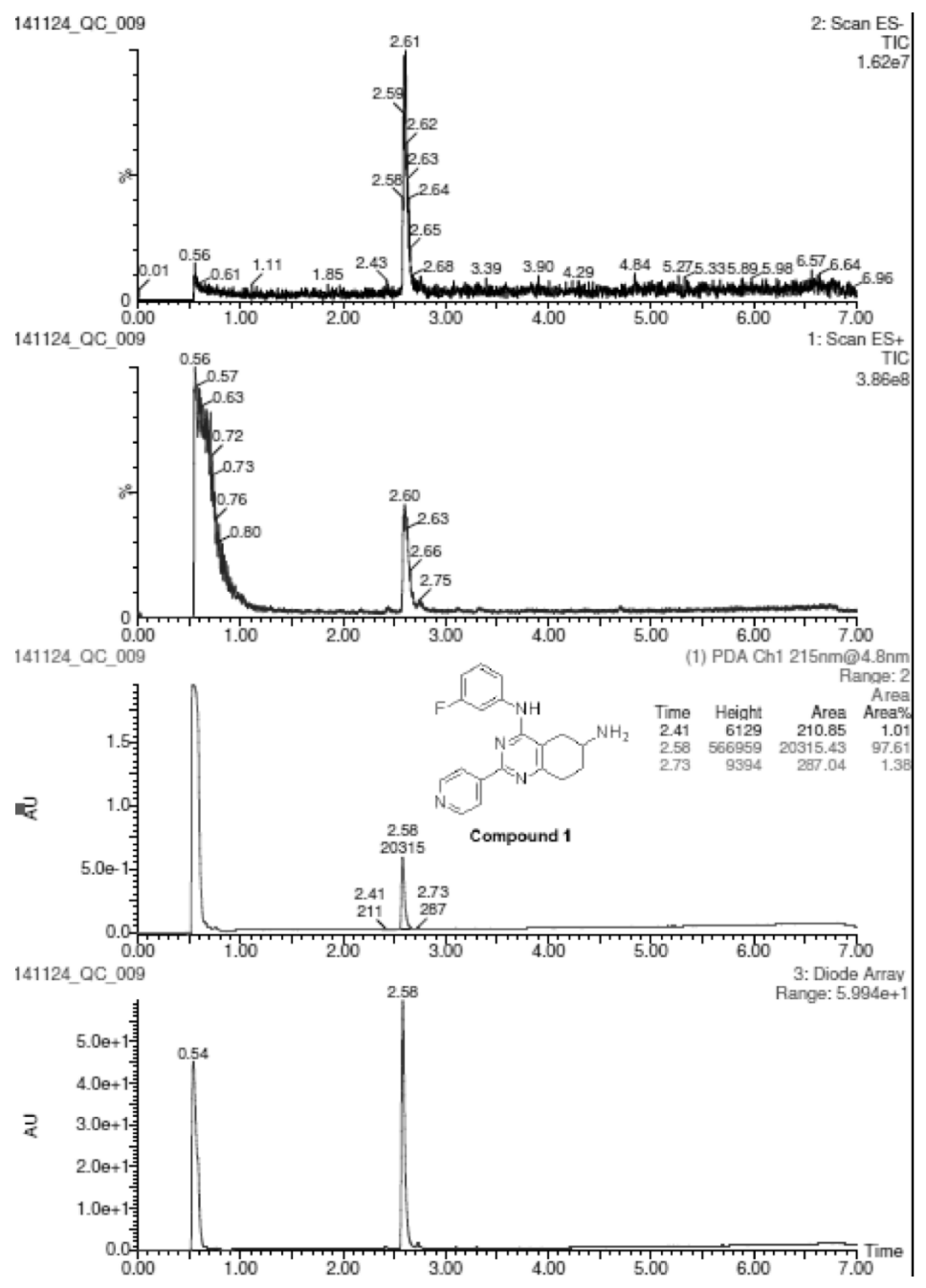

Mass spectrometry spectrum Compound 1

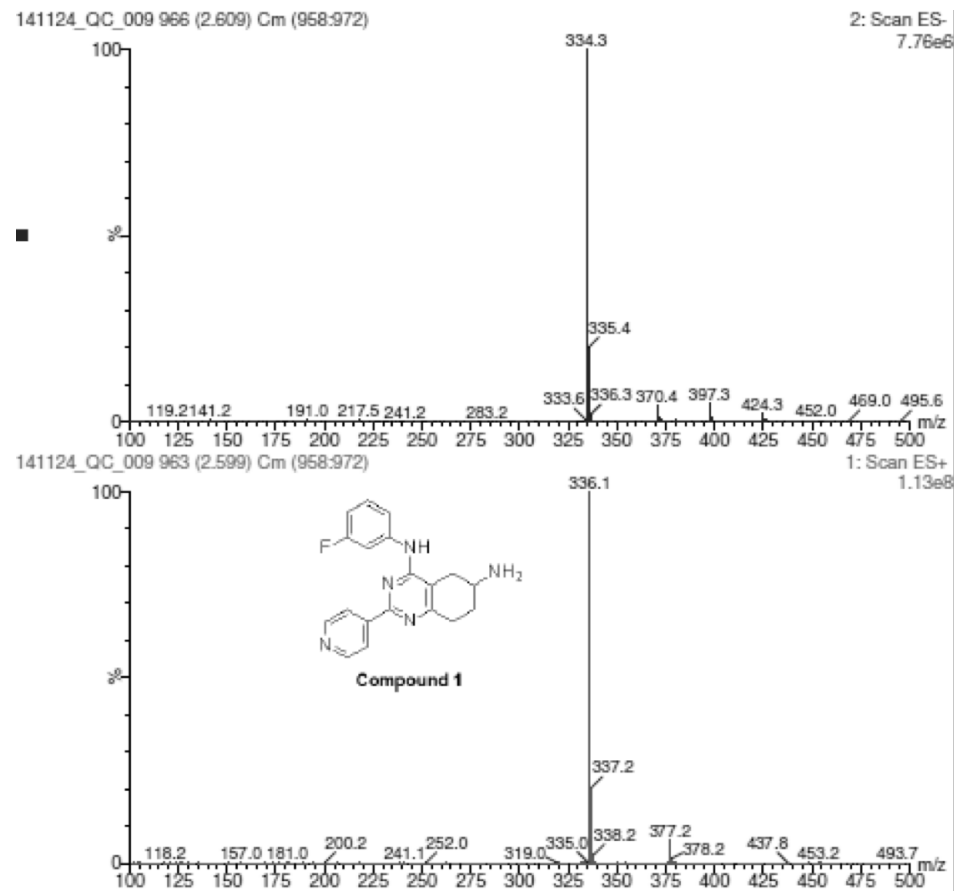


${ }^{1}$ H-NMR Compound 2

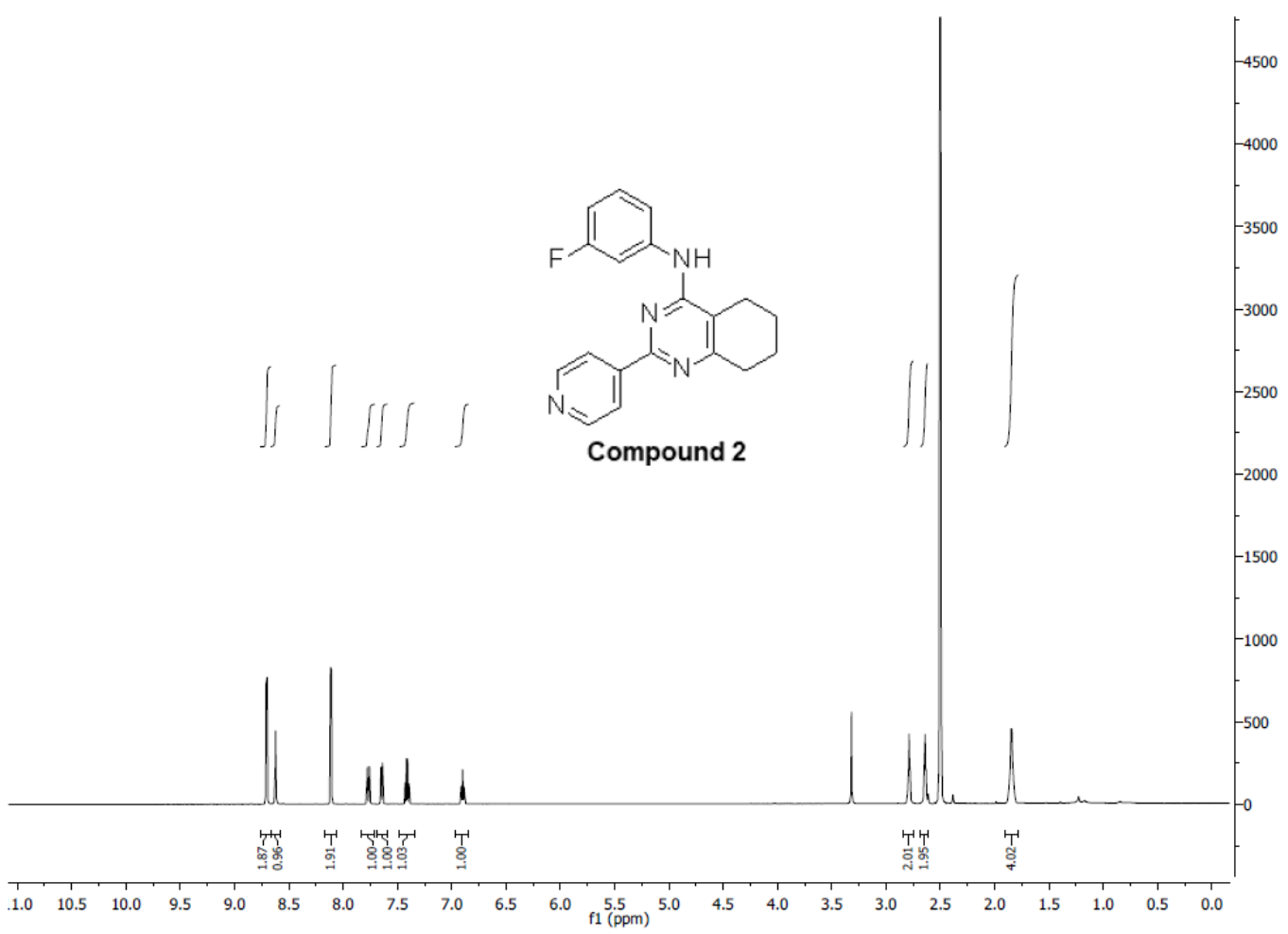

${ }^{13}$ C-NMR Compound 2

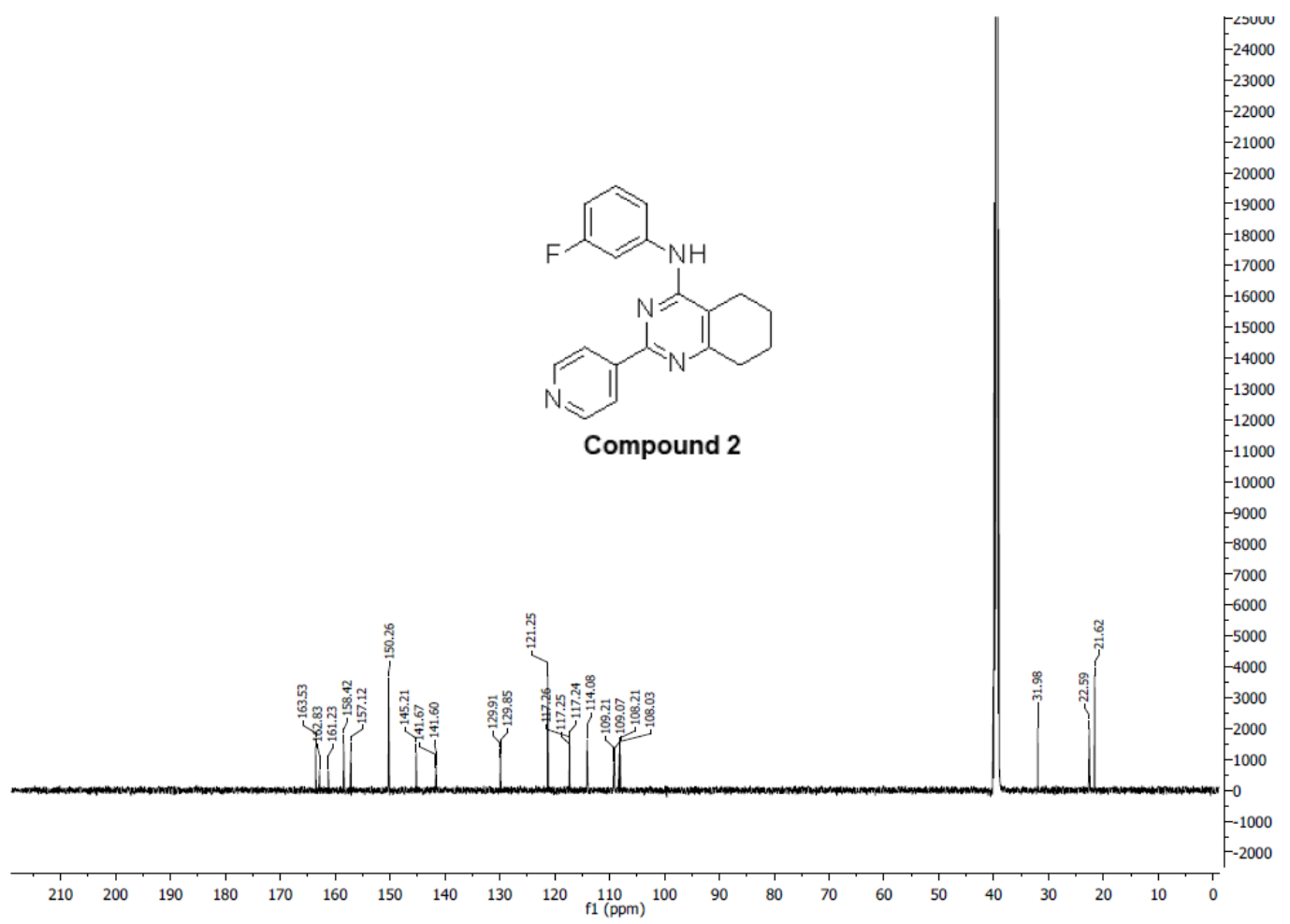


UPLC-MS analysis Compound 2

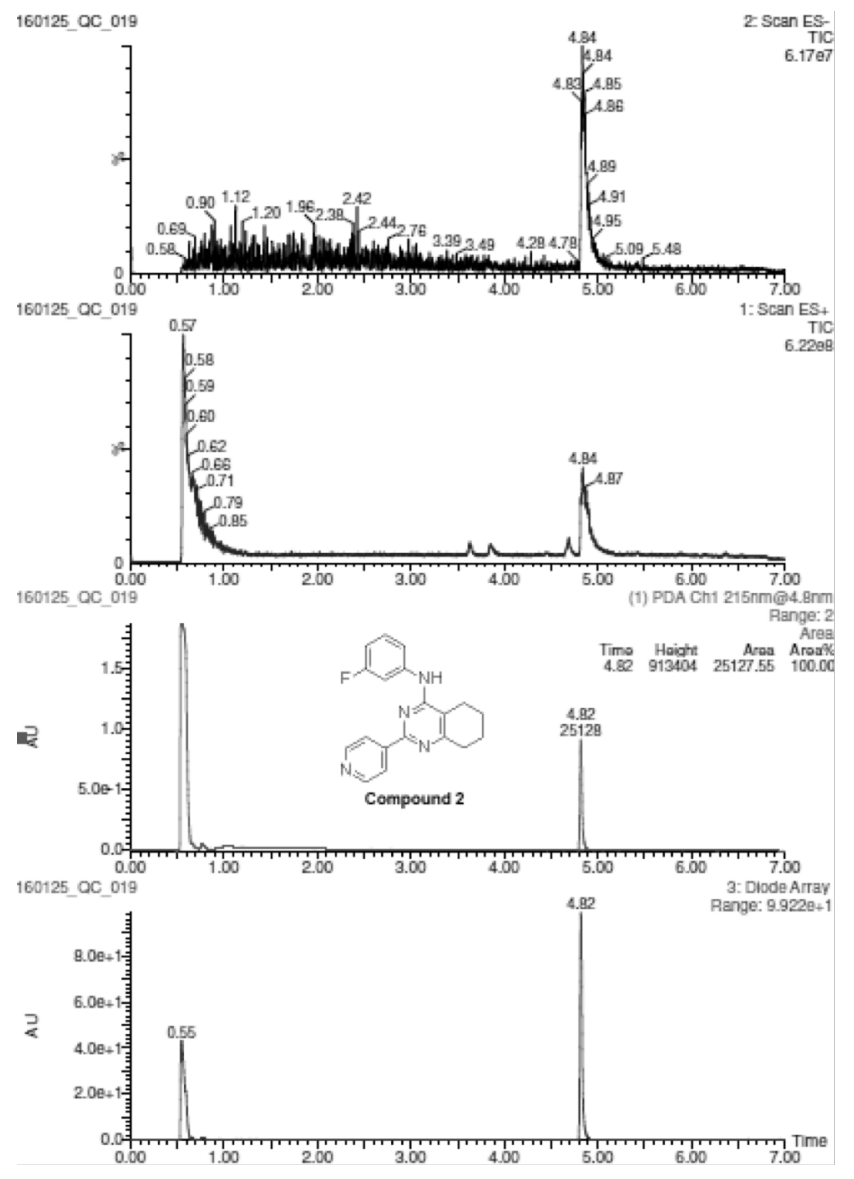

Mass spectrometry spectrum Compound 2

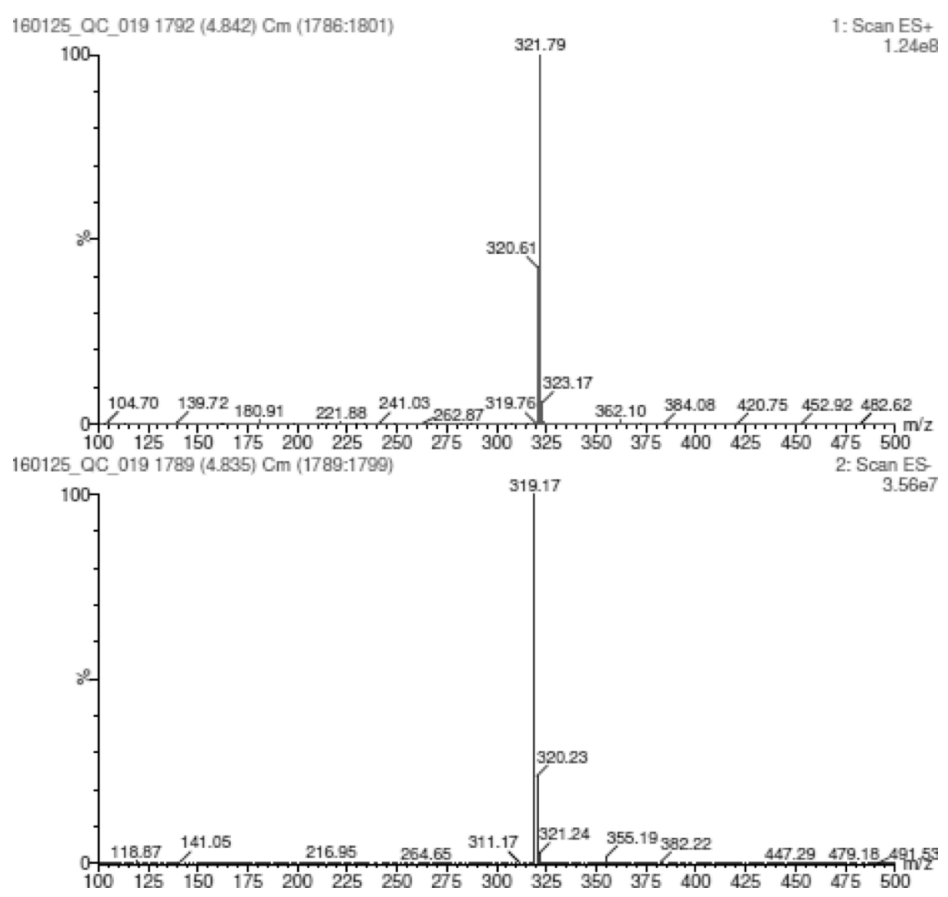




\section{${ }^{1} \mathrm{H}-N M R$ Compound 3}

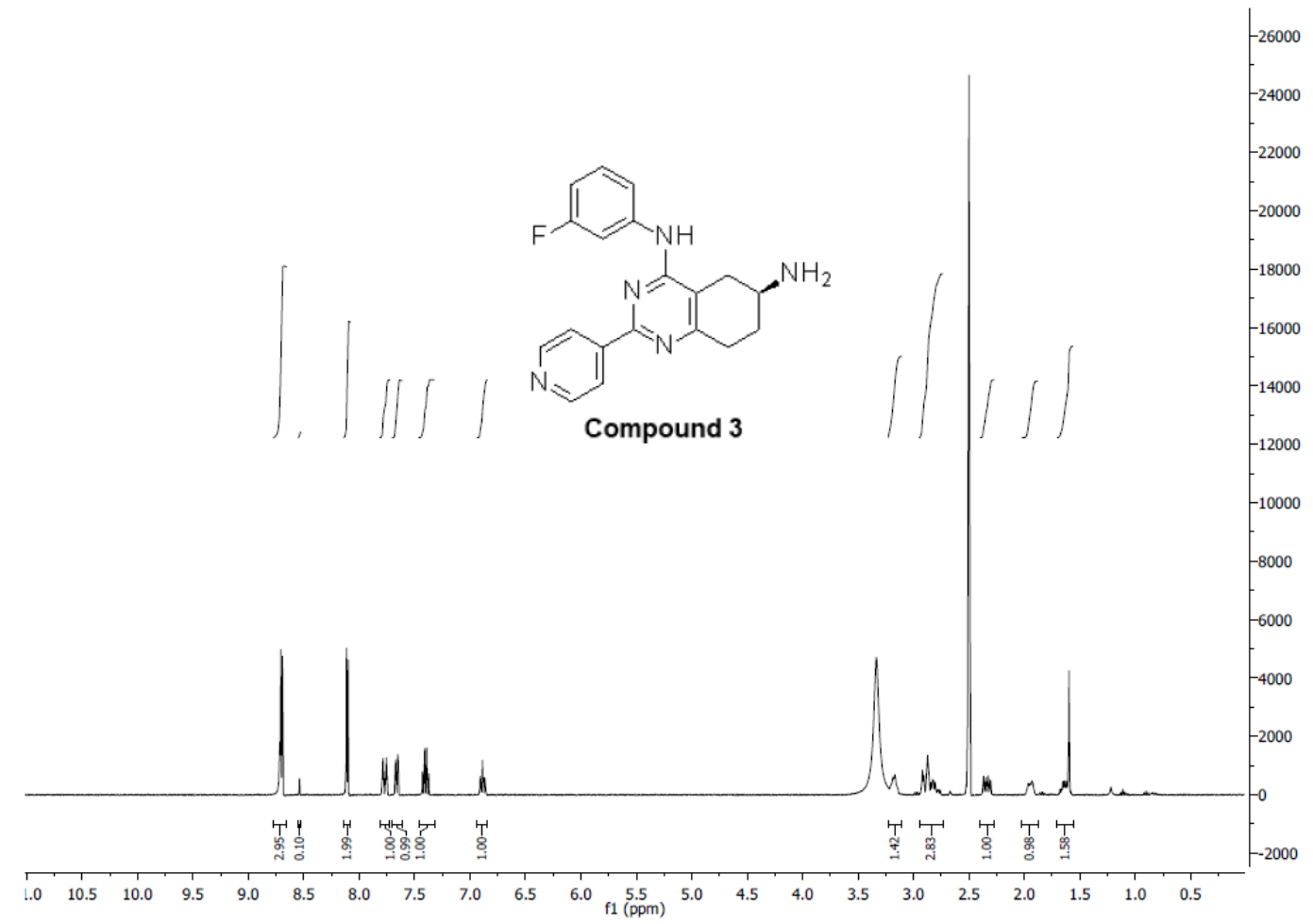

${ }^{13}$ C-NMR Compound 3

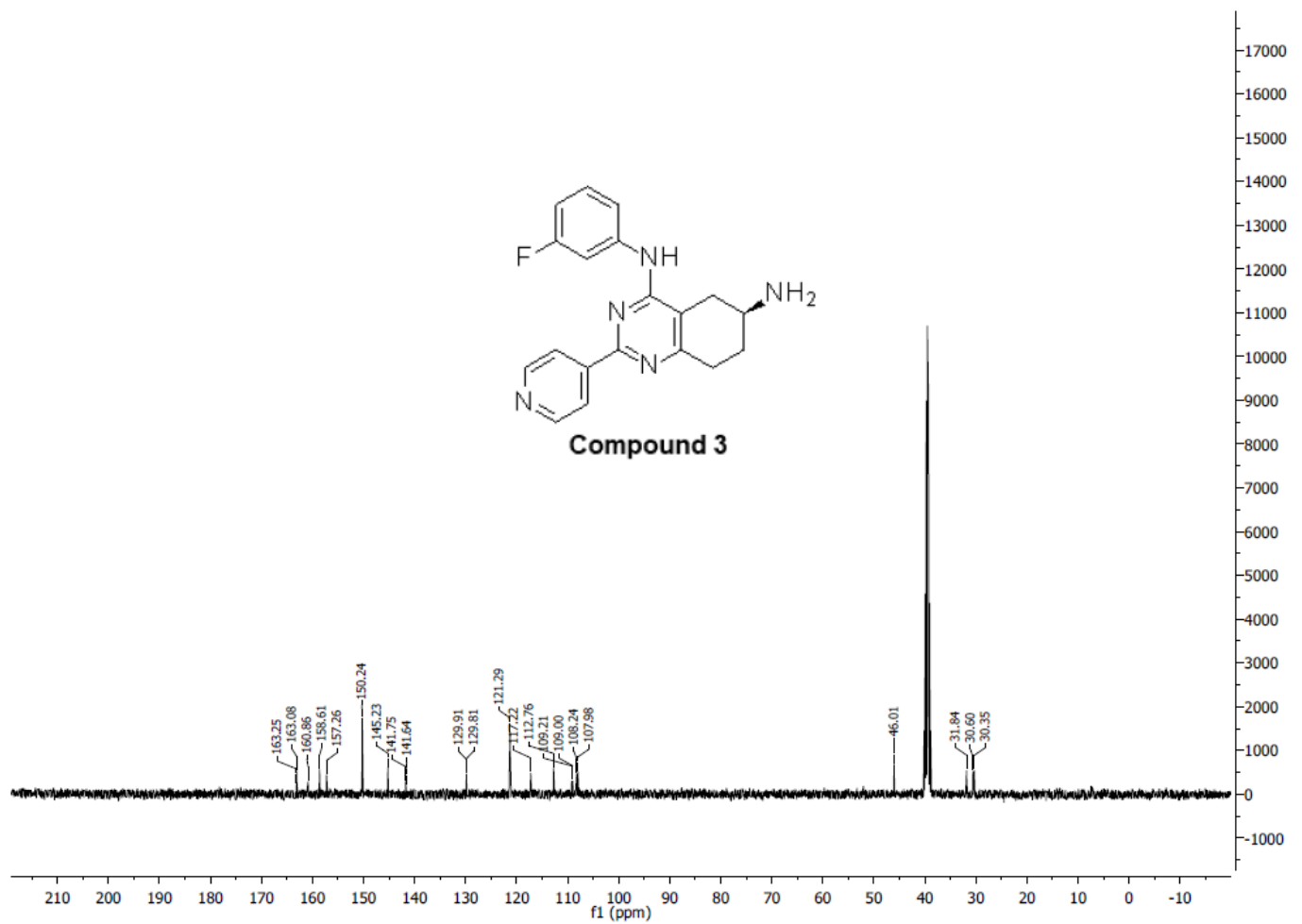




\section{UPLC-MS analysis Compound 3}

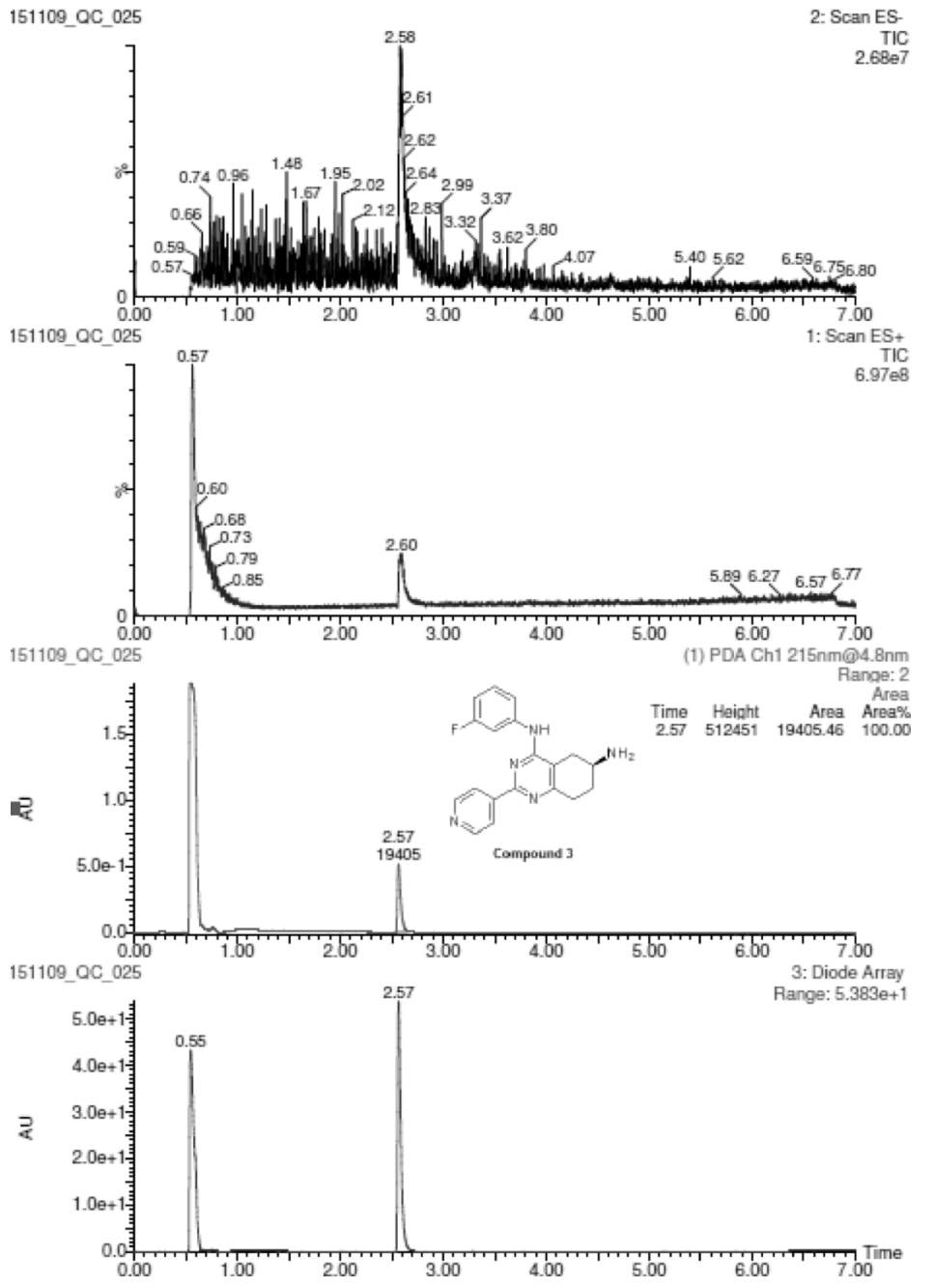

\section{Mass spectrometry spectrum Compound 3}

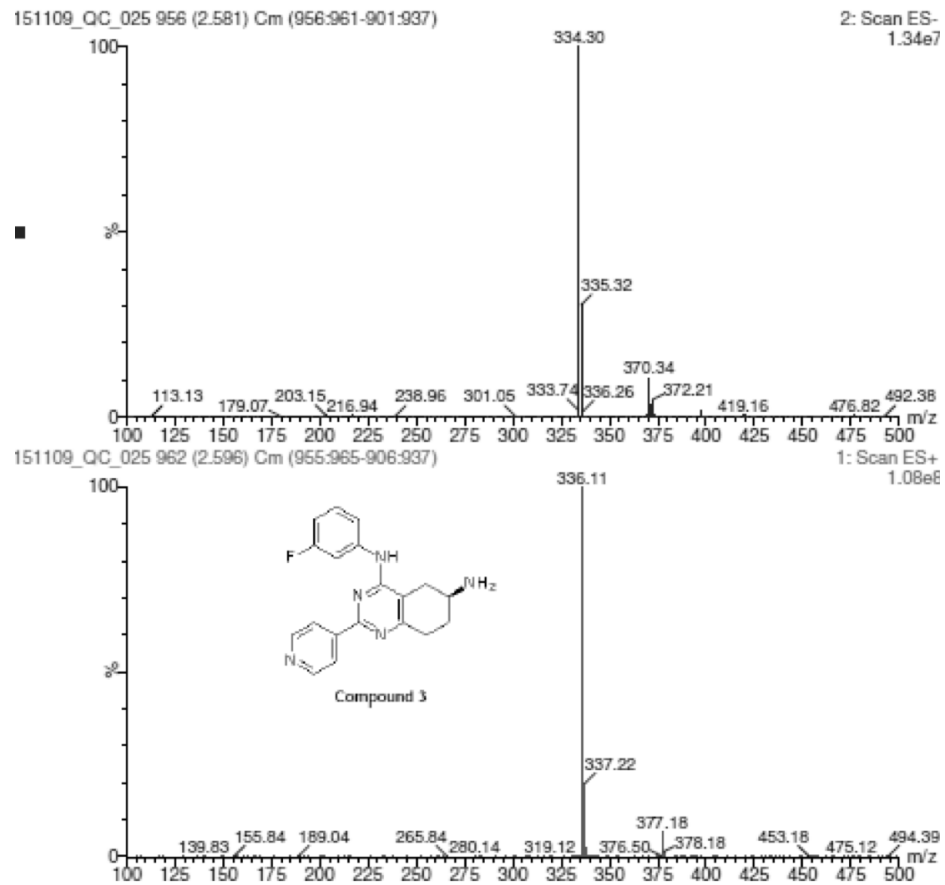




\section{${ }^{1}$ H-NMR Compound 4}

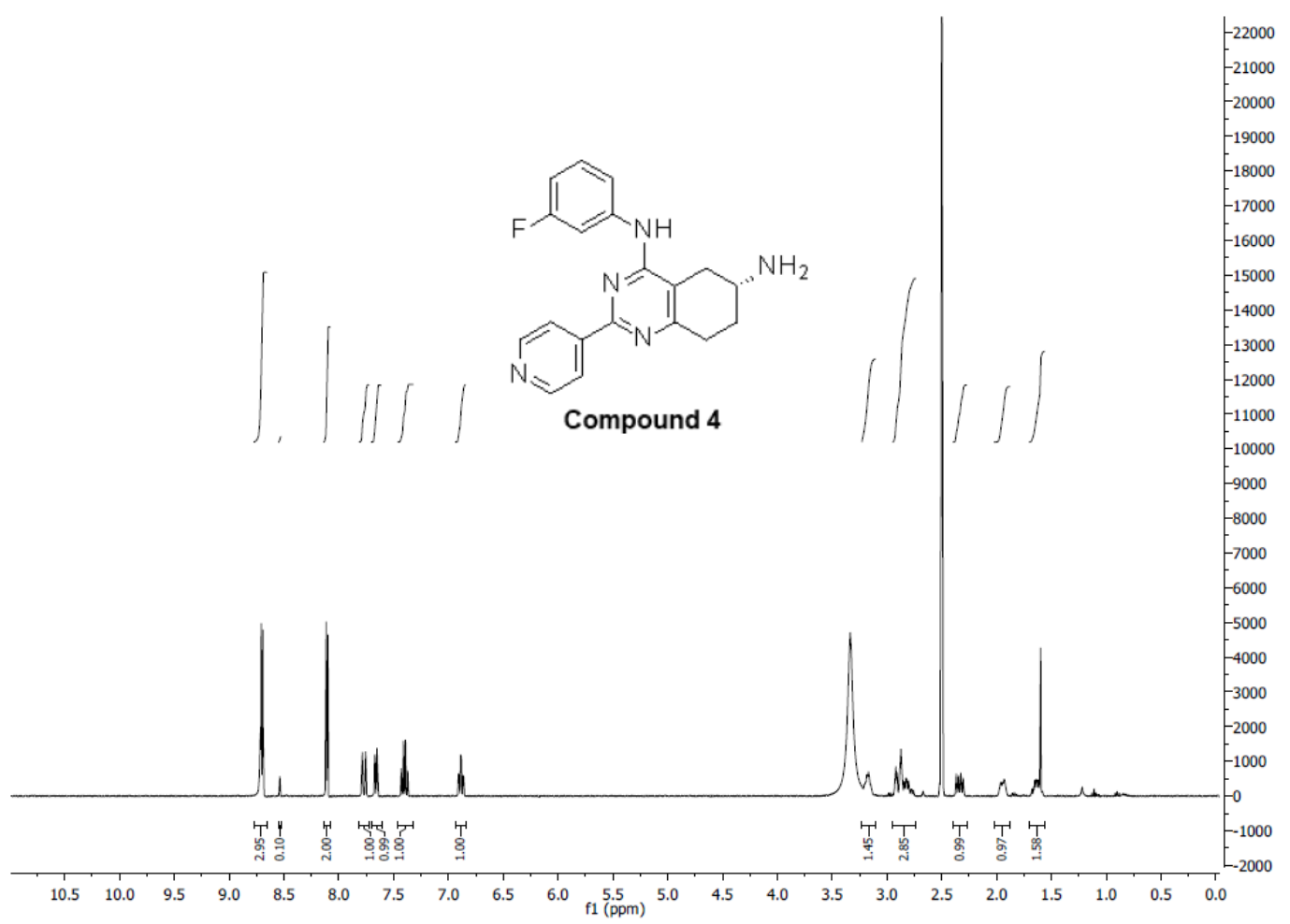

${ }^{13} \mathrm{C}$-NMR Compound 4

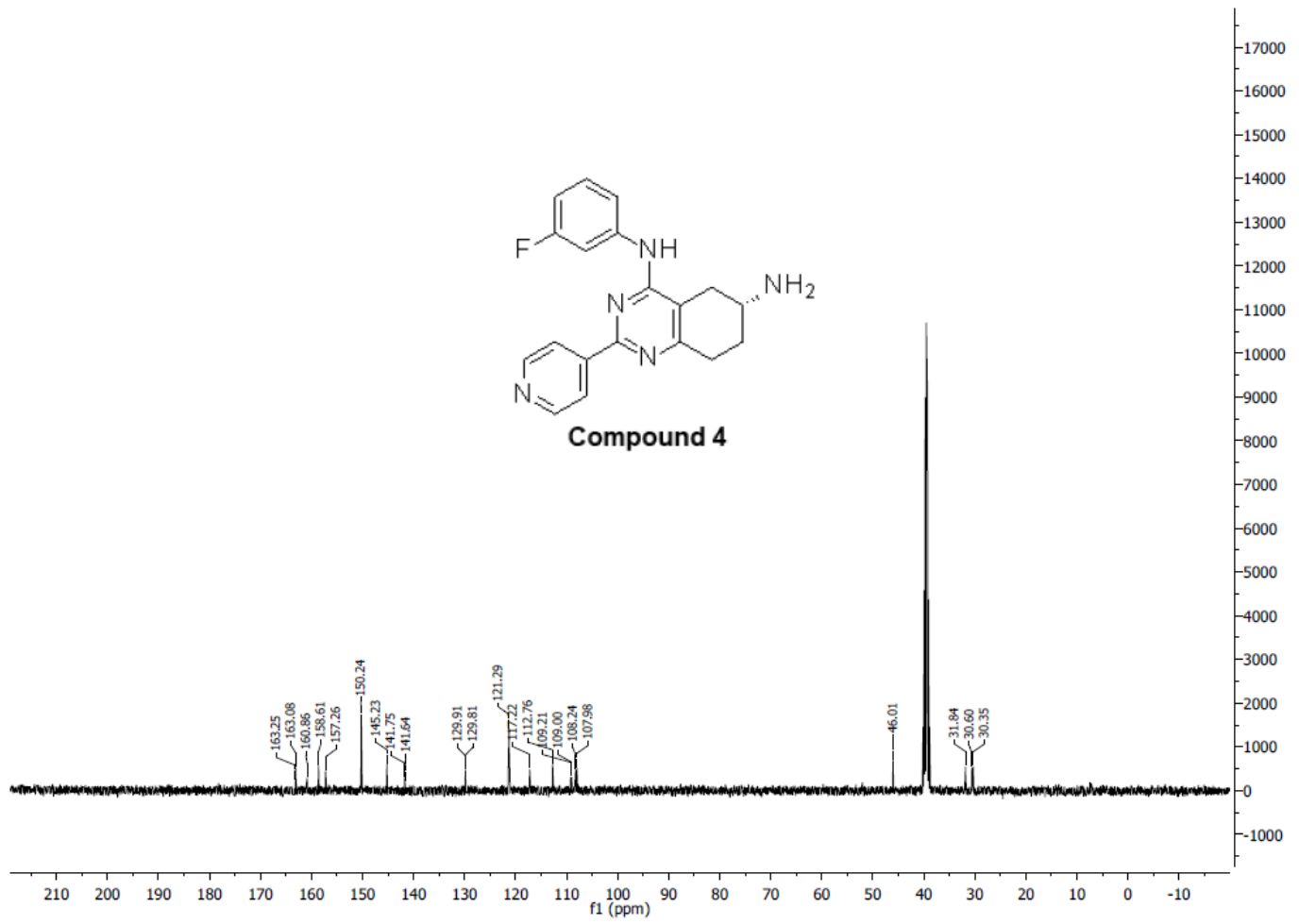


UPLC-MS analysis Compound 4

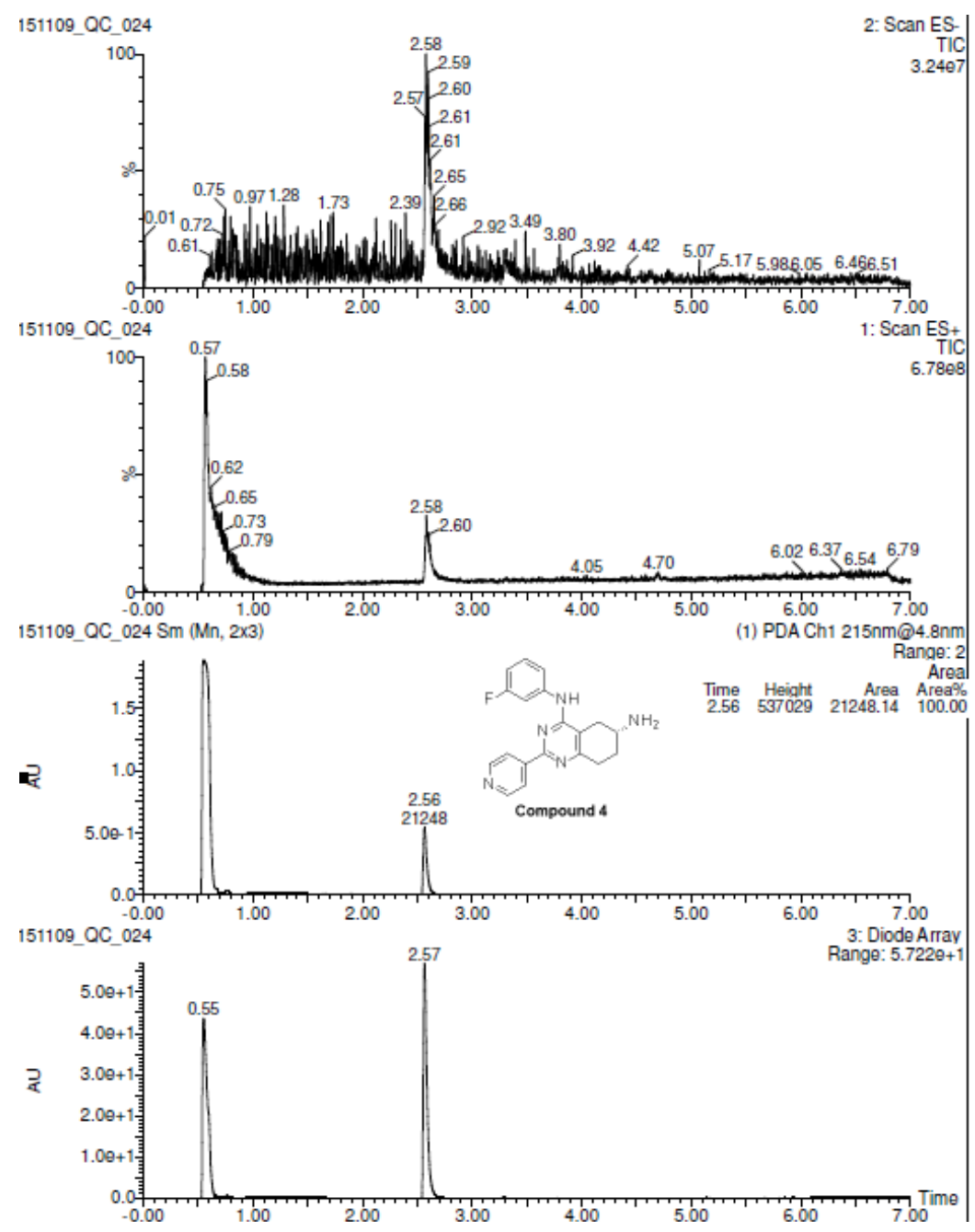

Mass spectrometry spectrum Compound 4

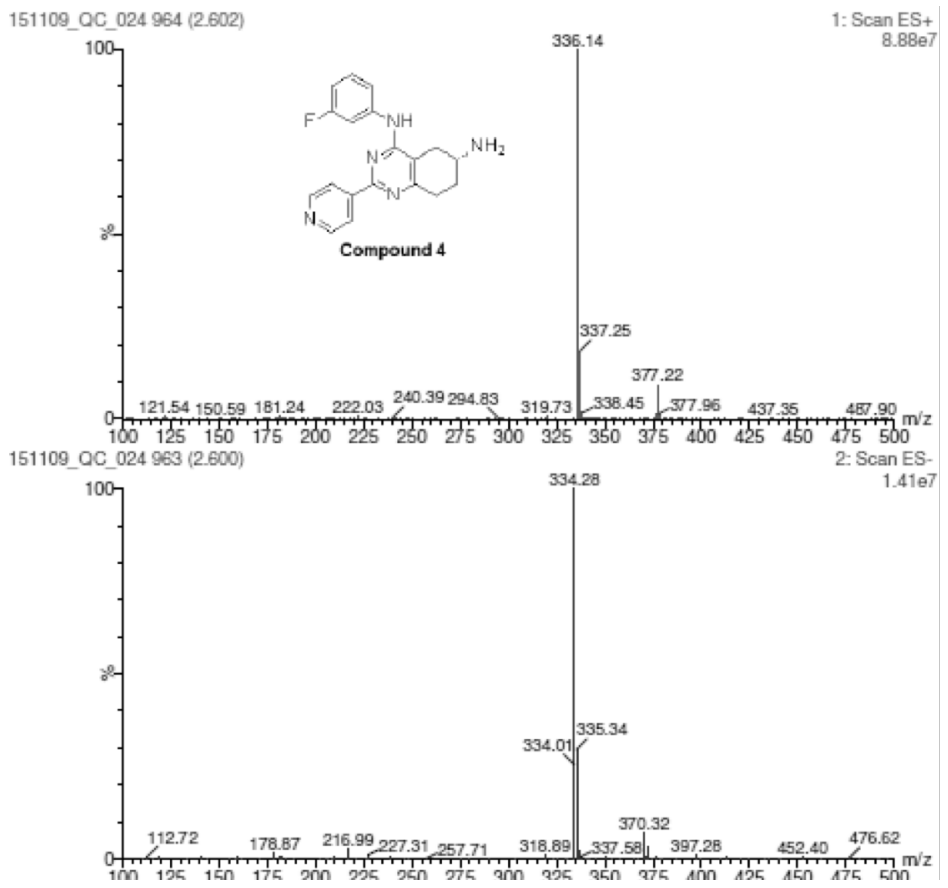




\section{${ }^{1} \mathrm{H}-N M R$ Compound 5}

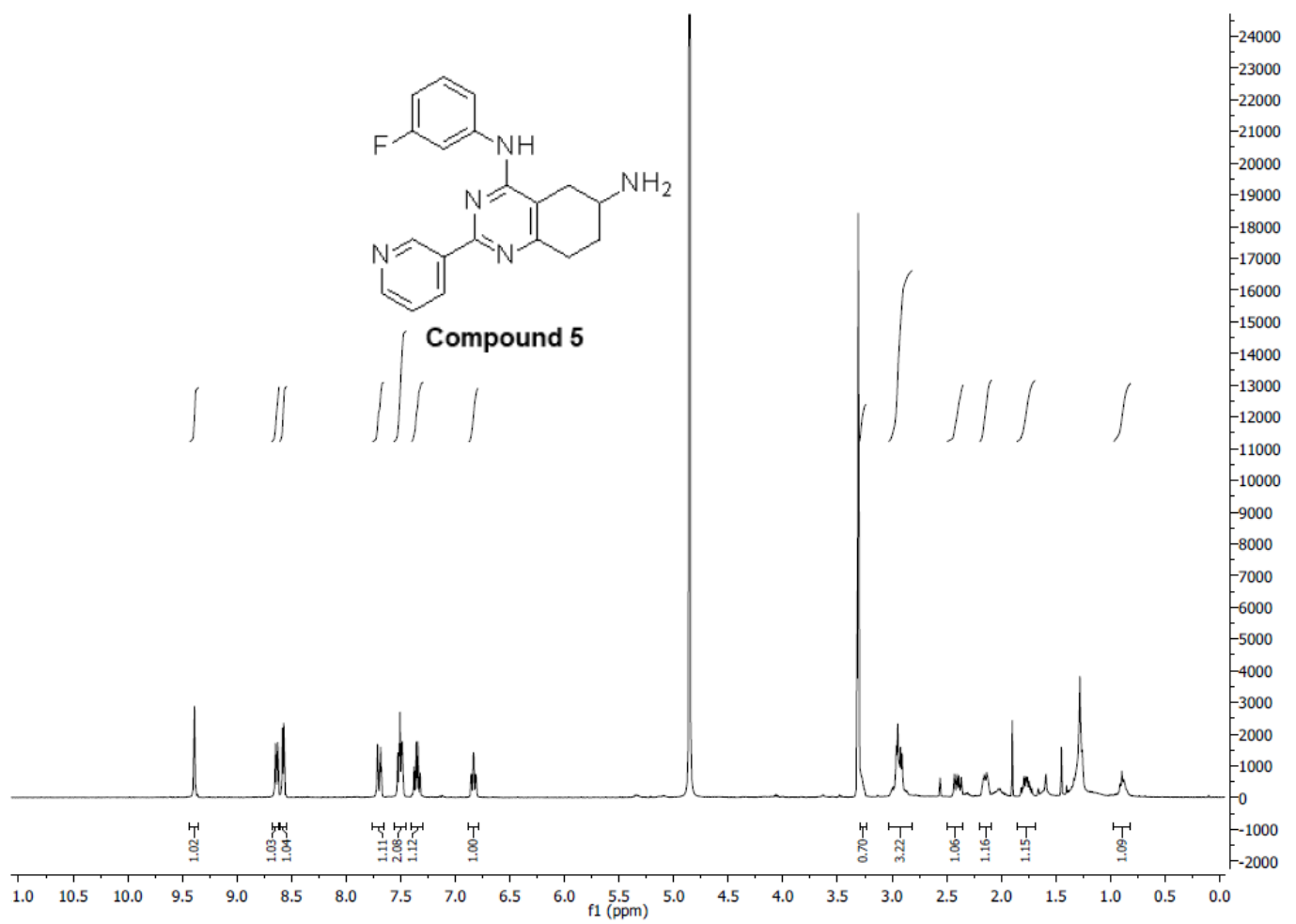

${ }^{13}$ C-NMR Compound 5

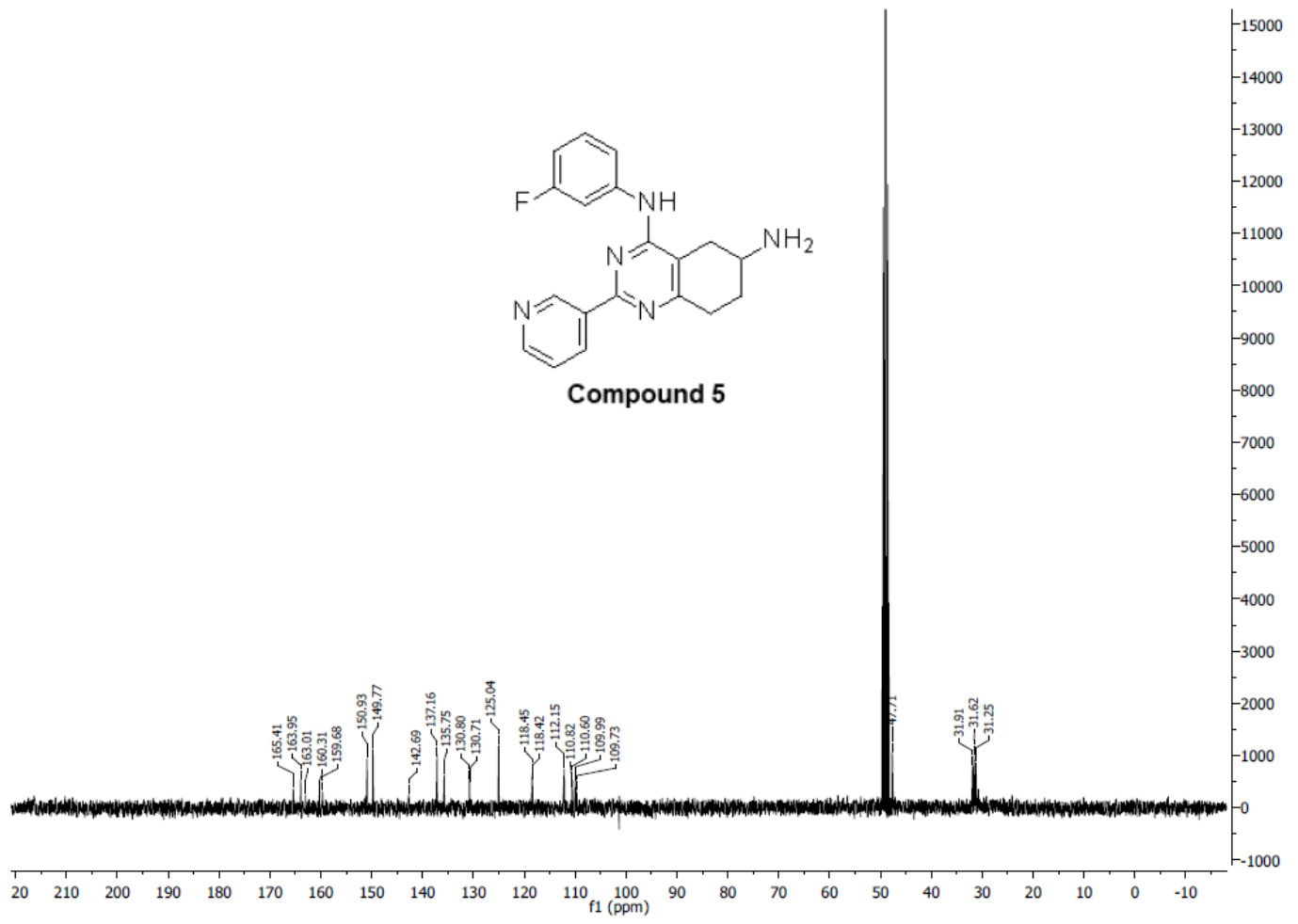




\section{UPLC-MS analysis Compound 5}

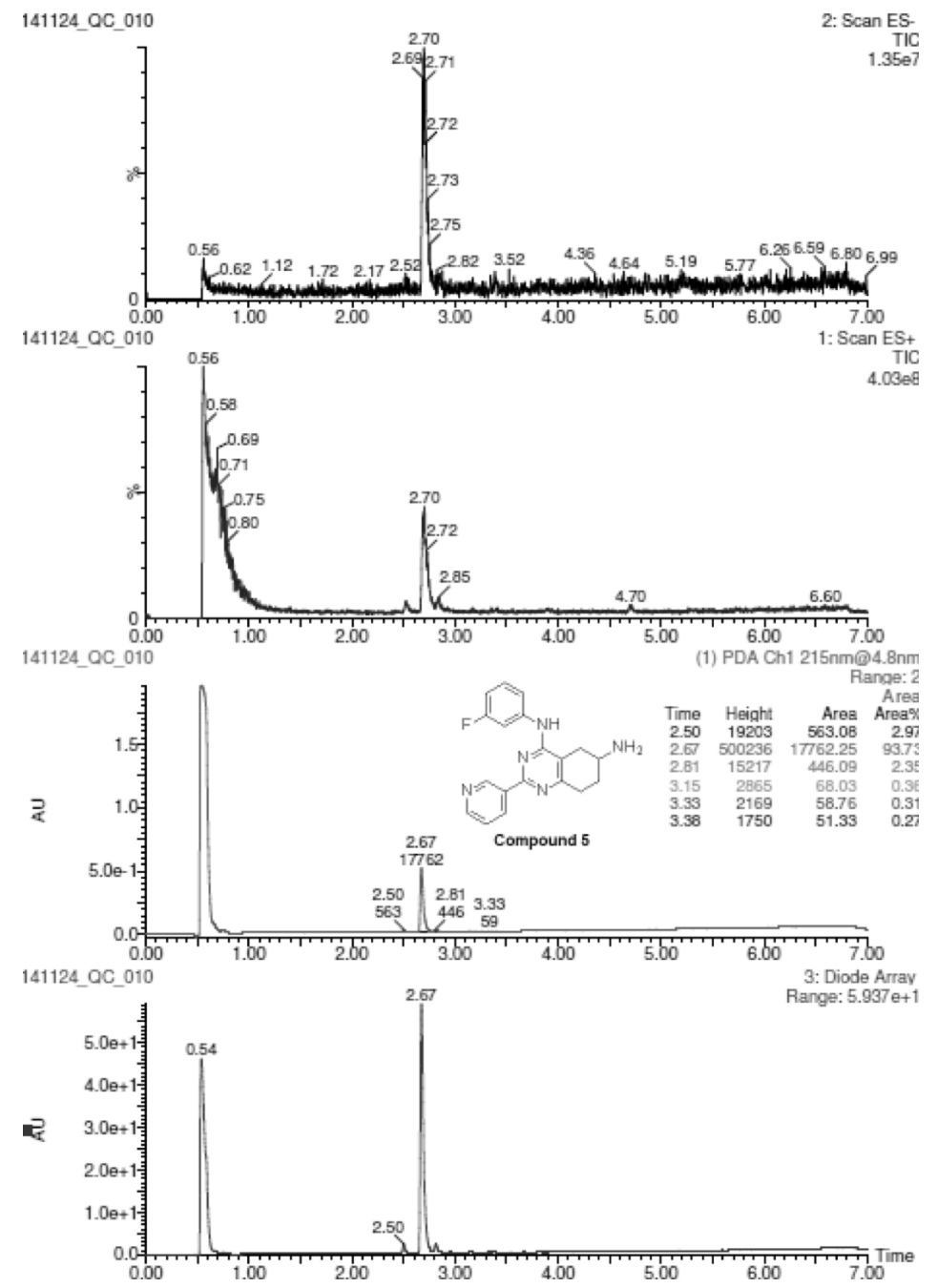

\section{Mass spectrometry spectrum Compound 5}

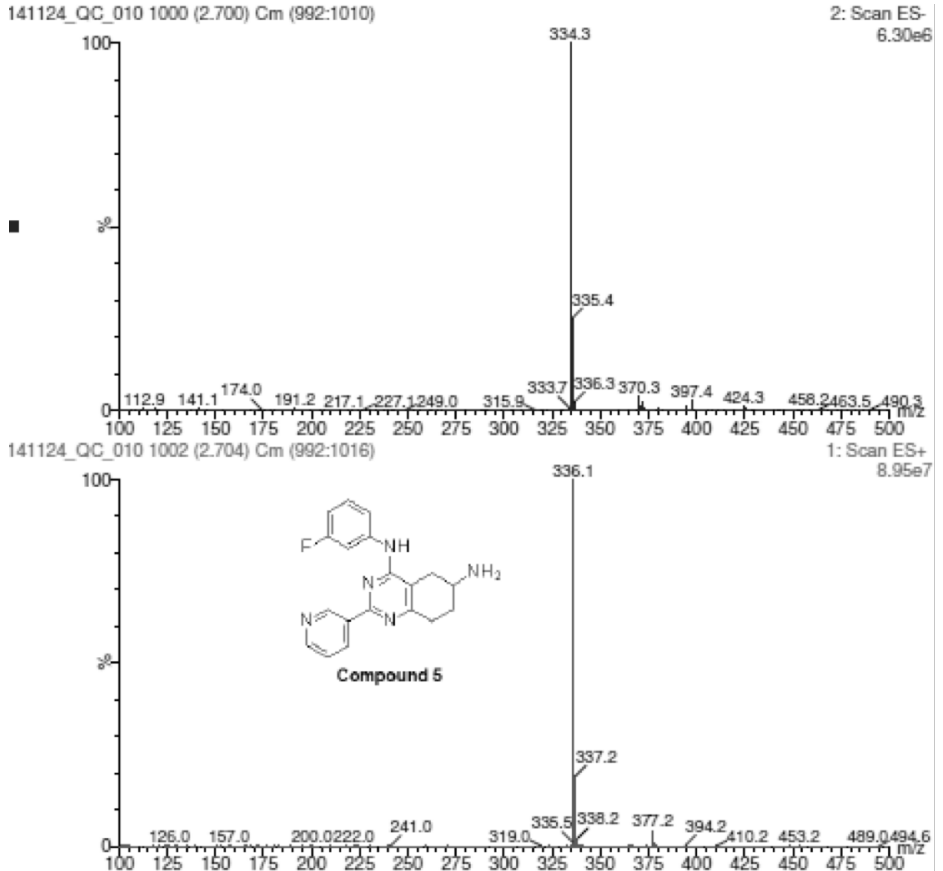




\section{${ }^{1}$ H-NMR Compound 6}

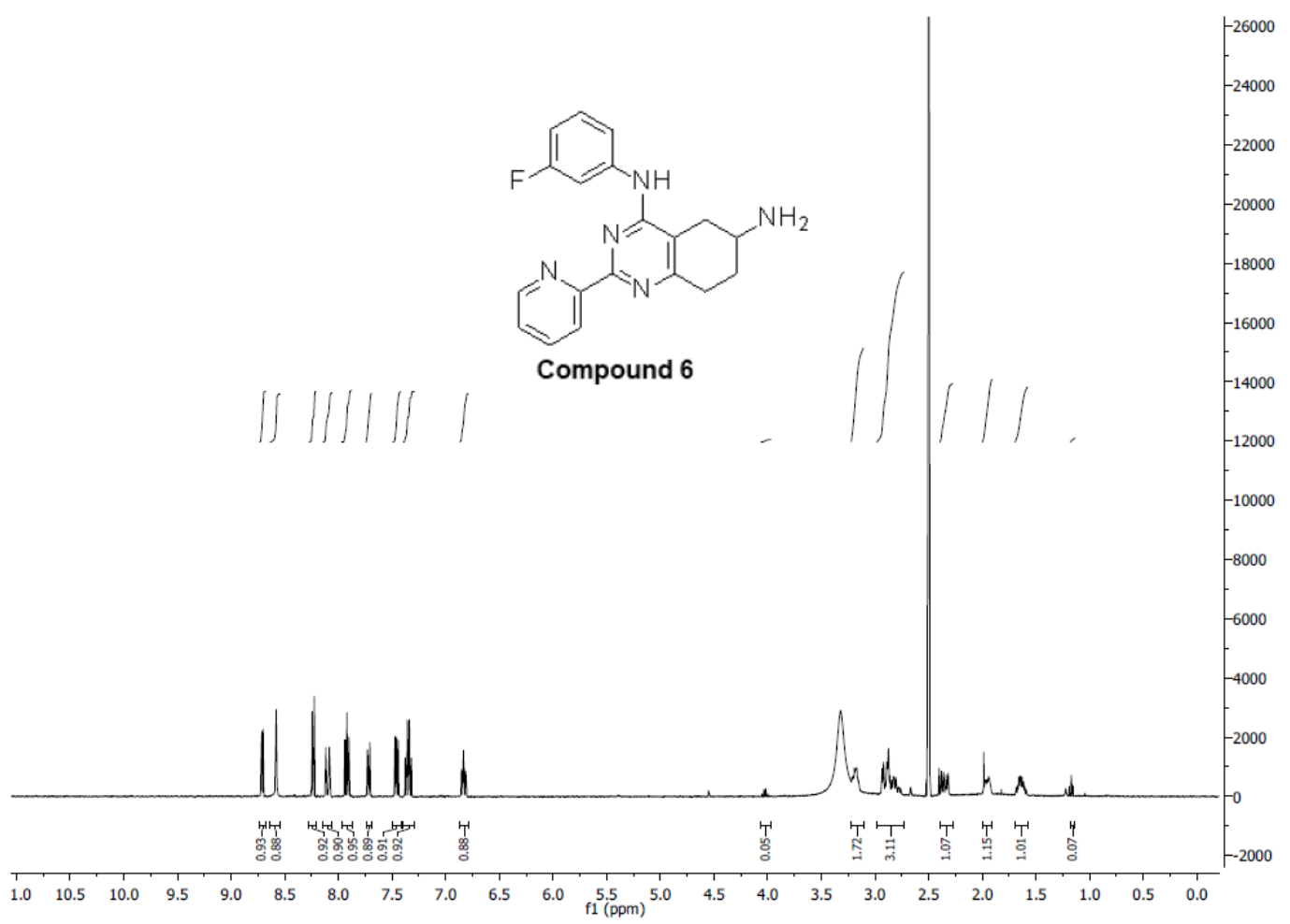

${ }^{13}$ C-NMR Compound 6

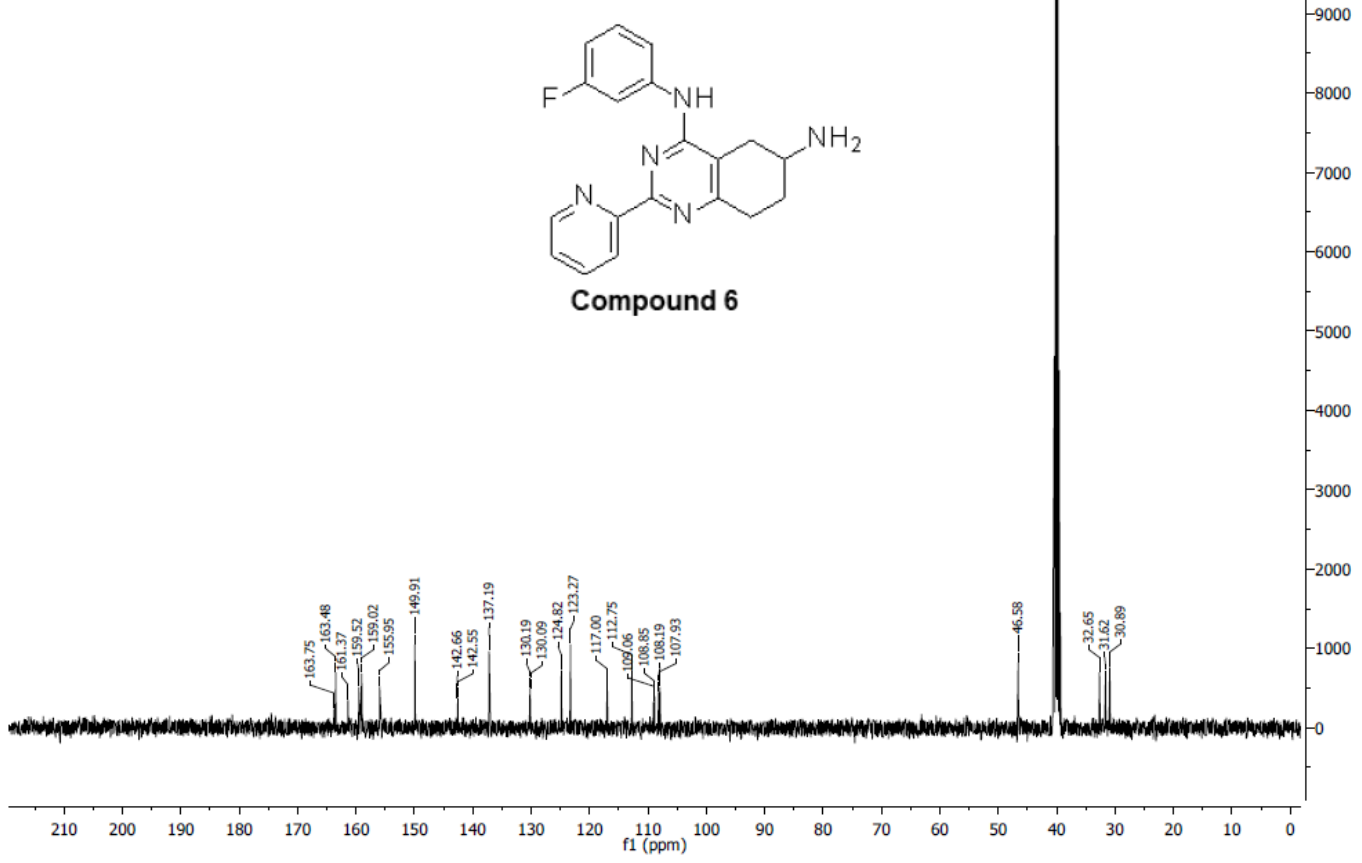




\section{UPLC-MS analysis Compound 6}

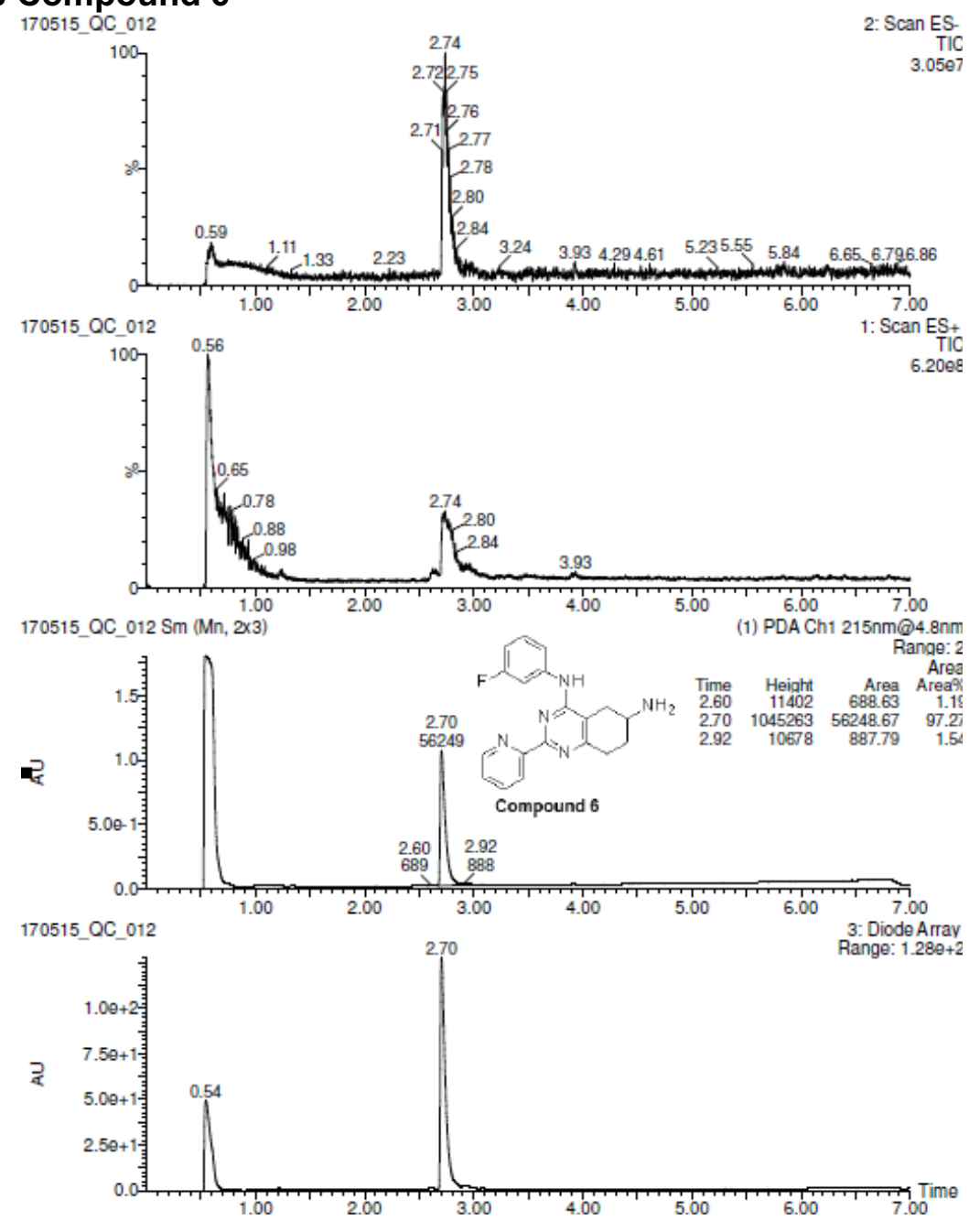

\section{Mass spectrometry spectrum Compound 6}

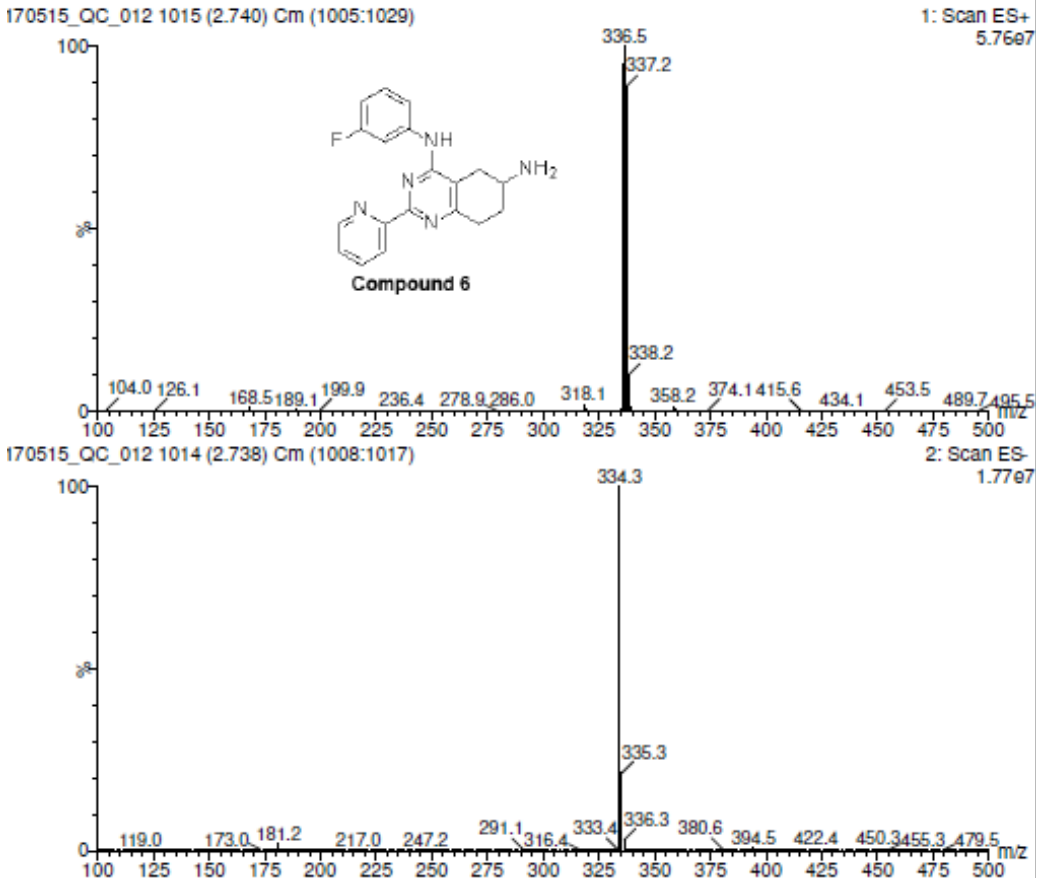




\section{${ }^{1}$ H-NMR Compound 7}

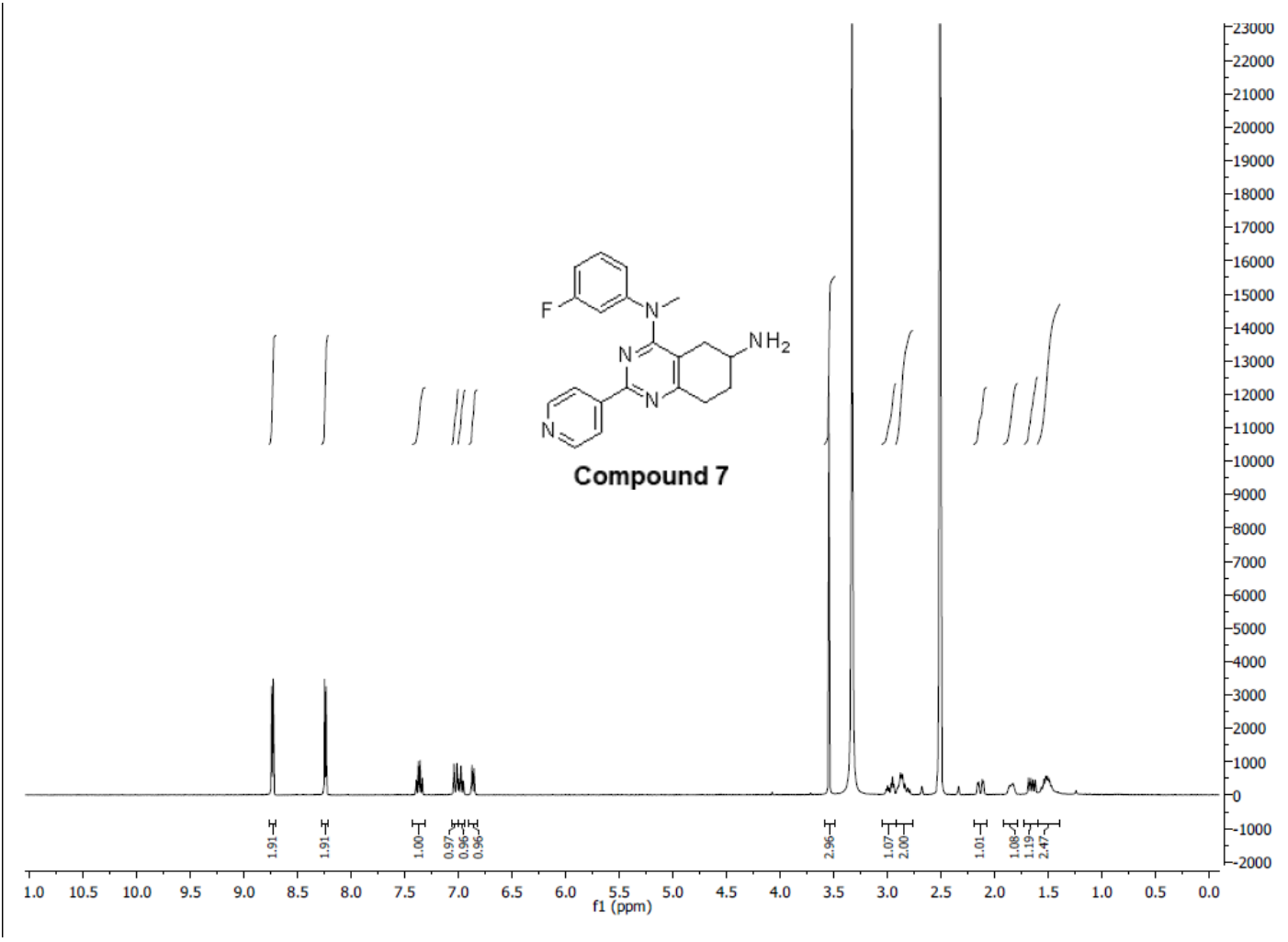

${ }^{13}$ C-NMR Compound 7

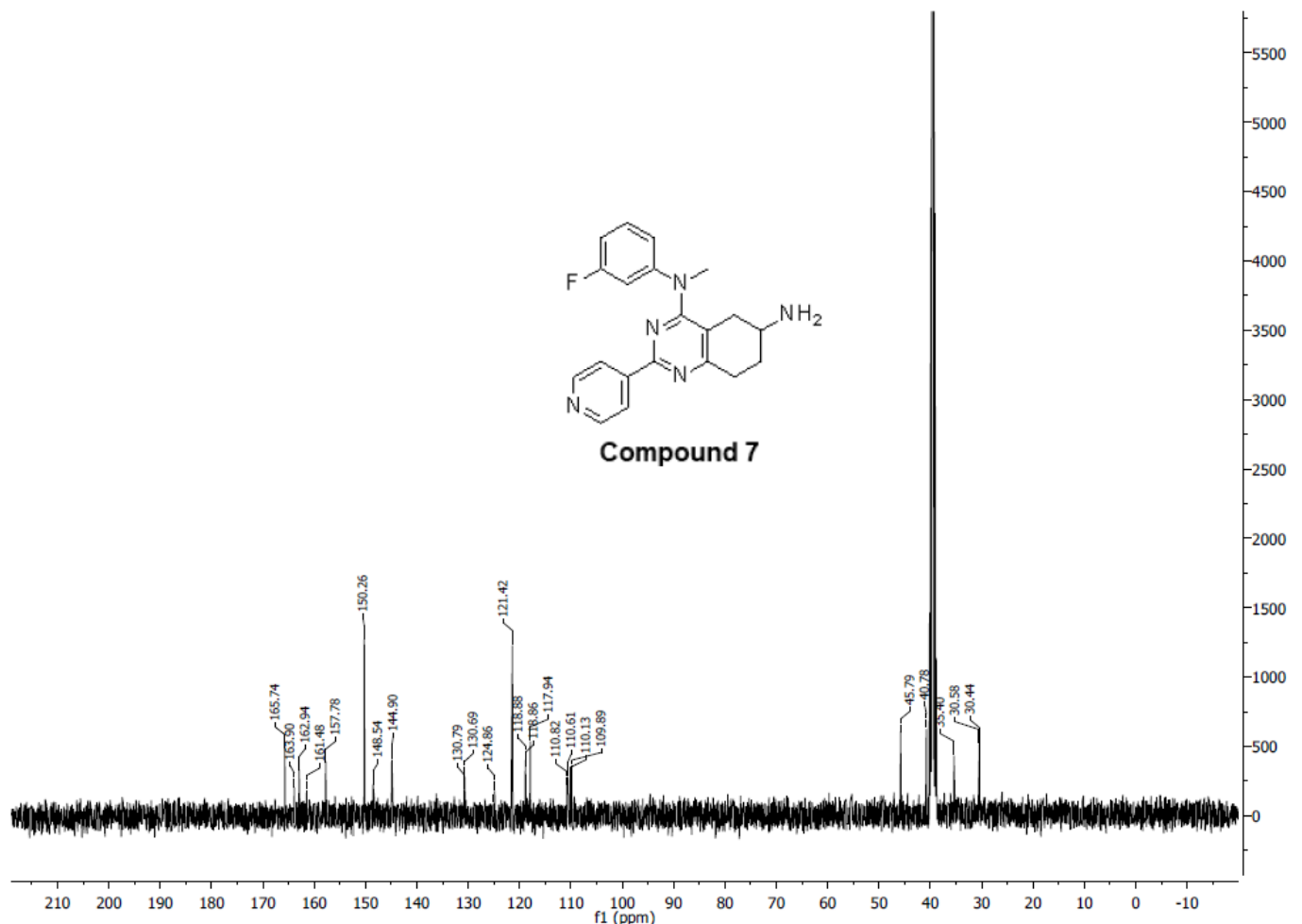




\section{UPLC-MS analysis Compound 7}

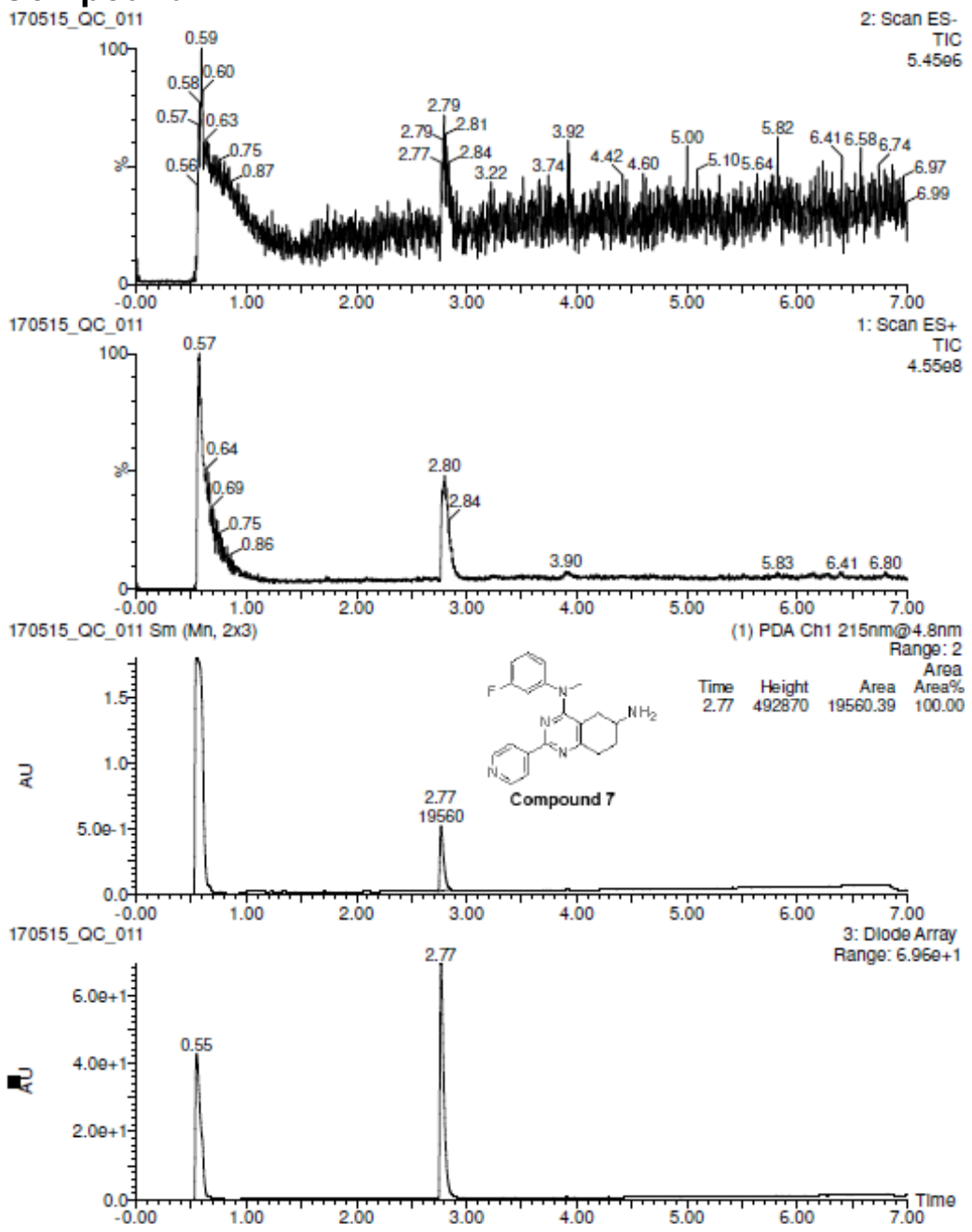

\section{Mass spectrometry spectrum Compound 7}

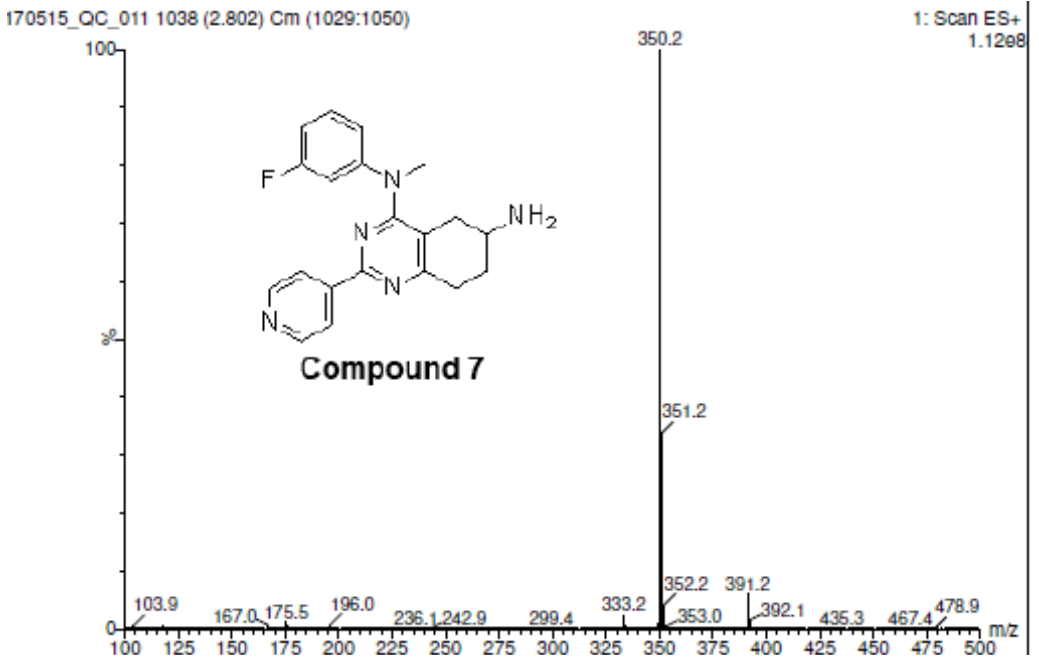




\section{${ }^{1}$ H-NMR Compound 8}

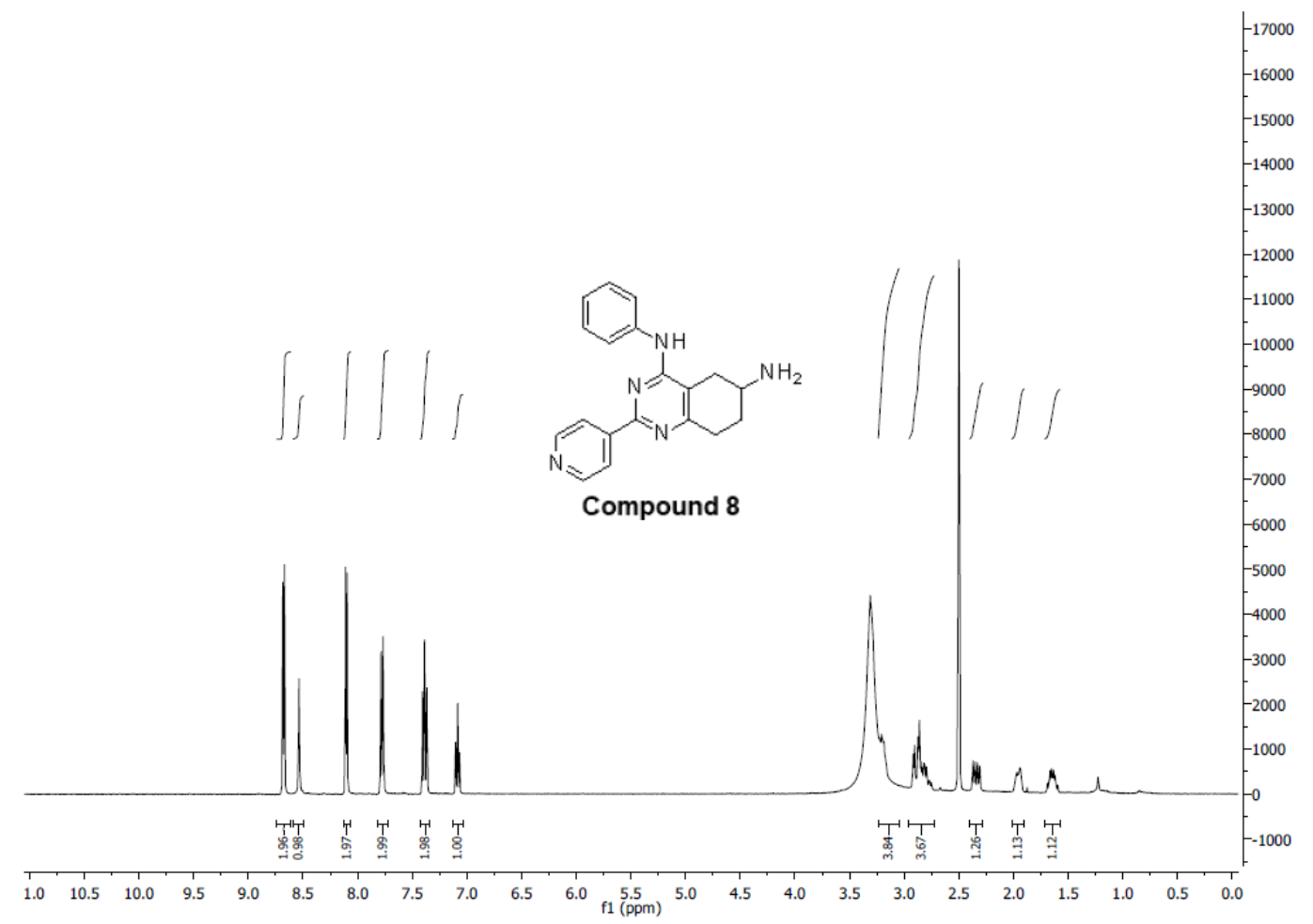

${ }^{13}$ C-NMR Compound 8

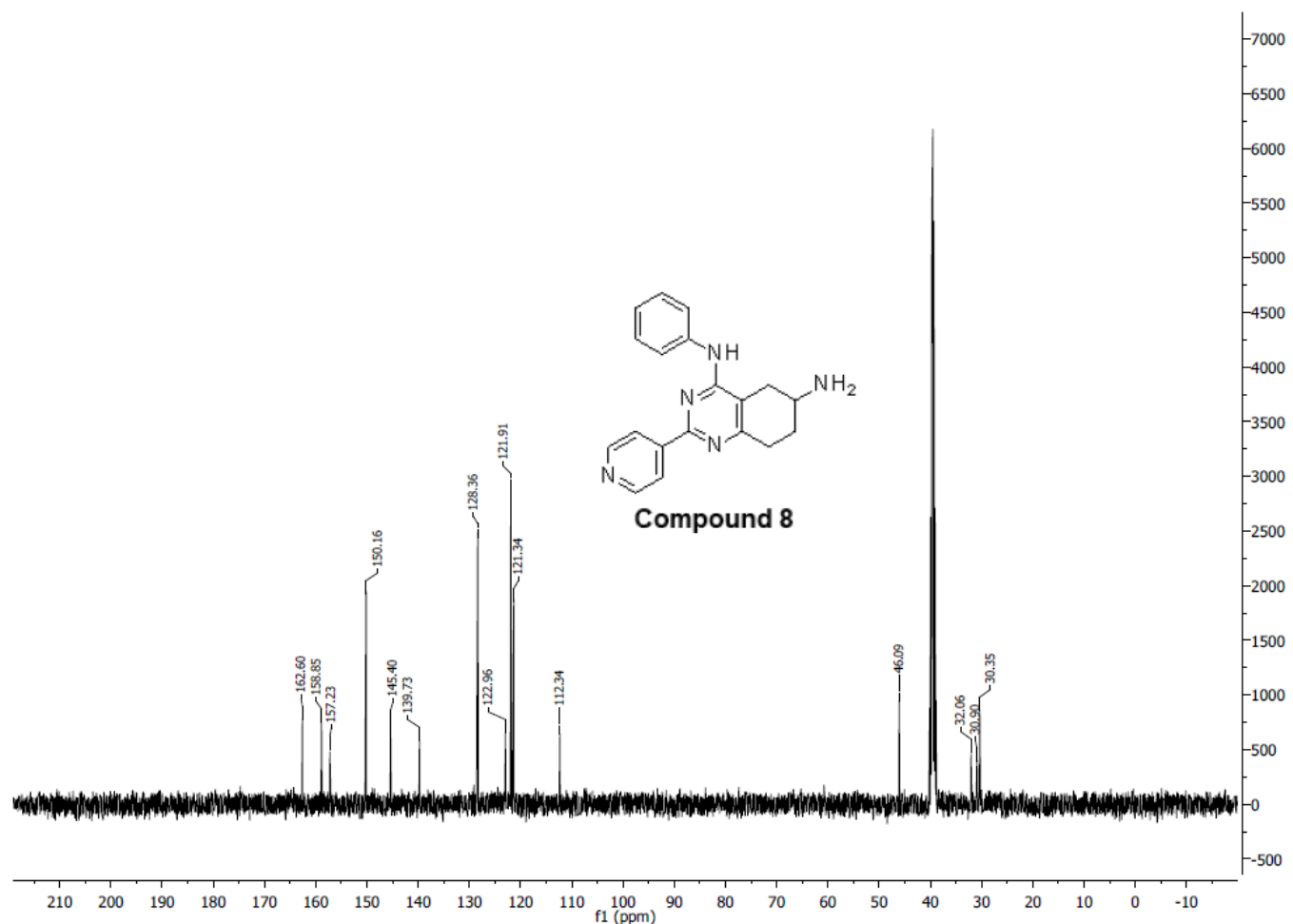


UPLC-MS analysis Compound 8

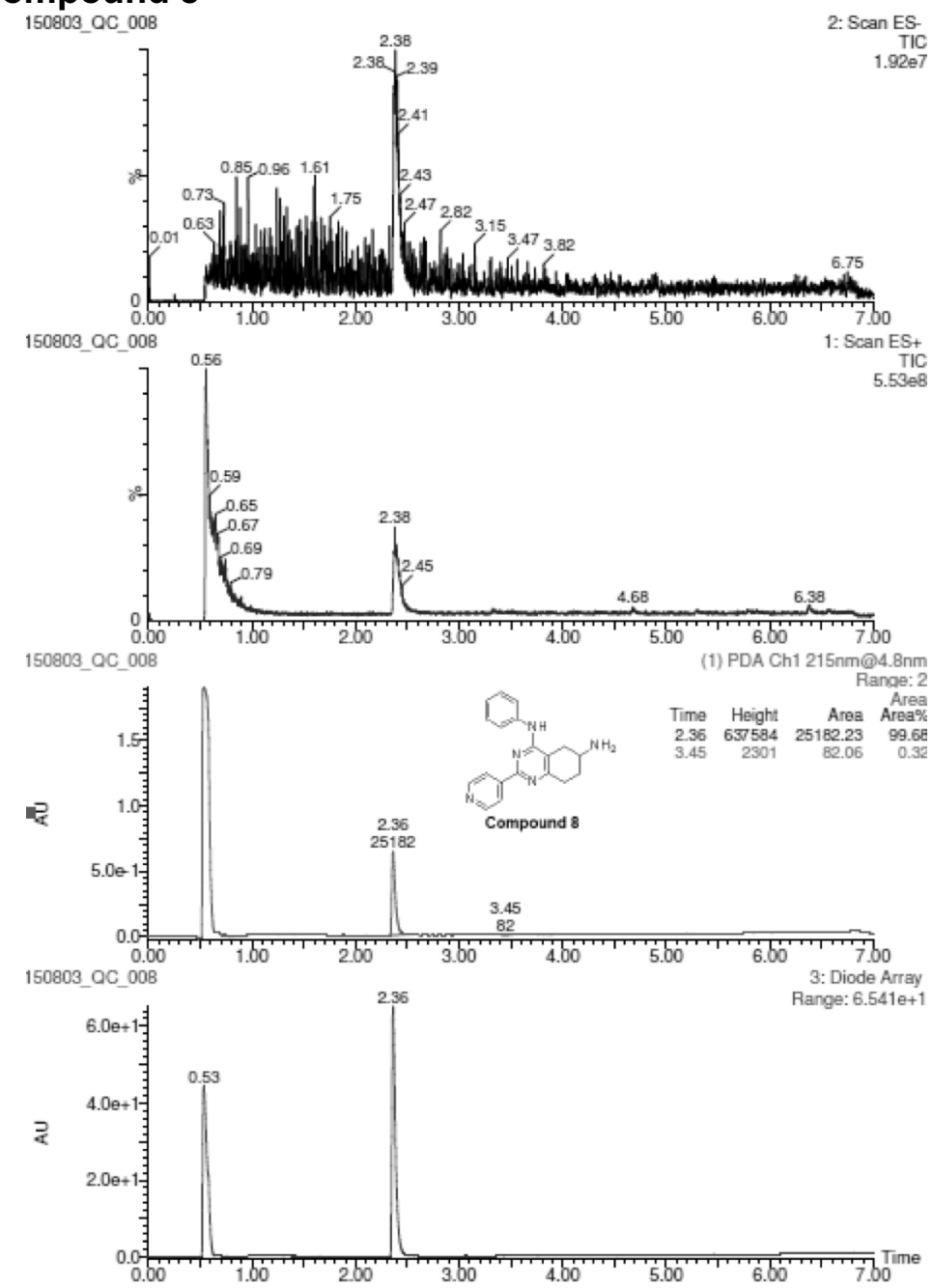

Mass spectrometry spectrum Compound 8

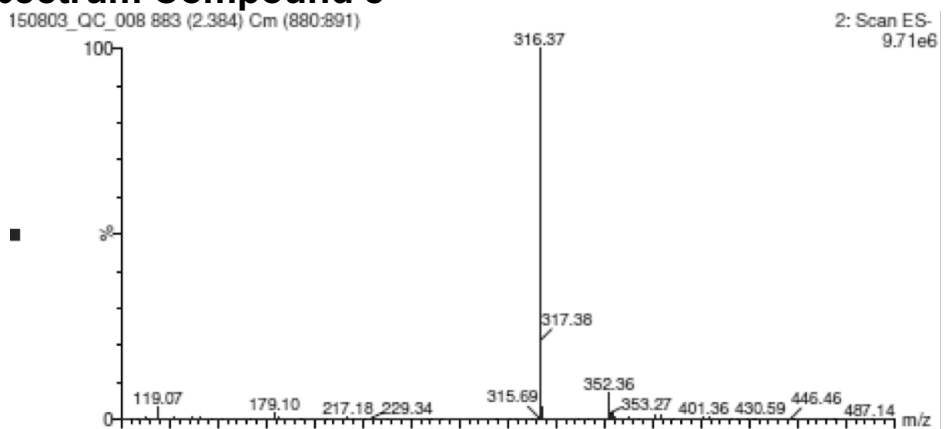

$\begin{array}{llllllllllllllllllllllllll}100 & 125 & 150 & 175 & 200 & 225 & 250 & 275 & 300 & 325 & 350 & 375 & 400 & 425 & 450 & 475 & 500\end{array}$

150803_OC_008 8B2 (2.390) Cm (879:893)

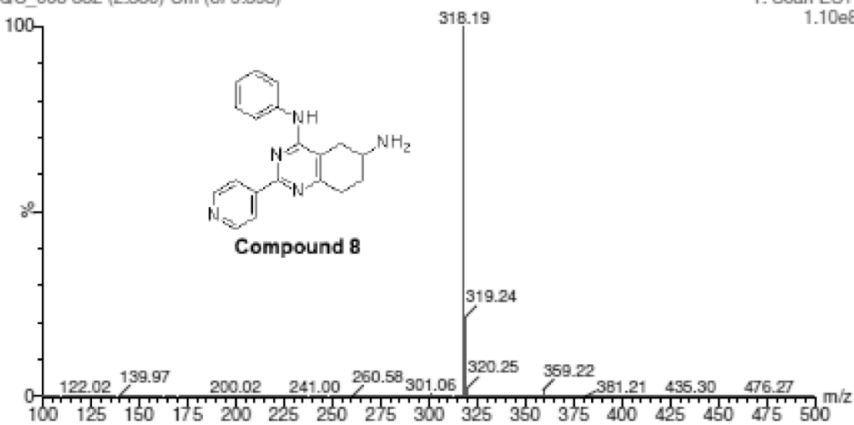




\section{${ }^{1}$ H-NMR Compound 9}

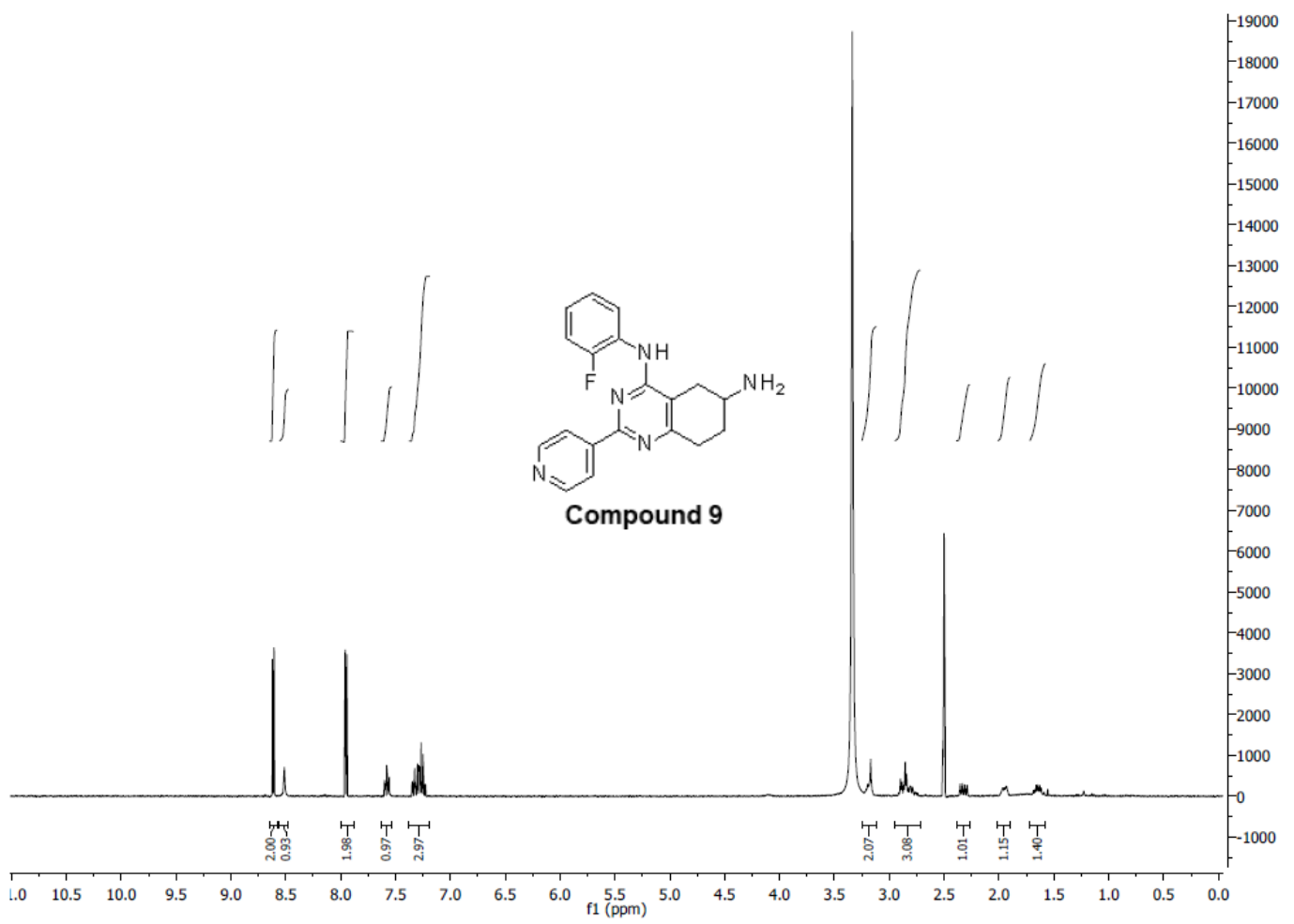

${ }^{13}$ C-NMR Compound 9

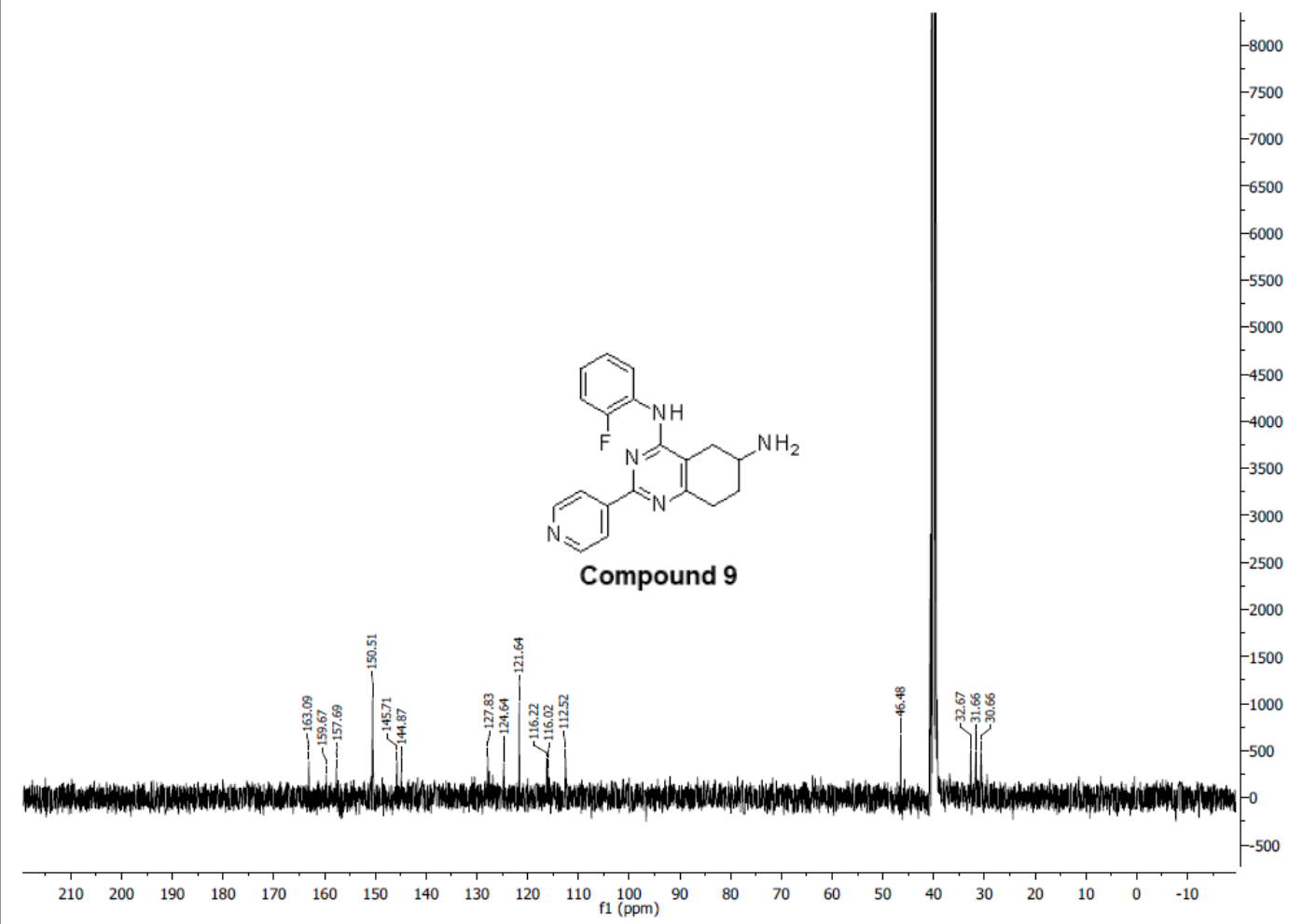




\section{UPLC-MS analysis Compound 9}

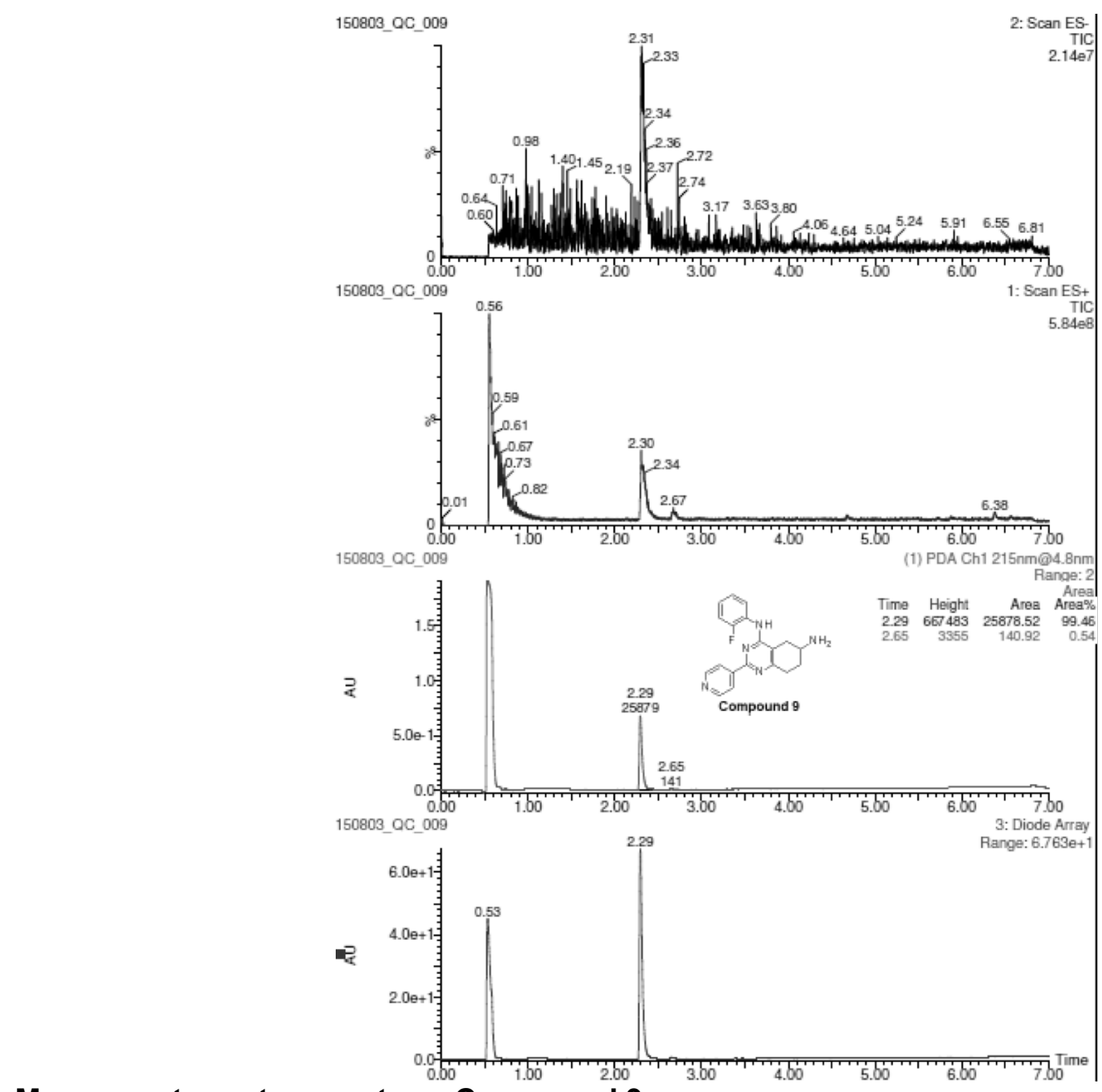

Mass spectrometry spectrum Compound 9

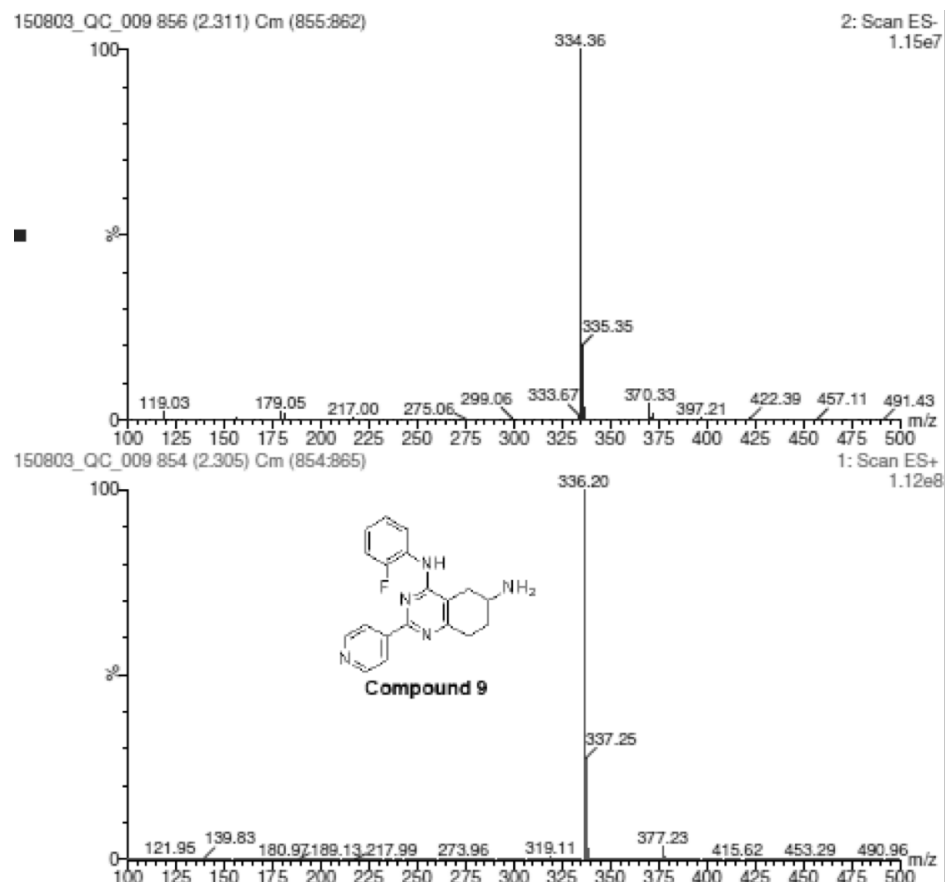




\section{${ }^{1} \mathrm{H}$-NMR Compound 10}

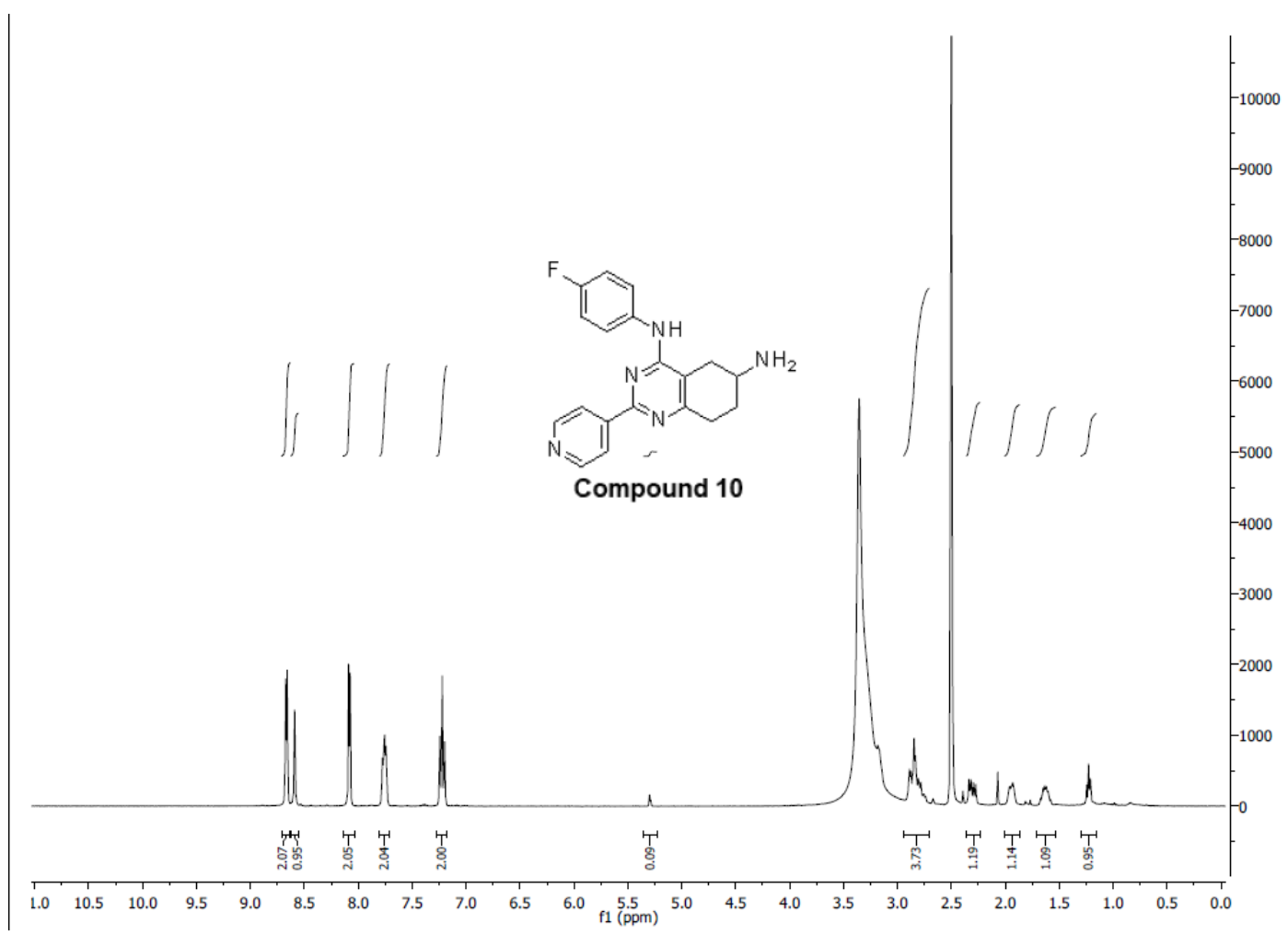

${ }^{13}$ C-NMR Compound 10

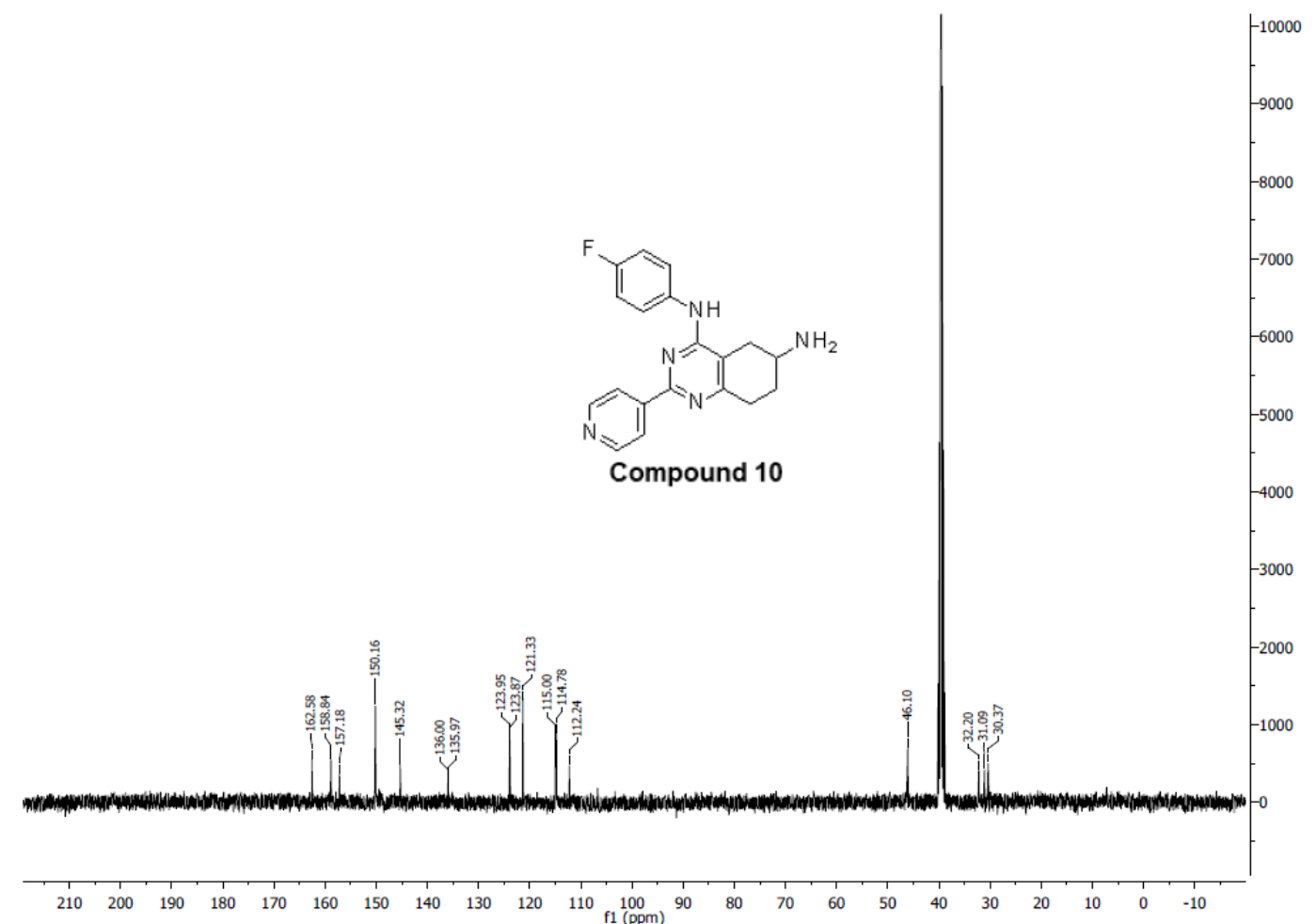




\section{UPLC-MS analysis Compound 10}

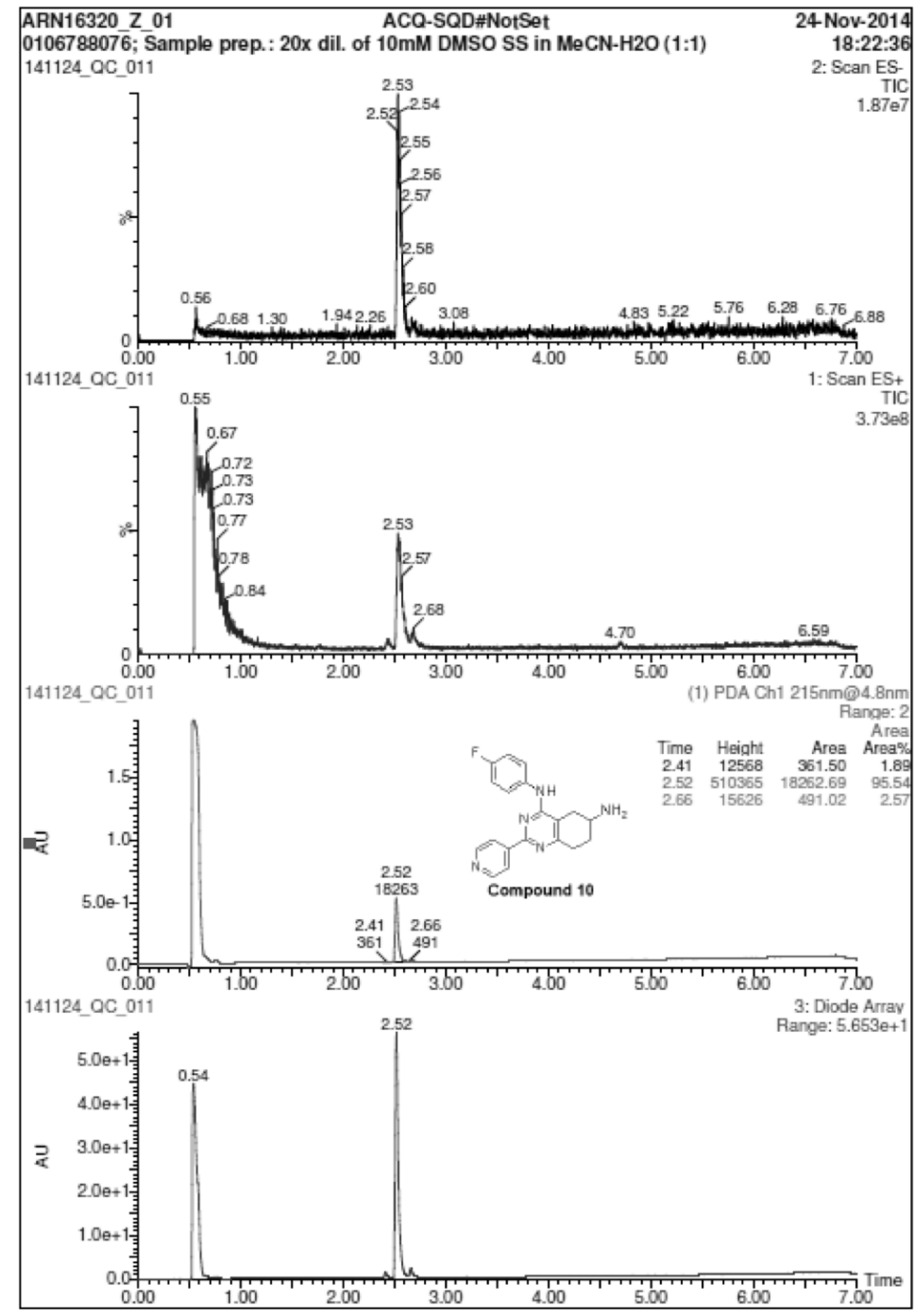

\section{Mass spectrometry spectrum Compound 10}

141124_aC_011937 (2.530) Cm (937 945)

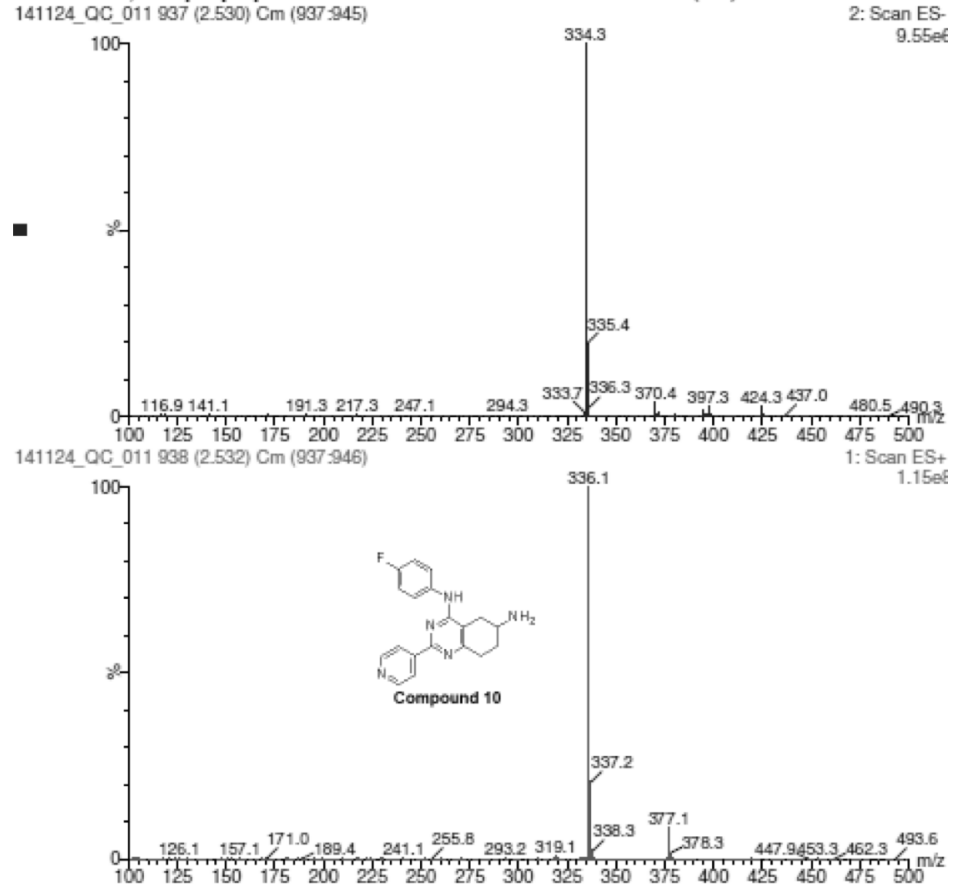




\section{${ }^{1}$ H-NMR Compound 11}

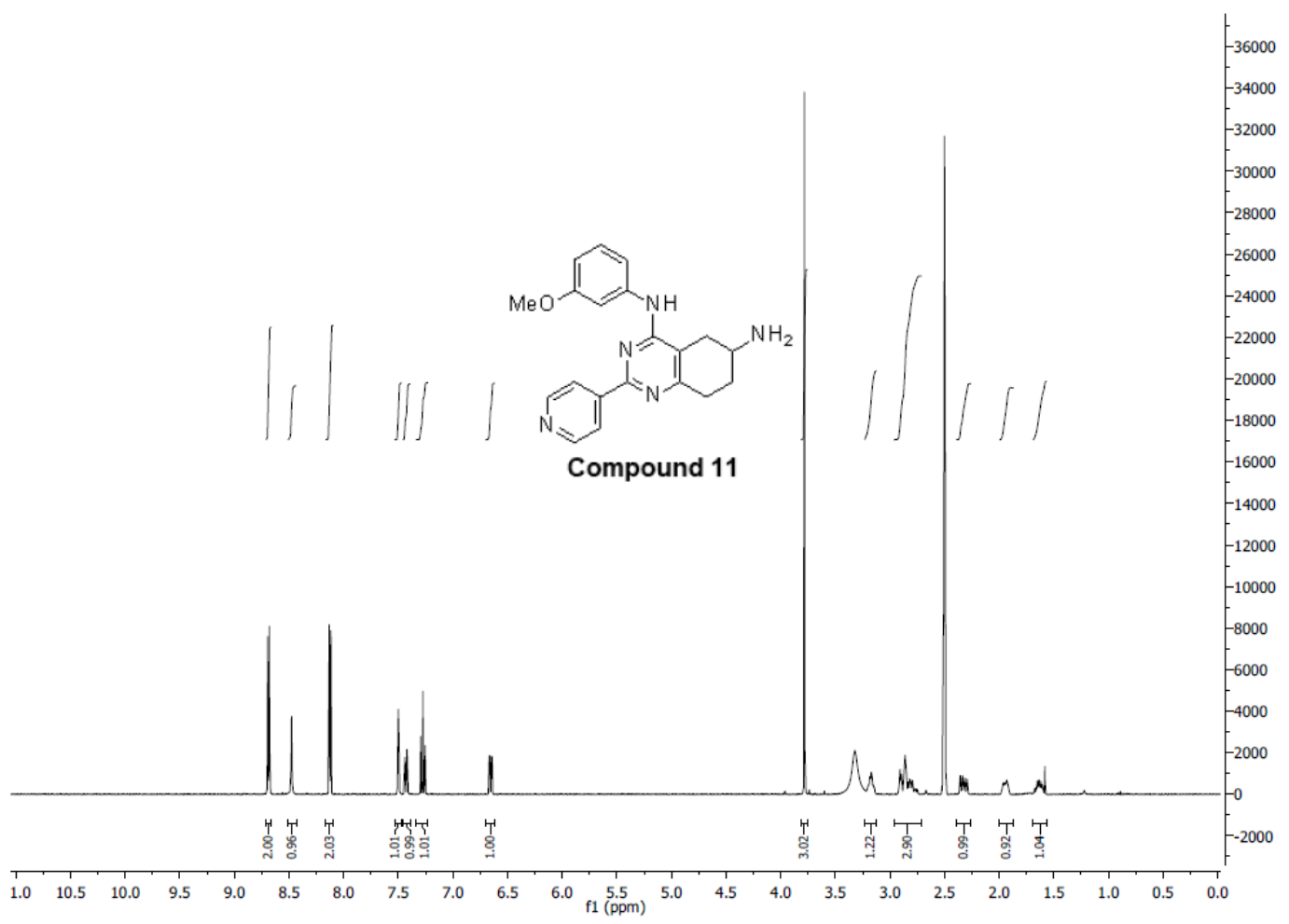

\section{${ }^{13}$ C-NMR Compound 11}

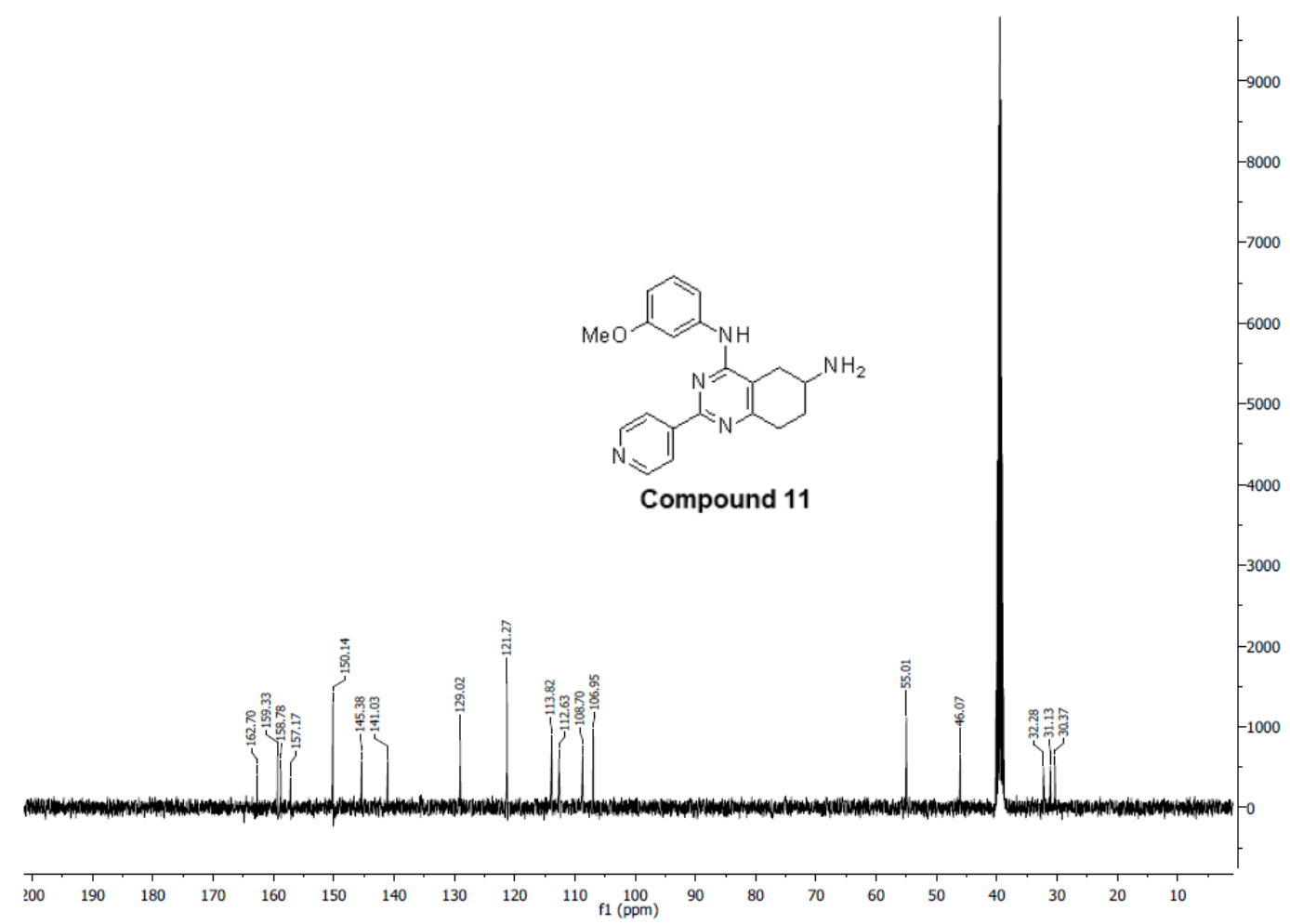


UPLC-MS analysis Compound 11

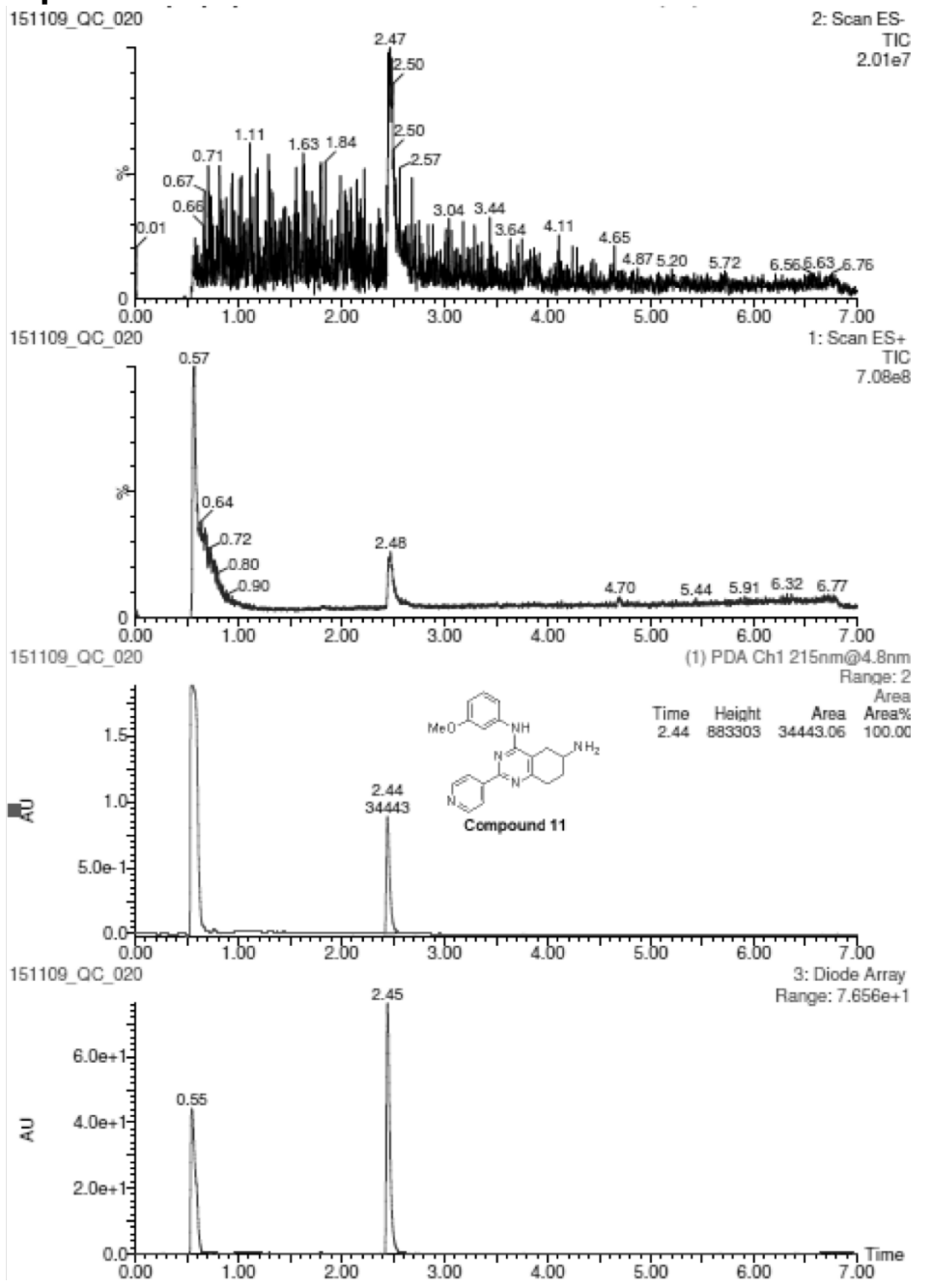

Mass spectrometry spectrum Compound 11

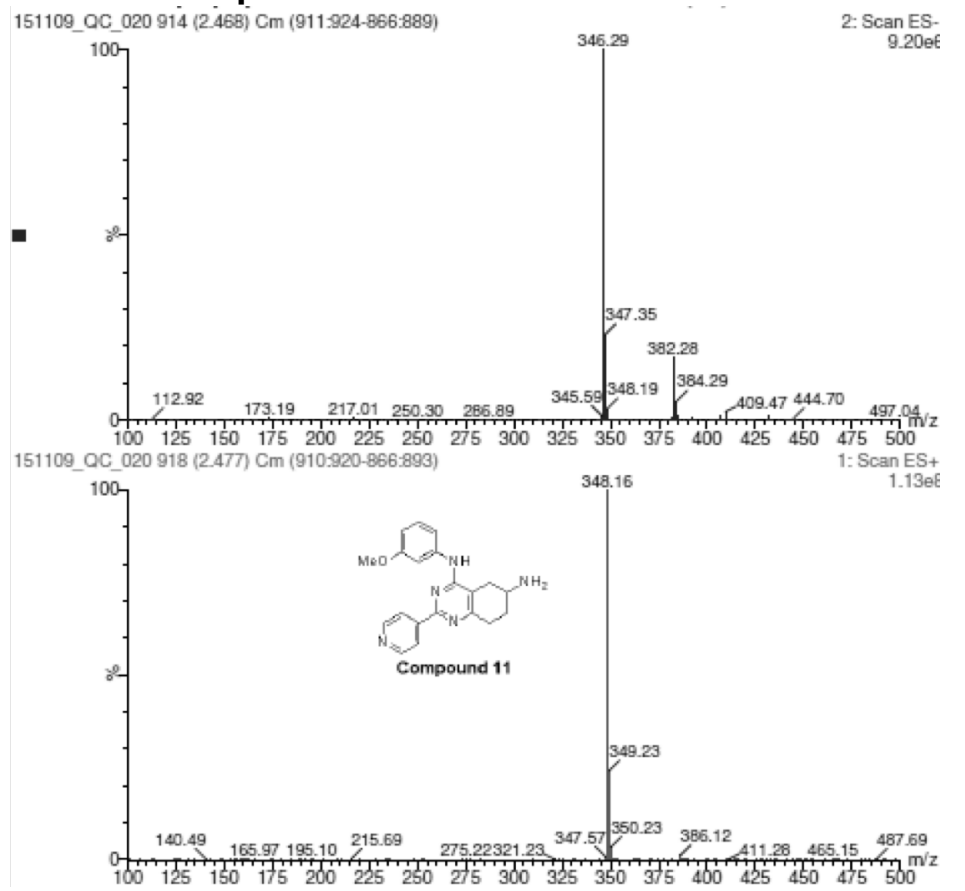




\section{${ }^{1}$ H-NMR Compound 12}

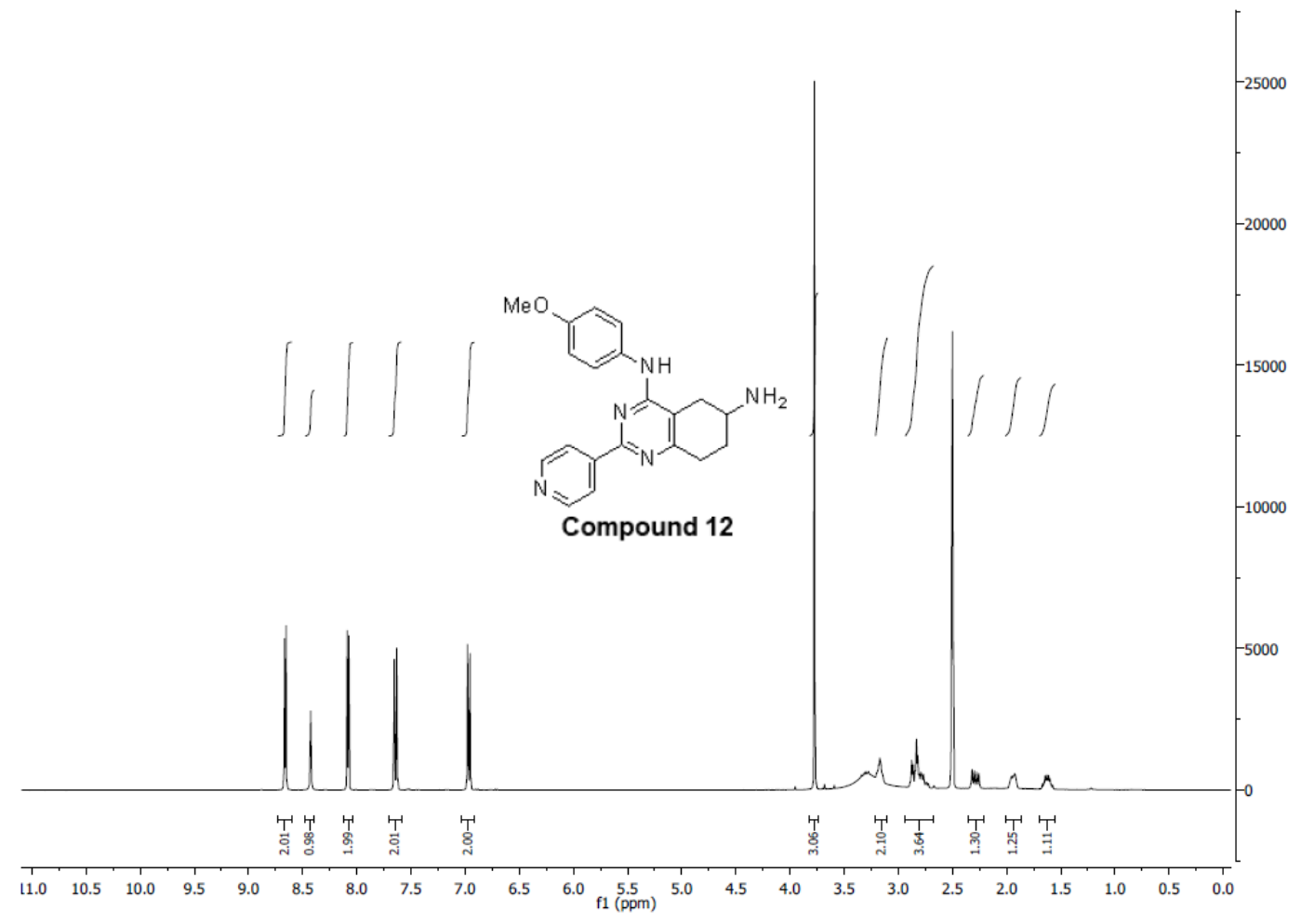

${ }^{13}$ C-NMR Compound 12

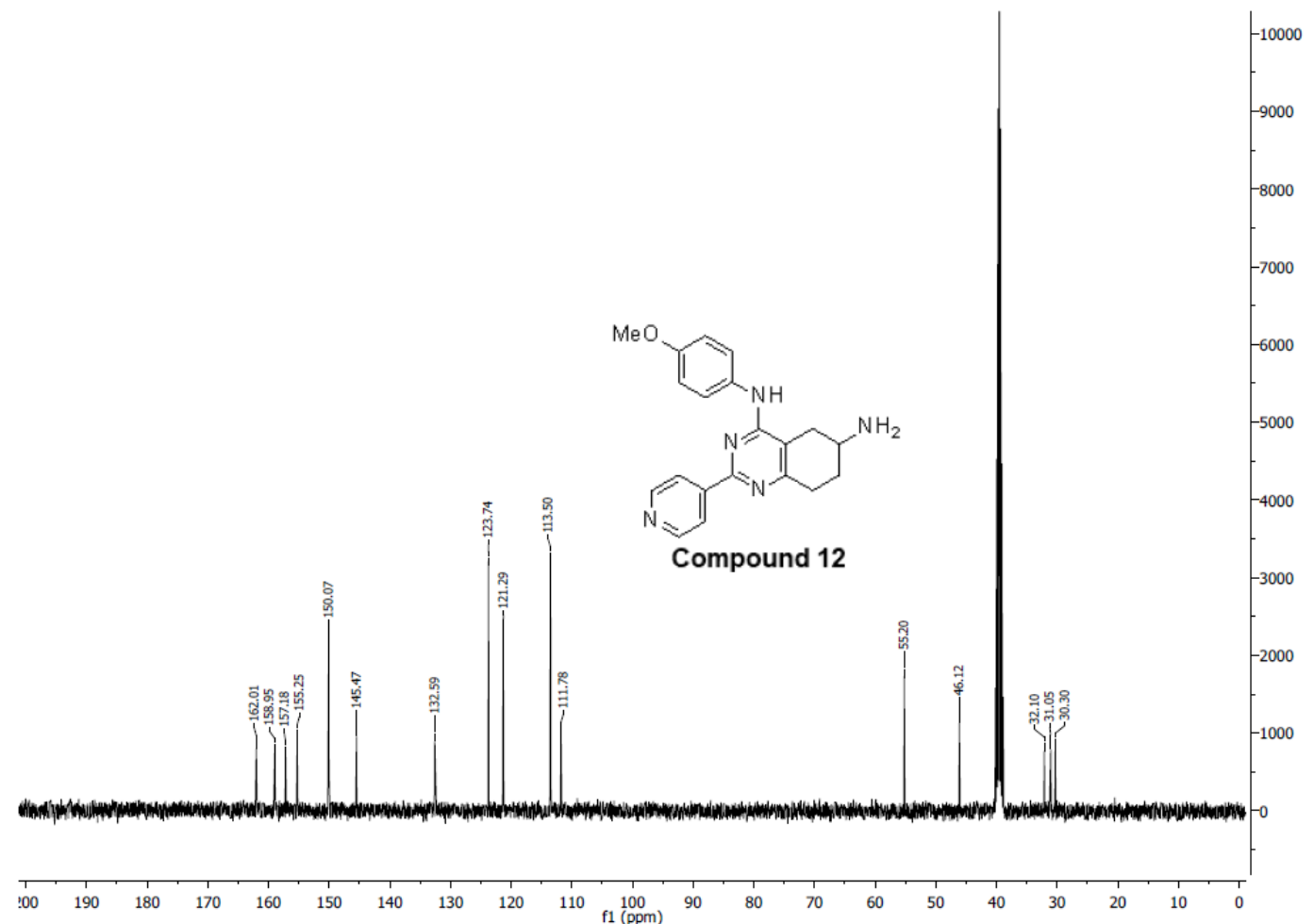




\section{UPLC-MS analysis Compound 12}

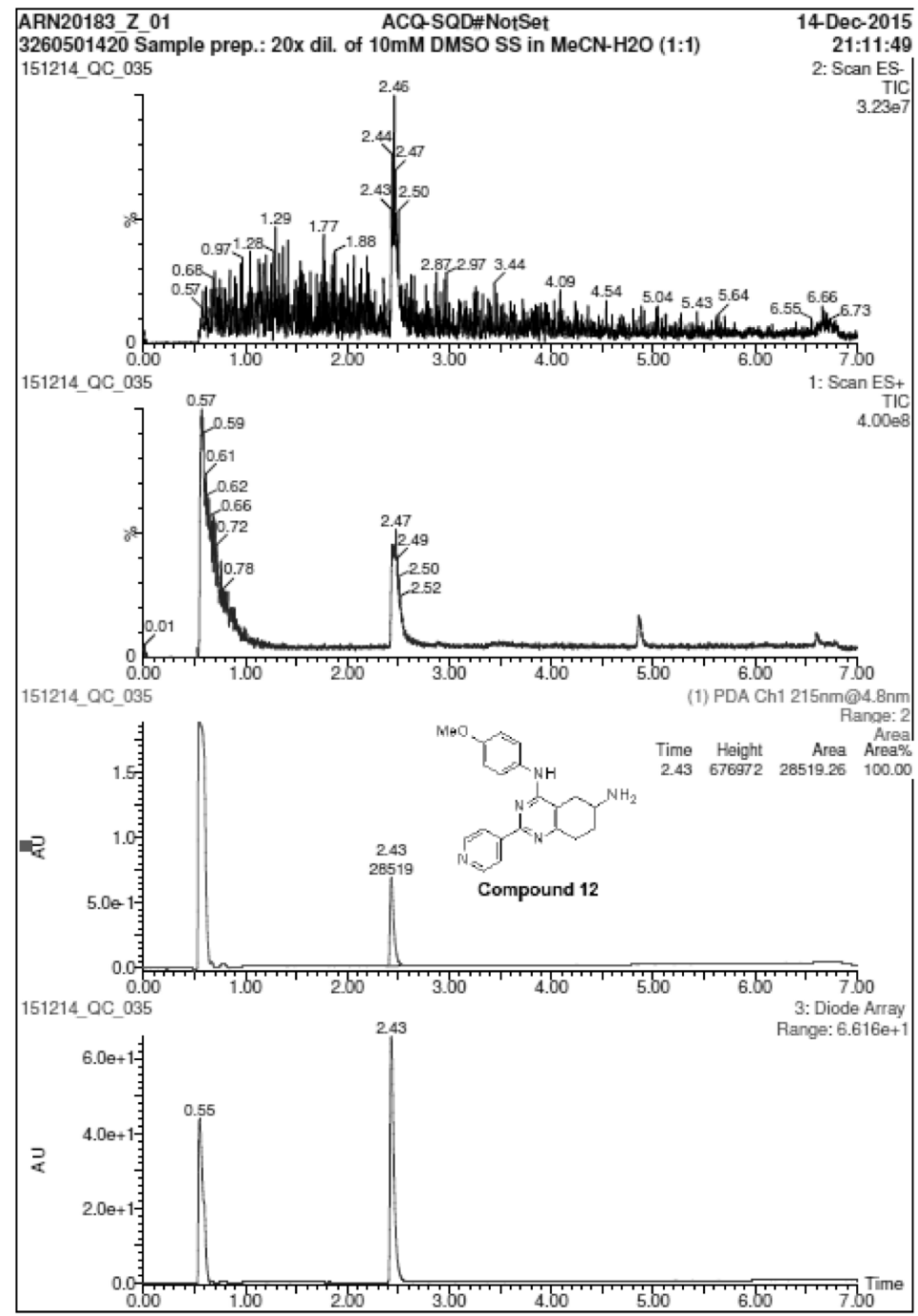

Mass spectrometry spectrum Compound 12

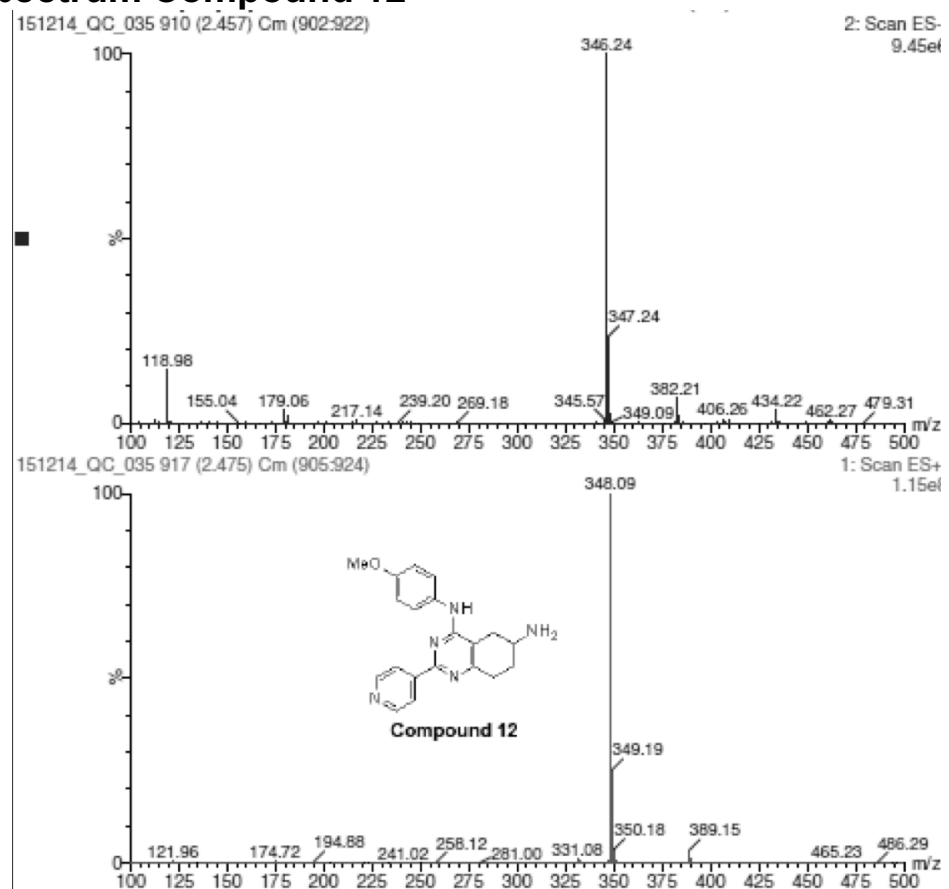




\section{${ }^{1}$ H-NMR Compound 13}

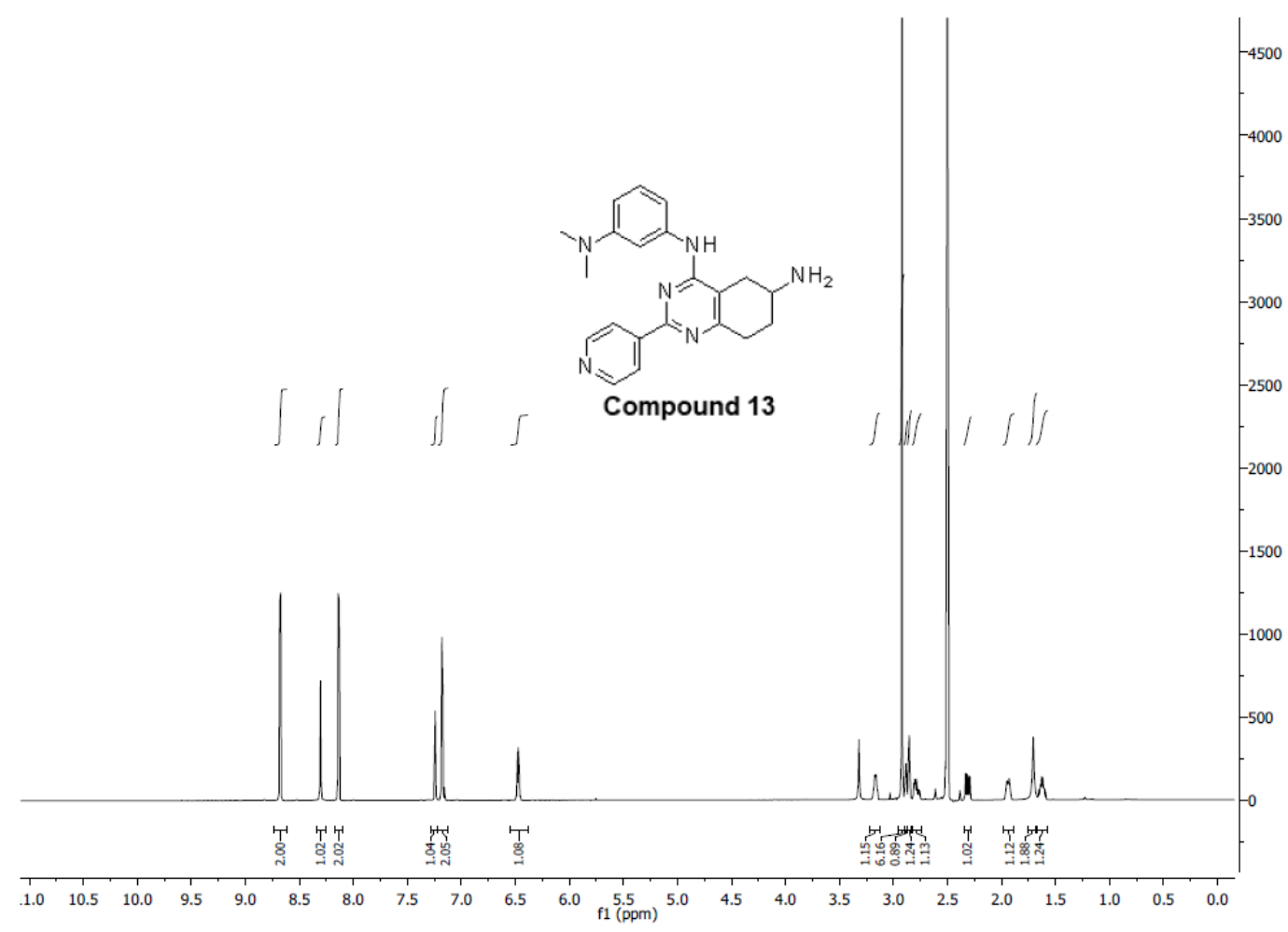

${ }^{13}$ C-NMR Compound 13

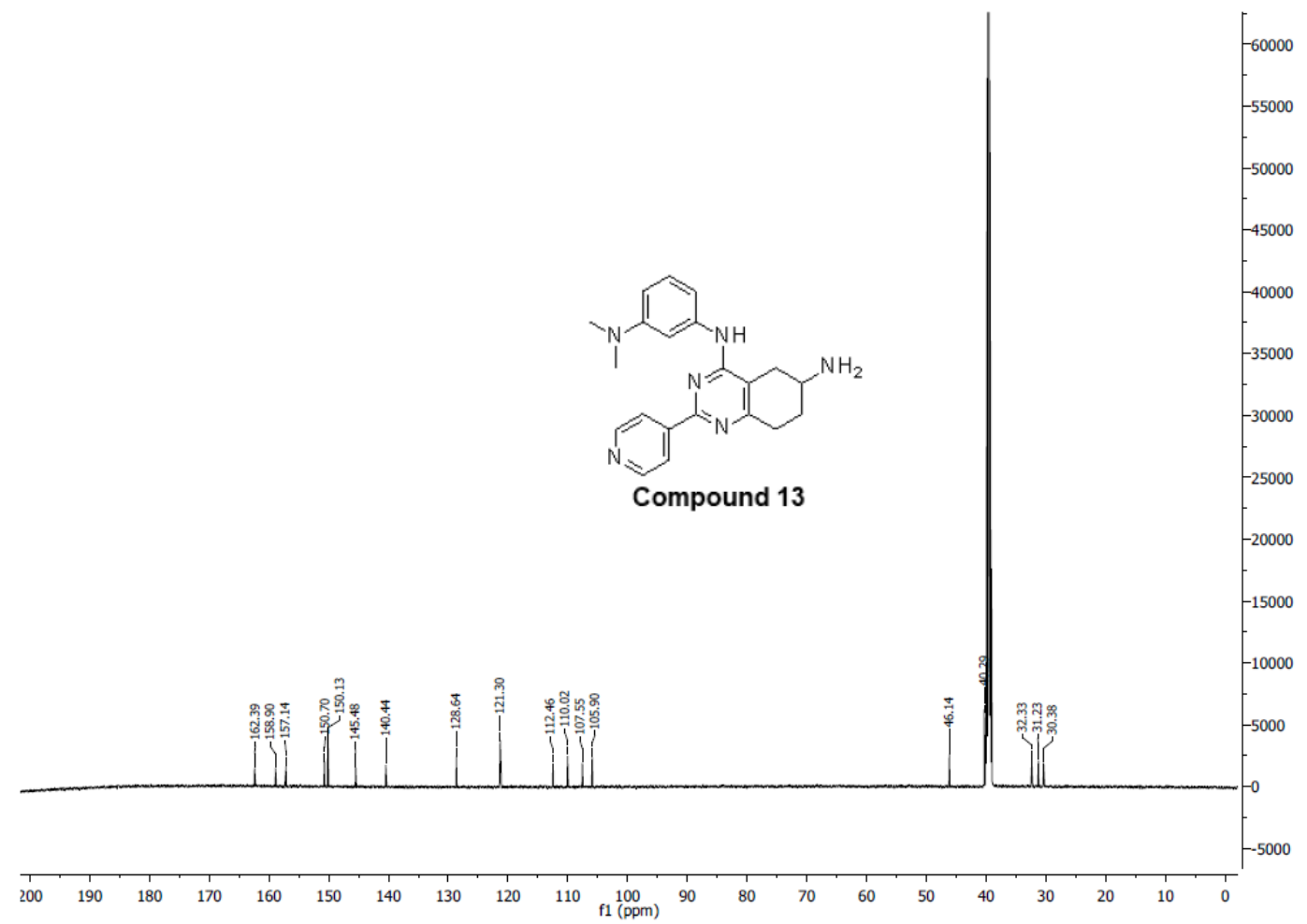




\section{UPLC-MS analysis Compound 13}

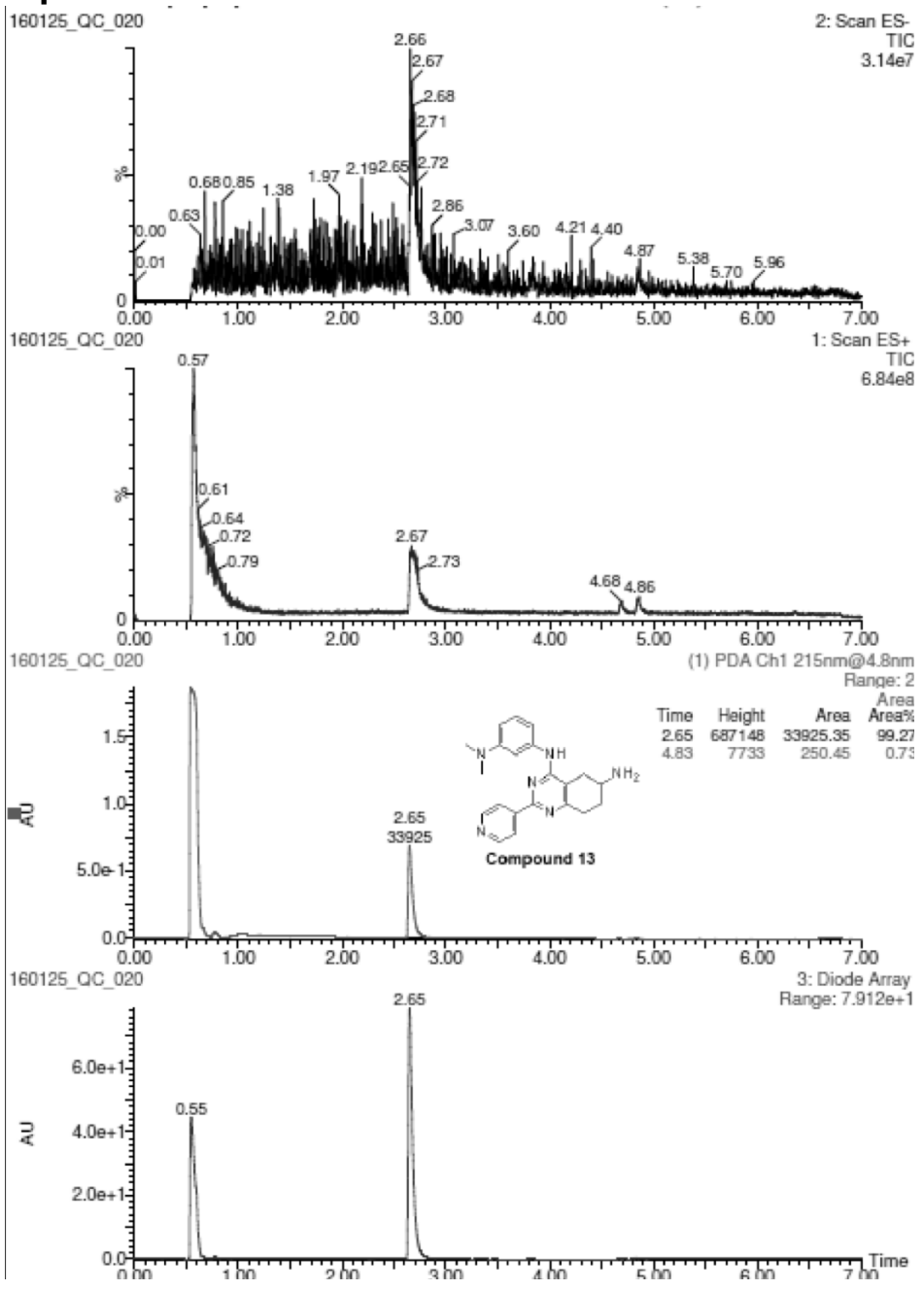

\section{Mass spectrometry spectrum Compound 13}

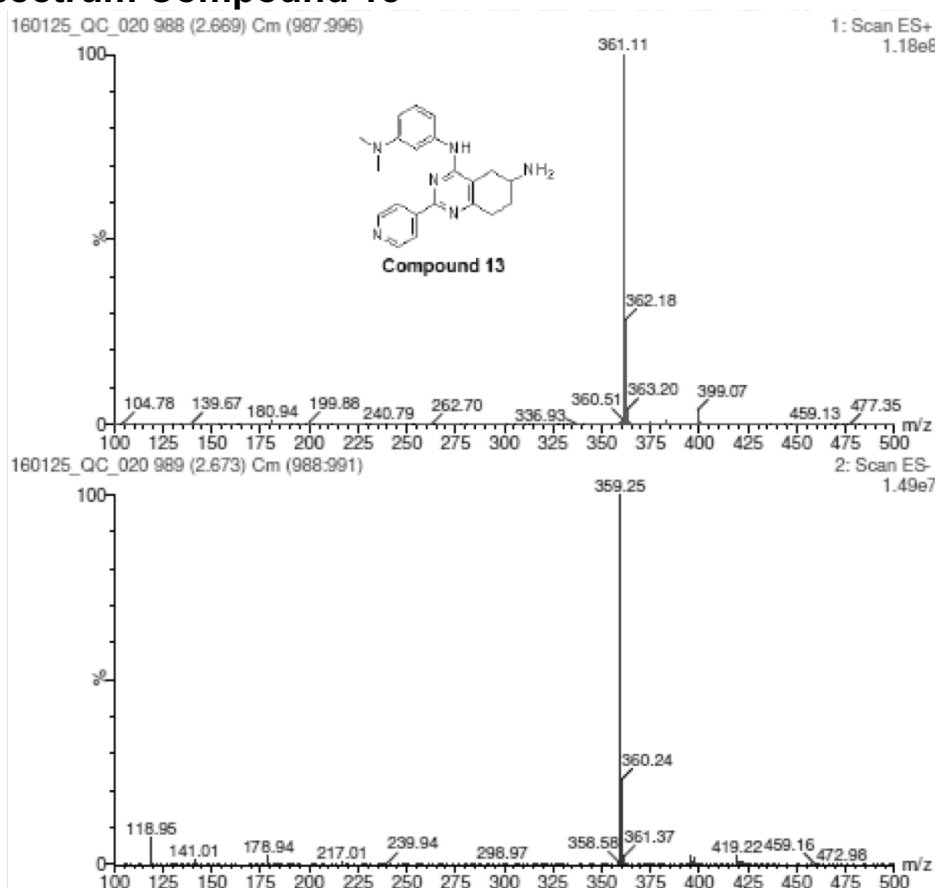




\section{${ }^{1} \mathrm{H}-\mathrm{NMR}$ Compound 14}

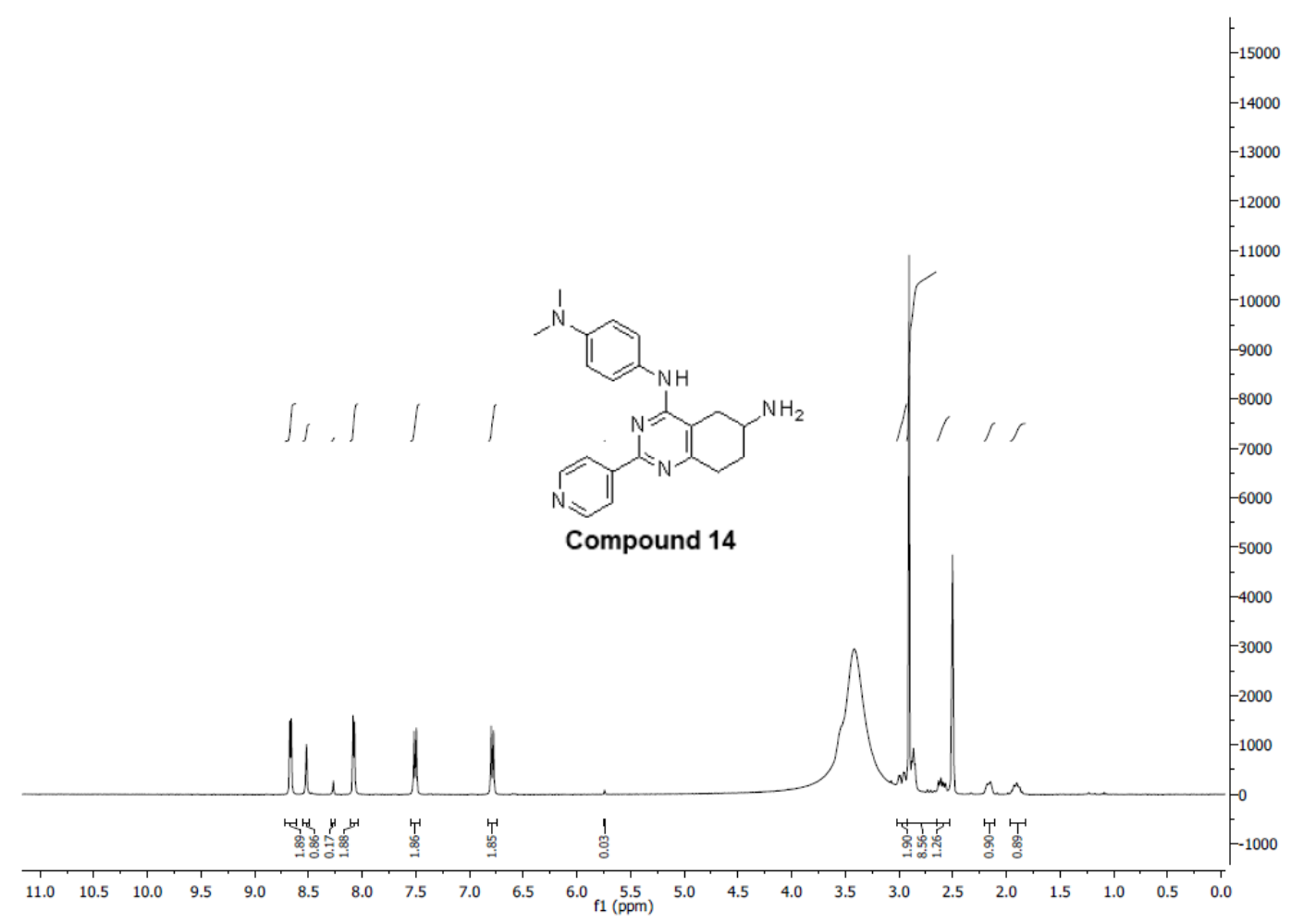

${ }^{13}$ C-NMR Compound 14

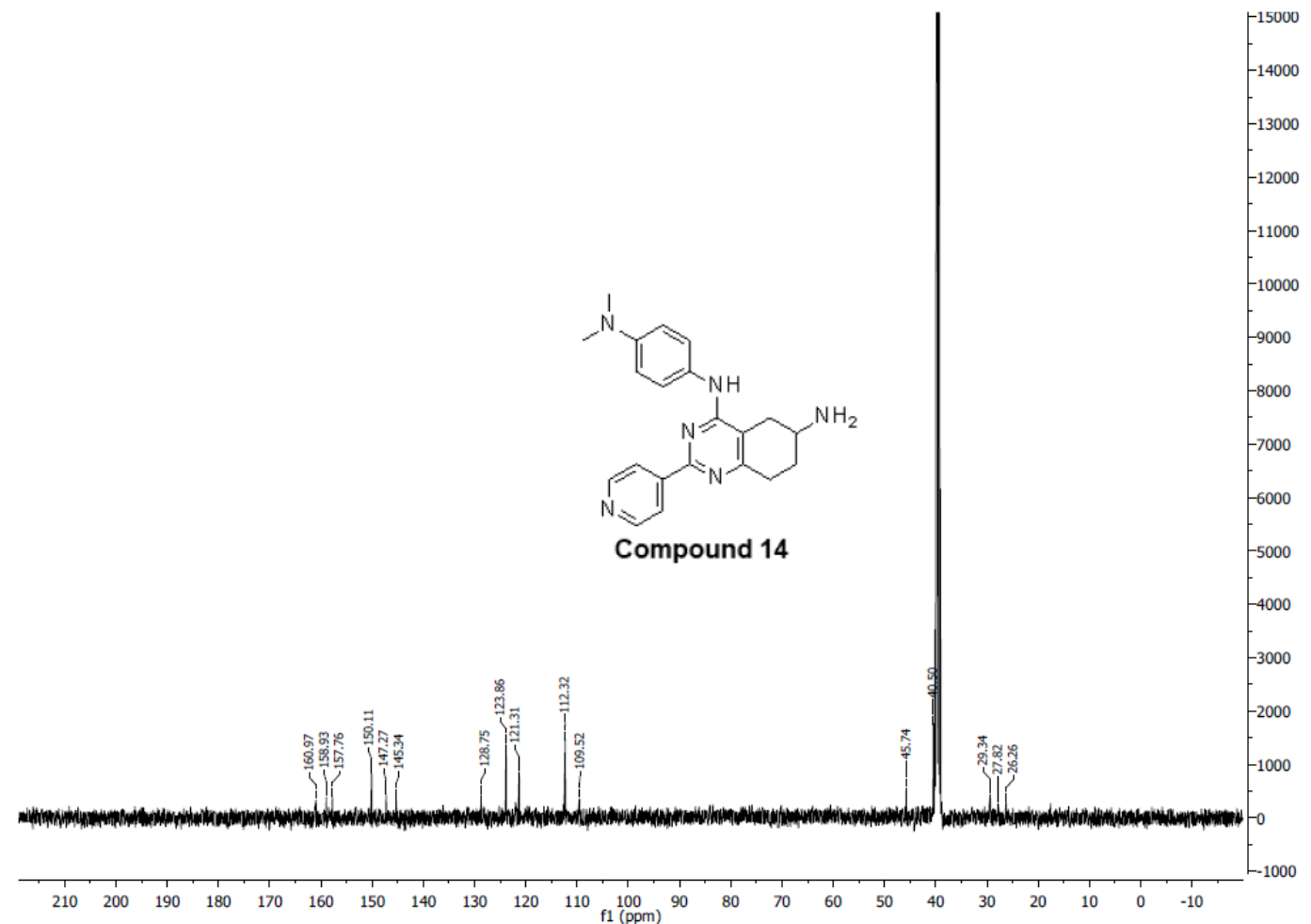


LCMS analysis Compound 14

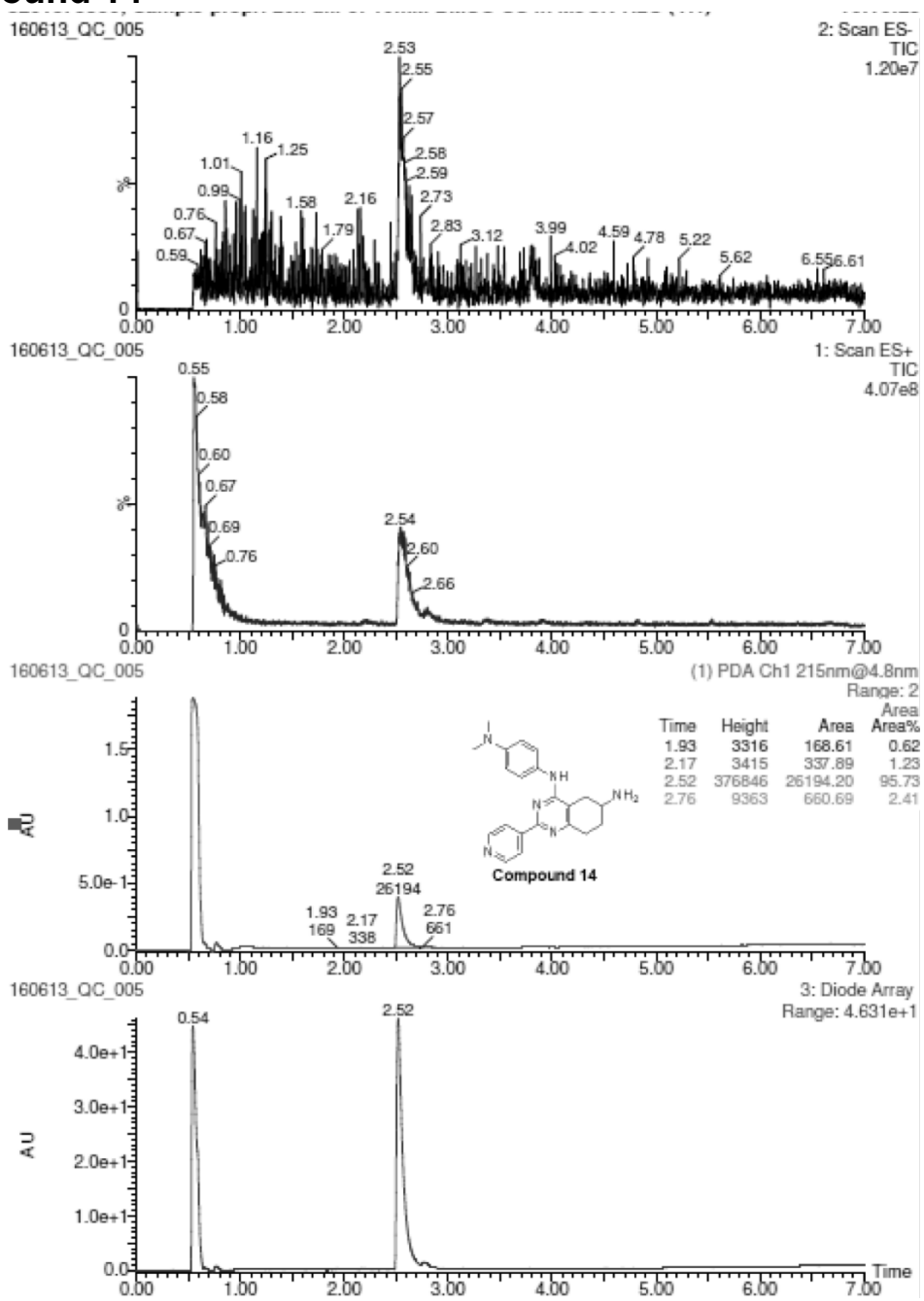

Mass spectrometry spectrum Compound 14

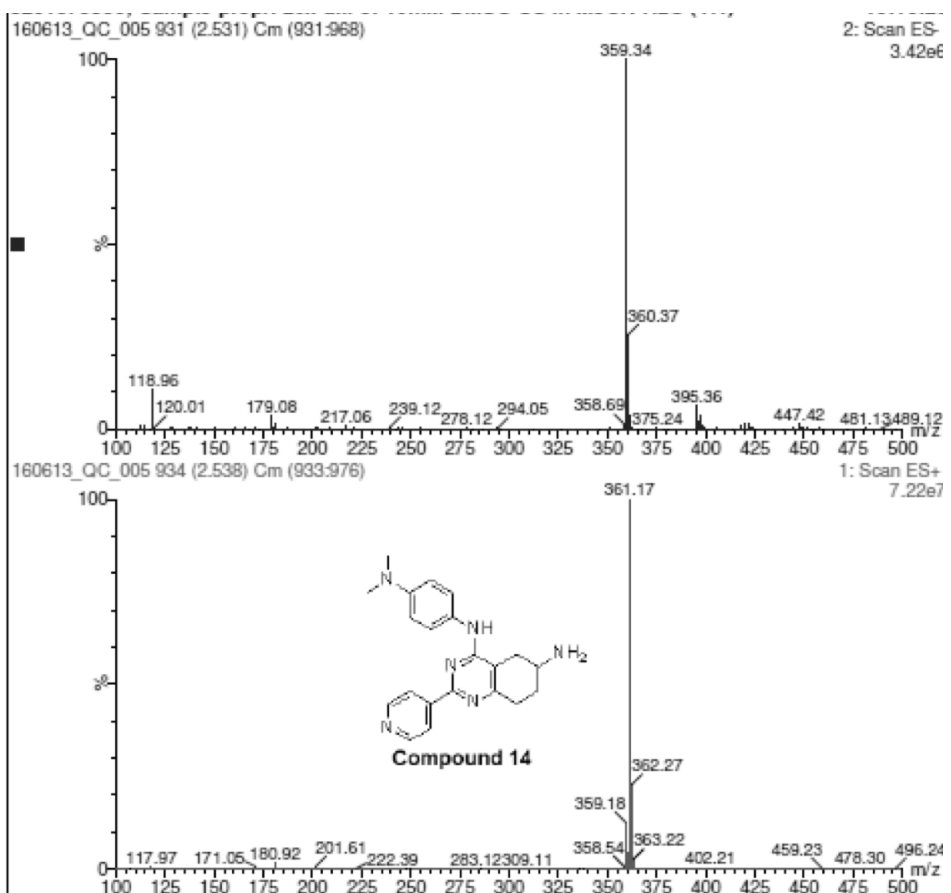




\section{S3. Cell Assays}

\section{A. Cell lines}

Human cancer cell lines A549 (lung adenocarcinoma, ATCC CCL-185), DU-145 (androgen-independent prostate cancer, ATCC HTB81), MCF7 (breast adenocarcinoma, ATCC HTB-22) and HeLa (cervical carcinoma, ATCC CCL-2) were obtained from ATCC. Human melanoma cell lines A375 (88113005) and G-361 (88030401) were obtained from European Collection of Authenticated Cell Cultures (ECACC). Cells were routinely grown in Minimal Essential Medium containing Eagle's salts and L-Glutamine (A549, DU-145, MCF7 and HeLa) or Dulbecco's Modified Minimal Essential Medium (A375 and G-361) supplemented with 10\% heat-inactivated FBS in a humidified atmosphere of $5 \% \mathrm{CO}_{2}$ at $37^{\circ} \mathrm{C}$.

\section{B. Cell Viability Assay}

To assess the antiproliferative activity of the compounds, cell viability was measured using the MTT assay. Cells were seeded at a density of 2500 cells/well (HeLa), 5000 cells/well (A549, DU-145 and A375) or 10000 cells/well (MCF7 and G-361) in 96 well plates. 24 hours after seeding, the cells were treated with compounds or vehicle (DMSO, final concentration $0.5 \%$ ) as control and incubated for 72 hours. Then, MTT solution was added to a final concentration of $0.5 \mathrm{mg} / \mathrm{ml}$ and cells were further incubated for 2 hours. After solubilization of the formazan crystals by the addition of a $10 \%$ SDS/0.01 N HCl solution, absorbance was measured at $570 \mathrm{~nm}$ (reference $690 \mathrm{~nm}$ ) in a plate reader (Infinite M200, Tecan). Inhibition curves consisted of 9 serial dilutions in triplicate in each case, and results were analyzed as sigmoidal dose-response curves using GraphPad Prism software (version 5.03). Values are reported as the mean $\pm S D$ of two independent experiments.

Table S2.Cell proliferation results in various cancer cell lines. Values shown correspond to the $\mathrm{IC}_{50}(\mu \mathrm{M}) \pm \mathrm{SD}$ of at least two independent experiments.

\begin{tabular}{|c|c|c|c|c|c|c|c|}
\hline Cell line & Compound 1 & Compound 3 & Compound 4 & Compound 11 & Compound 12 & Compound 14 & Etoposide \\
\hline DU145 & $15.1 \pm 5.5$ & $17.9 \pm 7.4$ & $11.1 \pm 6.5$ & $10.5 \pm 6.0$ & $8.8 \pm 1.5$ & $11.5 \pm 1.3$ & $0.5 \pm 0.2$ \\
\hline A549 & $19.4 \pm 1.8$ & $23.3 \pm 2.3$ & $17.8 \pm 0.6$ & $22.9 \pm 6.5$ & $18.0 \pm 0.1$ & $17.1 \pm 8.7$ & $2.4 \pm 2.0$ \\
\hline HeLa & $17.0 \pm 1.9$ & $17.1 \pm 3.2$ & $21.8 \pm 4.6$ & $20.8 \pm 4.5$ & $17.2 \pm 2.6$ & $38.2 \pm 9.1$ & $1.2 \pm 0.4$ \\
\hline MCF7 & $13.9 \pm 2.3$ & $14.2 \pm 2.5$ & $16.2 \pm 2.6$ & $16.0 \pm 0.5$ & $15.8 \pm 1.4$ & $15.8 \pm 1.3$ & $8.9 \pm 1.6$ \\
\hline A375 & $9.9 \pm 0.1$ & $10.7 \pm 0.1$ & $10.8 \pm 0.1$ & $12.3 \pm 1.8$ & $15.1 \pm 4.8$ & $12.6 \pm 0.7$ & $0.5 \pm 0.1$ \\
\hline G361 & $1.4 \pm 0.4$ & $1.6 \pm 0.5$ & $1.8 \pm 0.6$ & $3.0 \pm 0.7$ & $6.6 \pm 3.1$ & $8.1 \pm 2.9$ & $3.8 \pm 3.0$ \\
\hline
\end{tabular}

\section{Immunodetection of H2AX phosphorylation}

HeLa cells were seeded in 6 well plates at a density of $0.510^{6}$ cells/well and the following day were treated with etoposide, compound ARN21394 or DMSO as control for 90 minutes. The concentration of etoposide and compound 14 were 2.5 and $10 \mu \mathrm{M}$, respectively (IC50 concentration). After exposure to the compounds, media was removed and the cells were quickly washed with cold PBS, detached, pelleted by centrifugation, frozen immediately and stored at $-80^{\circ} \mathrm{C}$. Proteins were extracted using RIPA buffer including protease and phosphatases inhibitors and protein concentration was measured using the Bradford assay (BioRad). 30 $\mu$ g protein were then separated by electrophoresis using NuPAGE 4-12\% precast gels (Invitrogen) and transferred into nitrocellulose membranes. After blocking for 1 hour with $5 \%$ milk in $20 \mathrm{mMTrisHCl} \mathrm{pH} 7.6$ buffer containing $150 \mathrm{mMNaCl}$ and $0.1 \%$ Tween 20 (TBST), primary antibodies (anti-phospho-H2AX antibody (Ser139) at 1:1000 dilution; Cell Signaling Technology, \#9718S; anti-GAPDH at 1:2500 dilution; Sigma) were applied and incubated overnight at $4{ }^{\circ} \mathrm{C}$. Membranes were then washed several times in TBST and incubated with secondary antibodies conjugated to HRP for 1 hour at room temperature. LightaBlot $₫$ Extend chemiluminescent substrate (Euroclone) was applied and images were obtained using an ImageQuant LAS-4000 (Fujitsu) apparatus. 


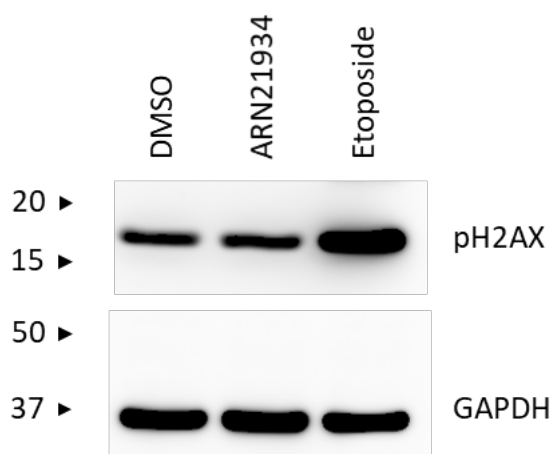

Figure S1. HeLa cells were treated for 90 minutes with the indicated topoll inhibitors at their $\mathrm{IC}_{50}$ concentration or with DMSO (control vehicle). After exposure, assessment of $\mathrm{H} 2 \mathrm{AX}$ phosphorylation as a reporter of DNA damage was performed by immunodetection using anti-phospho-H2AX antibody (Ser139) (Cell Signaling Technology, \#9718S). GAPDH was used as control for equal protein loading. Numbers on the left indicate MW (KDa). Clear increase of the phosphorylated form of H2AX indicative of DNA damage by topoll blockade is only visible with etoposide.

\section{S4. Additional Molecular Biology}

\section{A. Topoisomerase inhibition}

$0.125 \mu \mathrm{g}$ of pBR322 (Inspiralis) were incubated with increasing concentrations (0.5-200 $\mu \mathrm{M})$ of tested compounds for 1 hour at $37{ }^{\circ} \mathrm{C}$ in the presence/absence of $1 \mathrm{U}$ of human topoisomerase Ila (Inspiralis) in the required buffer (1X). Reaction products were resolved on a $1 \%$ agarose gel prepared in $1 \mathrm{X}$ TAE (10 mM Tris $1 \mathrm{mM}$ EDTA, $0.1 \%$ acetic acid, pH 8.0). After the electrophoretic run $(5 \mathrm{~V} / \mathrm{cm}$ for about $90 \mathrm{~min}$ ) the DNA bands were visualized by ethidium bromide staining, photographed and quantified using a Geliance 2000 apparatus.

Table S3. Topoisomerase Ila inhibition

\begin{tabular}{llllll}
\hline Compound & $\mathrm{IC}_{50}(\mu \mathrm{M})$ & Compound & $\mathrm{IC}_{50}(\mu \mathrm{M})$ & Compound & $\mathrm{IC}_{50}(\mu \mathrm{M})$ \\
\hline 1 & $160 \pm 20$ & 6 & not active & 11 & $170 \pm 15$ \\
2 & not active & 7 & not active & 12 & not active \\
3 & $160 \pm 20$ & 8 & not active & 13 & not active \\
4 & $160 \pm 20$ & 9 & not active & 14 & $2 \pm 0.5$ \\
5 & $200 \pm 15$ & 10 & $220 \pm 30$ & & \\
\hline
\end{tabular}

\section{B. Topoll inhibition mechanism characterization of compound 14}

\section{Materials}

Recombinant wild-type human topoisomerase $\| \boldsymbol{\alpha}$ (topoll $\boldsymbol{\alpha}$ ) and topoisomerase $\| \beta$ (topoll $\beta$ ) were expressed in Saccharomyces cerevisiae JEL-1 $\Delta$ top 1 and purified as described previously. ${ }^{1-3}$ The enzymes were stored at $-80{ }^{\circ} \mathrm{C}$ as $1.5 \mathrm{mg} / \mathrm{mL}$ stocks in $50 \mathrm{mM}$ Tris- $\mathrm{HCl}, \mathrm{pH}$ 7.9, $0.1 \mathrm{mM} \mathrm{NaEDTA}, 750 \mathrm{mM} \mathrm{KCl}$, and 40\% glycerol. Negatively supercoiled pBR322 DNA was prepared from Escherichia coli using a Plasmid Mega Kit (Qiagen) as described by the manufacturer and exonuclease treated to remove any chromosomal DNA contaminants from the plasmid. ${ }^{4}$ Analytical grade etoposide and ethidium bromide were purchased from SigmaAldrich. [ $\gamma^{32}$ P]ATP $\left(3000 \mathrm{Ci} / \mathrm{mmol}\right.$ stock) was purchased from Perkin Elmer. Compound 14 was stored at $-20^{\circ} \mathrm{C}$ as a $20 \mathrm{mM}$ solution in dimethyl sulfoxide. 


\section{DNA Relaxation}

DNA relaxation reactions were carried out using the procedure of Fortune and Osheroff. ${ }^{5}$ Reaction mixtures contained $5 \mathrm{nM}$ negatively supercoiled pBR322 DNA, $3 \mathrm{nM}$ human topoll $\alpha$ or $4 \mathrm{nM}$ topoll $\beta, 1 \mathrm{mM}$ ATP and 0-200 $\mu \mathrm{M}$ compound 14 in a total of $20 \mu \mathrm{L}$ of $10 \mathrm{mM}$ Tris- $\mathrm{HCl}, \mathrm{pH} 7.9,5 \mathrm{mM} \mathrm{MgCl}, 175 \mathrm{mM} \mathrm{KCl}, 0.1 \mathrm{mM} \mathrm{NaEDTA}$, and 2.5\% (v/v) glycerol. Mixtures were incubated at $37{ }^{\circ} \mathrm{C}$ for $4 \mathrm{~min}$. Reactions were stopped by the addition of $3 \mu \mathrm{L}$ of $0.77 \%$ SDS-77 mM NaEDTA, pH 8.0. Samples were mixed with $2 \mu \mathrm{L}$ of agarose loading dye [ $60 \%$ sucrose $(\mathrm{w} / \mathrm{v}), 10 \mathrm{mM}$ Tris- $\mathrm{HCl}, \mathrm{pH} 7.9,0.5 \%$ bromophenol blue, $0.5 \%$ xylene cyanol], heated for $2 \mathrm{~min}$ at $45{ }^{\circ} \mathrm{C}$, and subjected to electrophoresis in a $1 \%$ agarose gel in $100 \mathrm{mM}$ Tris-borate, $\mathrm{pH} 8.3$, and $2 \mathrm{mM}$ EDTA. Gels were stained for 30 min using $1.0 \mu \mathrm{g} / \mathrm{mL}$ ethidium bromide and rinsed in deionized water. DNA bands were visualized by medium wave UV light and quantified using an Alpha Innotech digital imaging system. DNA Relaxation was monitored by the loss of supercoiled plasmid molecules.

\section{DNA Cleavage}

DNA cleavage reactions were performed using the procedure of Fortune and Osheroff. ${ }^{5}$ Reaction mixtures contained $10 \mathrm{nM}$ negatively supercoiled pBR322 DNA and $150 \mathrm{nM}$ human topoll $\alpha$ in a final volume of $20 \mu \mathrm{L}$ of cleavage buffer [10 mM Tris- $\mathrm{HCl}, \mathrm{pH} 7.9,5 \mathrm{mM}$ $\mathrm{MgCl}_{2}, 100 \mathrm{mM} \mathrm{KCl}, 0.1 \mathrm{mM} \mathrm{NaEDTA}$, and 2.5\% (v/v) glycerol] containing 0-200 $\mu \mathrm{M}$ compound 14. Reactions were incubated for 6 min at $37{ }^{\circ} \mathrm{C}$ and enzyme-DNA cleavage complexes were trapped by the addition of $2 \mu \mathrm{L}$ of $4 \%$ SDS followed by $2 \mu \mathrm{L}$ of $250 \mathrm{mM}$ NaEDTA, pH 8.0. Proteinase $\mathrm{K}\left(2 \mu \mathrm{L}\right.$ of a $0.8 \mathrm{mg} / \mathrm{mL}$ solution) was added, and samples were incubated for 30 min at $45^{\circ} \mathrm{C}$ to digest the enzyme. Samples were mixed with $2 \mu \mathrm{L}$ of agarose loading dye, heated for $2 \mathrm{~min}$ at $45^{\circ} \mathrm{C}$, and subjected to electrophoresis in a $1 \%$ agarose gel in $40 \mathrm{mM}$ Tris-acetate, $\mathrm{pH} 8.3$, and $2 \mathrm{mM}$ EDTA containing $0.5 \mu \mathrm{g} / \mathrm{mL}$ ethidium bromide. DNA bands were visualized and quantified as described above. DNA cleavage was monitored by the conversion of supercoiled plasmid to linear molecules.

\section{DNA Intercalation}

DNA intercalation was carried out using the protocol of Fortune et al. ${ }^{6}$ Calf thymus DNA topoisomerase I (Invitrogen, $0.5 \mathrm{U}$ ) and $5 \mathrm{mM}$ of relaxed pBR322 were incubated in $10 \mathrm{mM}$ Tris- $\mathrm{HCl}, \mathrm{pH} 7.5,10 \mathrm{mM} \mathrm{KCl}, 2 \mathrm{mM} \mathrm{MgCl}, 0.02 \mathrm{mM}$ EDTA, $0.1 \mathrm{mM}$ dithiothreitol, 6 $\mu \mathrm{g} / \mathrm{mL}$ bovine serum albumin. Assays were carried out in the presence of 0-25 $\mu \mathrm{M}$ compound 14. Mixtures were incubated for $15 \mathrm{~min}$ at $37^{\circ} \mathrm{C}$. Reactions containing $10 \mu \mathrm{M}$ ethidium bromide (a well-characterized intercalator), or $100 \mu \mathrm{M}$ etoposide (a non-intercalative topoisomerase II poison) were used as positive or negative controls, respectively. Samples were extracted using $20 \mu \mathrm{L}$ of phenol:chloroform:isoamyl alcohol (25:24:1), and the aqueous layer was mixed with $2 \mu \mathrm{L}$ of agarose loading dye and heated for 5 min at $45^{\circ} \mathrm{C}$. Reactions were stopped by the addition of $3 \mu \mathrm{L}$ of $0.77 \%$ SDS-77 mM NaEDTA, pH 8.0. Samples were mixed with $2 \mu \mathrm{L}$ of agarose loading dye, heated for $2 \mathrm{~min}$ at $45^{\circ} \mathrm{C}$, and subjected to electrophoresis in a $1 \%$ agarose gel in $100 \mathrm{mM}$ Tris-borate, pH 8.3 , and $2 \mathrm{mM}$ EDTA. Gels were stained for $30 \mathrm{~min}$ using $1.0 \mu \mathrm{g} / \mathrm{mL}$ ethidium bromide and rinsed in deionized water. DNA bands were visualized and quantified as described above. DNA intercalation was monitored by the conversion of relaxed to supercoiled plasmid molecules.

\section{ATP hydrolysis}

ATPase assays were performed as described by Osheroff et al. ${ }^{7}$ Reaction mixtures contained $30 \mathrm{nM}$ human topoll $\boldsymbol{\alpha}, 1 \mathrm{mM}\left[\gamma^{32} \mathrm{P}\right] \mathrm{ATP}$, and 0-25 $\mu \mathrm{M}$ compound 14 in a total of $20 \mu \mathrm{L}$ of cleavage buffer. Some assays were carried out in the presence of $5 \mathrm{nM}$ negatively supercoiled pB322 DNA. Reactions were initiated by the addition of topoll $\alpha$ and mixtures were incubated at $37^{\circ} \mathrm{C}$ for $8 \mathrm{~min}$. Samples $(2.0 \mu \mathrm{L})$ were removed and spotted on to polyethyleneimine-impregnated thin layer cellulose chromatography plates. Plates were developed by chromatography in freshly prepared $400 \mathrm{mM} \mathrm{NH}_{4} \mathrm{HCO}_{3}$, and released ${ }^{32} \mathrm{P}$ was visualized and quantified using a Bio-Rad Pharos FX Plus Molecular Imager. 

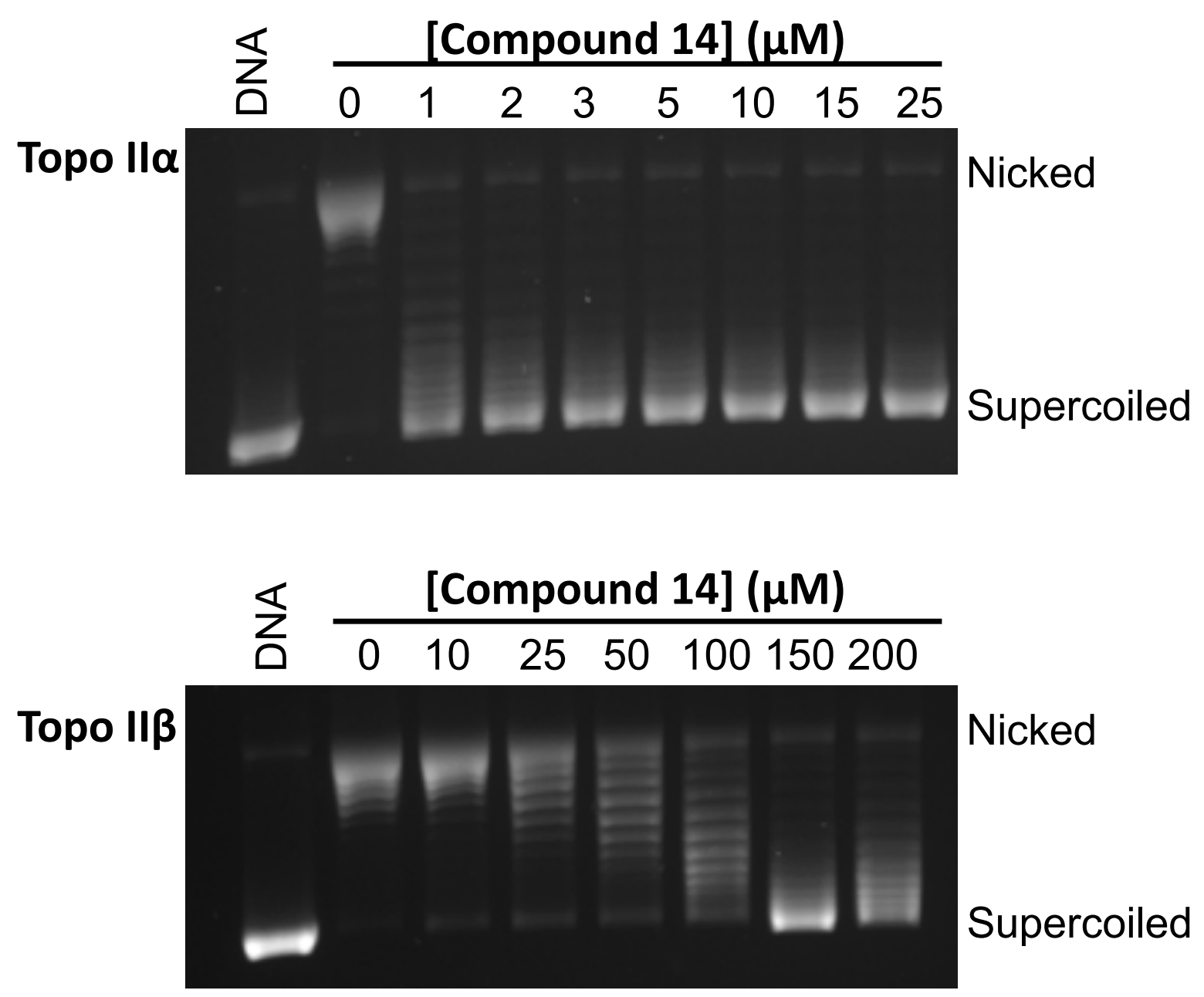

Figure S2. Inhibition of DNA relaxation by compound 14. Ethidium bromide-strained agarose gels are shown for DNA relaxation catalyzed by human topoll $\alpha$ (top gel) or topoll $\beta$ (bottom gel). A negatively supercoiled DNA control (DNA) is included. The positions of nicked and supercoiled DNA are indicated. Relaxed DNA bands display an electrophoretic mobility between the nicked (more relaxed) and supercoiled (less relaxed) bands. Gels are representative of at least three independent experiments. Whereas the $\mathrm{IC}_{50}$ of 14 for DNA relaxation catalyzed by topoll $\alpha$ is $<1 \mu \mathrm{M}$, that for DNA relaxation by topoll $\beta$ exceeds $100 \mu \mathrm{M}$. 


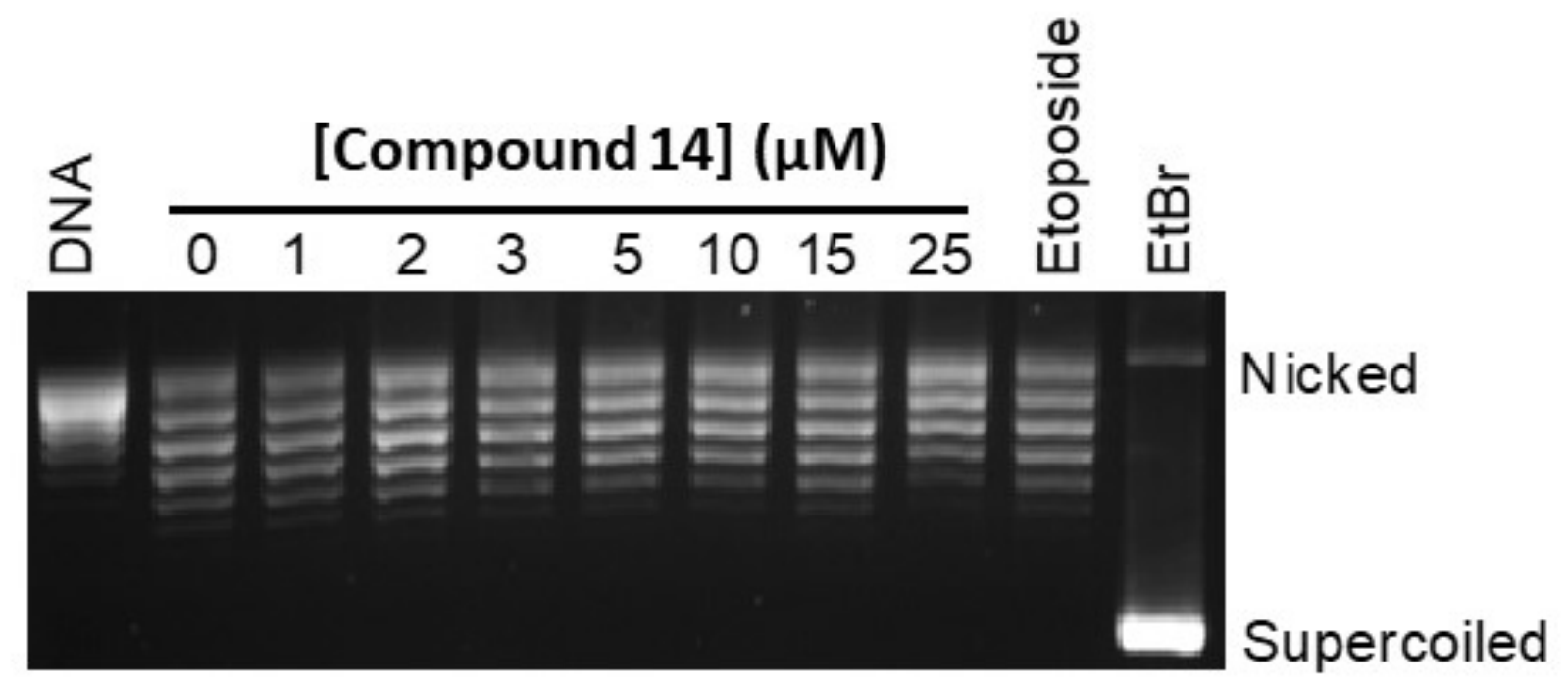

Figure S3. Compound 14 does not intercalate into DNA in the concentration range in which it inhibits topolla. A topoisomerase I-DNA unwinding assay was used to monitor intercalation. An ethidium bromide-strained agarose gel is shown. A relaxed DNA control (DNA) is included. The positions of nicked and supercoiled DNA are indicated. Relaxed DNA bands display an electrophoretic mobility between the nicked (more relaxed) and supercoiled (less relaxed) bands. Intercalation is indicated by the shift in the position of the plasmid from relaxed to negatively supercoiled. The effects of $10 \mu \mathrm{M}$ ethidium bromide ( $\mathrm{EtBr}$, a strong intercalator) and $100 \mu \mathrm{M}$ etoposide (a non-intercalator) on the DNA unwinding assay are shown as controls. The gel is representative of at least three independent experiments.

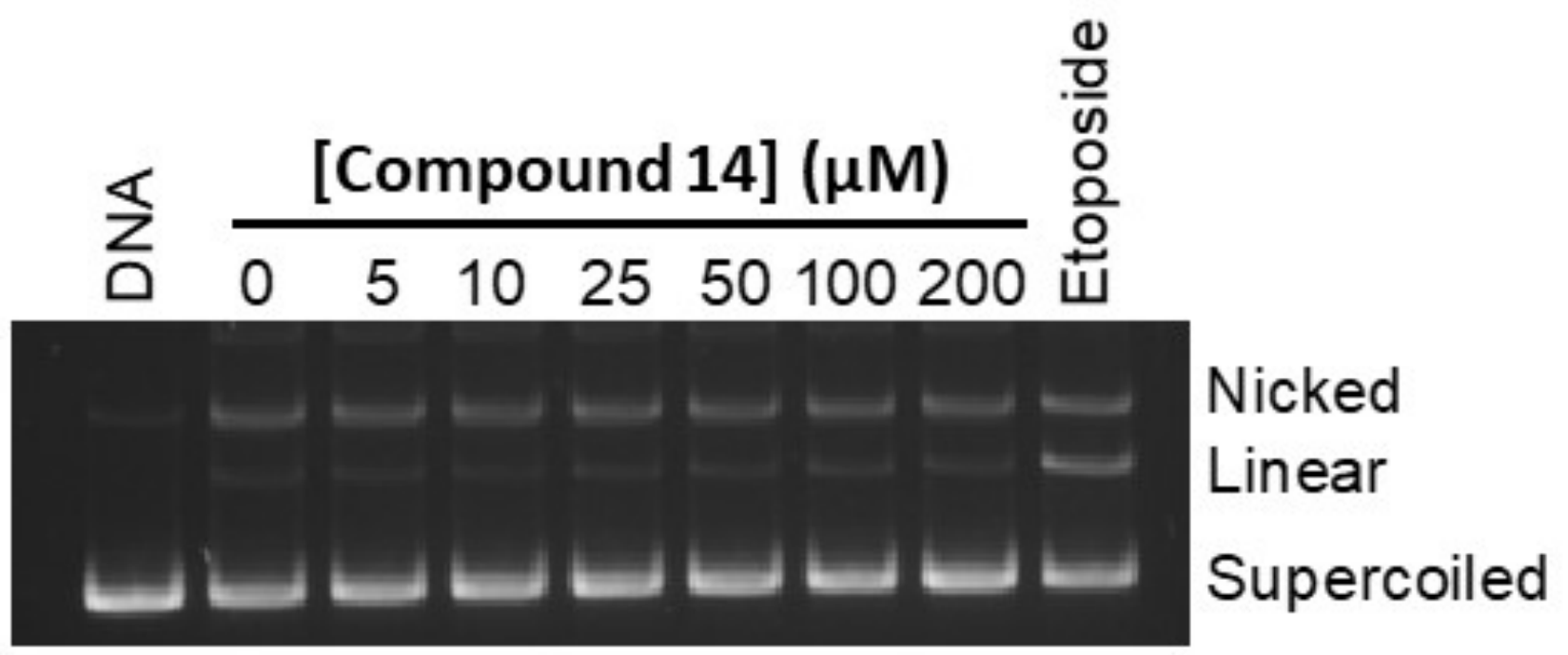

Figure S4. Compound 14 does not induce DNA cleavage mediated by human topoll $\alpha$. An ethidium bromide-strained agarose gel is shown. A negatively supercoiled DNA control (DNA) is included. The positions of nicked, linear, and supercoiled DNA are indicated. Single- and double-stranded DNA cleavage are indicated by the conversion of supercoiled to nicked and linear DNA respectively. The effects of $50 \mu \mathrm{M}$ etoposide (a topoisomerase II poison) on DNA cleavage mediated by topoll $\alpha$ are shown as a positive control. The gel is representative of at least three independent experiments. 


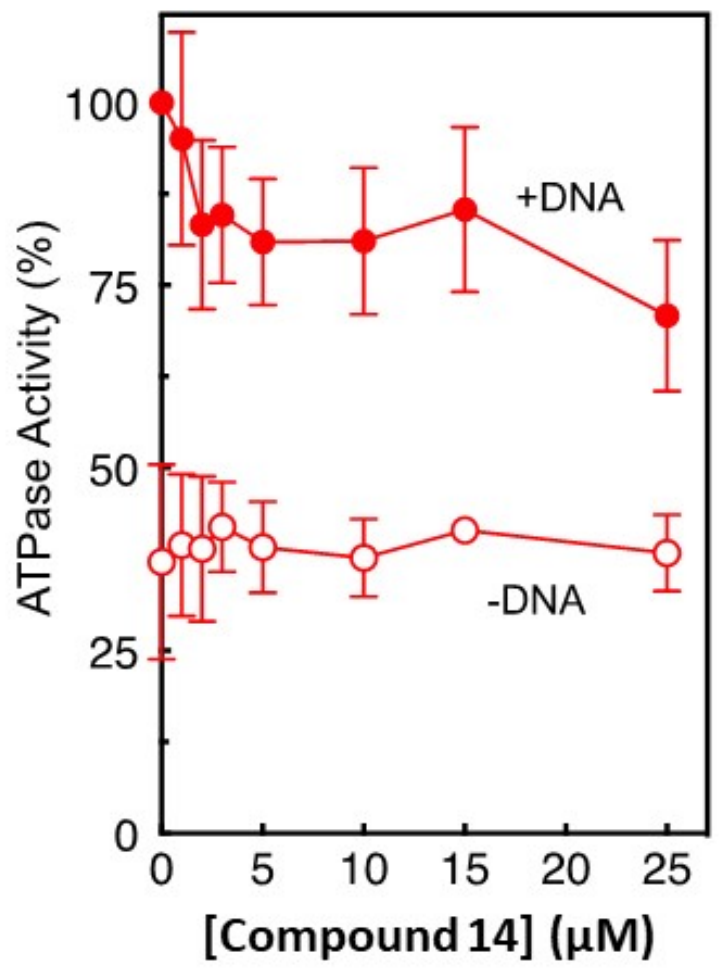

Figure S5. Effects of compound 14 on ATP hydrolysis catalyzed by human topolla. Results for reactions carried out in the absence or presence of negatively supercoiled DNA are shown as empty or filled circles, respectively. Note that rates of ATP hydrolysis are higher in the presence of negatively supercoiled DNA.7 ATPase activity determined in the presence of DNA and the absence of 14 was set to $100 \%$. Error bars represent standard error of the mean for two independent experiments.

\section{References}

[1] Worland, S. T., and Wang, J. C. (1989) Inducible overexpression, purification, and active site mapping of DNA topoisomerase II from the yeast Saccharomyces cerevisiae, J. Biol. Chem. 264, 4412-4416.

[2] Wasserman, R. A., Austin, C. A., Fisher, L. M., and Wang, J. C. (1993) Use of yeast in the study of anticancer drugs targeting DNA topoisomerases: expression of a functional recombinant human DNA topoisomerase II alpha in yeast, Cancer Res. 53, 35913596.

[3] Kingma, P. S., Greider, C. A., and Osheroff, N. (1997) Spontaneous DNA lesions poison human topoisomerase Il $\alpha$ and stimulate cleavage proximal to leukemic 11q23 chromosomal breakpoints, Biochemistry 36, 5934-5939.

[4] Minniti, E., Byl, J. A. W., Riccardi, L., Sissi, C., Rosini, M., De Vivo, M., Minarini, A., and Osheroff, N. (2017) Novel xanthonepolyamine conjugates as catalytic inhibitors of human topoisomerase II, Bioorg. Med. Chem. Lett. 27, 4687-4693.

[5] Fortune, J. M., and Osheroff, N. (1998) Merbarone inhibits the catalytic activity of human topoisomerase Il $\boldsymbol{\alpha}$, J. Biol. Chem. 273, $17643-17650$.

[6] Fortune, J. M., Velea, L., Graves, D. E., Utsugi, T., Yamada, Y., and Osheroff, N. (1999) DNA topoisomerases as targets for the anticancer drug TAS-103: DNA interactions and topoisomerase catalytic inhibition, Biochemistry 38, 15580-15586.

[7] Osheroff, N., Shelton, E. R., and Brutlag, D. L. (1983) DNA topoisomerase II from Drosophila melanogaster. Relaxation of supercoiled DNA, J Biol Chem 258, 9536-9543. 


\section{S5. Virtual screening}

The Small Molecule Drug Discovery Suite 2016-1 (Schrödinger LLC)[1] was used for docking calculations. Human Topoll enzyme (PBDid: 4FM9, $2.9 \AA$ resolution)[2] was prepared for docking calculation by using Protein Preparation Wizard routine embedded in the Schrödinger suite. Side-chain orientation and protonation states were assigned at pH 7 using PROPKA[3] in Epik v3.5. Small molecules were drawn with Maestro v10.5 and their protonation states assigned at pH $7.0 \pm 2$ in Epik. Conformers were assigned using LigPrep with the OPLS force field v3.[4] Docking was performed as follows: i) side chain rotamers in metal-centered Topoll-a active site were optimized with induced-fit docking,[5] ii) the Standard Precision[6] scoring function was used for the first docking stage followed by an iii) additional refinement run now using a more accurate XP[7] function. Next, iv) small molecules were docked into Topoll-alpha metal-core allowing for small molecule flexibility while keeping the protein rigid to obtain a maximum of 10 optimal binding poses. Along the whole process, a fixed docking-box $(7 \times 7 \times 9 \AA 3)$ centered on the Topoll binding site was considered for computations. Glide XP scoring function was employed, and the strain energy was included in the final docking score. Planarity of aromatic groups was enforced. Top-10 poses were then rescored with the MM/GBSA protocol to allow side chain relaxation around the small molecule, using the VSGB solvent model.[8] Final binding poses were selected based on a combination of visual inspection, chemical intuition, and score.

\section{References}

1. Small-Molecule Drug Discovery Suite 2016-1: Maestro, version 10.5, LigPrep, version 3.7; Epik, version 3.5; Glide version 7.0; Prime version 4.3 (Schrödinger LLC, New York, NY, 2016).

2. T. J. Wendorff, B. H. Schmidt, P. Heslop, C. A. Austin, J.M. Berger, J. Mol. Biol., 2012, 109-124

3. M.H. Olsson, C.R. Sondergaard, M. Rostkowski, J.H. Jensen, J. Chem. Theory. Comput., 2011, 7, 525-537.

4. E. Harder, W. Damm, J. Maple, C. Wu, M. Reboul, J.Y. Xiang, L. Wang, D. Lupyan, M.K Dahlgren, J.L. Knight, J.W. Kaus, D.S. Cerutti, G. Krilov, W. L. Jorgensen, R. Abel, R. A. Friesner, J. Chem. Theory Comput., 2016, 12, 281-296.

5. W. Sherman, T. Day, M. P. Jacobson, R. A. Friesner, R. Farid, J. Med. Chem., 2006, 49, 534-553.

6. R. A. Friesner, J. L. Banks, R. B. Murphy, T. A. Halgren, J. J. Klicic, D. T. Mainz, M. P. Repasky, E. H. Knoll, M. Shelley, J. K. Perry, D. E. Shaw, P. Francis, P. S. Shenkin, J. Med. Chem., 2004, 47, 1739-1749.

7. R. A. Friesner, R. B. Murphy, M. P. Repasky, L. L. Frye, J. R. Greenwood, T. A. Halgren, P. C. Sanschagrin, D. T. Mainz, J. Med. Chem., 2006, 49, 6177-6196.

8. J. Li, R. Abel, K. Zhu, Y. Cao, S. Zhao, R. A. Friesner, Proteins, 2011, 79, 2794-2812.

\section{S.6 Docking calculations}

Our virtual screening campaign led to the identification of hit compound 1. The virtual screening, which docked a library of molecules into a human topoisomerase lla (topoll), suggested that compound 1 could bind stably to the cleaved complex. To compare this binding mode with one of our lead compound 14 (ARN-21934), we used rigid-receptor docking calculations, starting from the PDB entry 5GWK (poisoned cleavage complex bound to the drug etoposide ${ }^{1}$ ). Our simulations indicate that both compounds display a nearly identical configuration when bound to the cleavage site of topoll (Figure S6). In this conformation, the ligands form a salt-bridge network between their cationic amino group and the anionic backbone of the DNA and stack their $\pi$-conjugated rings onto the nitrogenous bases of DNA (Figure S7A). Indeed, our docking simulations show that the protonated amine in ARN-21934 can form two simultaneous salt bridges with the cleaved backbone of $C_{-1}$ and $T_{+1}$. The poisoned complex is further stabilized by the $\pi$-stacking of the ligands' aromatic systems with the nitrogenous bases of $\mathrm{C}_{-1}$ and $\mathrm{G}^{\prime}+3$. Lastly, the binding is also promoted by favorable van der Waals (dispersive) interactions with Arg487, Gly760, Met762, and Met766.

Based on our experimental results, we opted for studying alternative, potentially complementary binding modes. We considered another mechanism commonly exploited by known inhibitors, i.e., ATP competitive binding at the N-terminal of the enzyme. ${ }^{2}$ The ATP gate of topoll was modeled starting from the PDB entry 1ZXM, where the binding site is occupied by phosphoaminophosphonic acidadenylate ester, a non-hydrolyzable analog of ATP. ${ }^{3}$ Importantly, topoll contains an Mg (II) ion at the ATP binding site that stabilizes 
the ATP (and eventually ADP) in the pocket. To account for a transiently inactive form of the enzyme, we considered the receptor in the presence (Figure S7B) and the absence (Figure S7C) of the metallic cofactor.

Our calculations on the N-terminal indicate that ARN-21934 can fit the ATP in different ways according to the presence/absence of the cofactor, each mode being stabilized by specific interactions. In detail, when inhibitor ARN21934 binds to the ATPase domain in the presence of Mg (II) (Figure S7B), the pyridyl group forms a m-cation interaction with the metal and an H-bond with Gly164, while a weaker, aromatic $\mathrm{H}$-bond bridges the $\mathrm{N}, \mathrm{N}$-dimethylaniline substituent with the backbone of Asp94. In this scenario, the positive charge of the ligand is partly neutralized by vicinal electronegative atoms from Asn95 and Thr215. Interestingly, if the metallic cofactor is absent (Figure S7C), the N, N-dimethylaniline substituent forms a m-cation pair with Arg98 at the same time as it attracts Asp94 and Ser149 through weaker $\mathrm{H}$-bond interactions. In this alternative binding mode, the charged amino group forms two $\mathrm{H}$-bonds with Asn91 and Asn120 residues. In sum, docking calculations on the DNA cleaved complex and the ATP binding site suggest that the lead compound ARN-21934 could inhibit the action of topoll by multiple, complementary binding modes enabled at different stages of the enzyme's catalytic cycle.

Methods. The native ligand was removed from all the crystal structures. The receptors were prepared with the Protein Preparation Wizard ${ }^{4}$ routine embedded in Maestro-v11.8. ${ }^{5}$ Missing sidechains and loops were completed with Prime-v5.4, ${ }^{6}$ the protonation state of the amino acids was determined with PROPKA ${ }^{7}$ at a $\mathrm{pH}$ range of $7.0 \pm 2.0$, and the receptor was minimized using the OPLS3 force field. ${ }^{8}$ In parallel, the hit compound 1 and ARN-21934 was processed with Epik-v4.6, generating all possible tautomers and ionization states at a pH of $7.0 \pm 2.0 .^{9}$ We then docked the different protonation states of the ligands into the receptor using Glide-v8.1. ${ }^{10-12}$ In the docking setup, we i) employed the extra precision (XP) scoring function, ii) rewarded the planarity of conjugated $\pi$ groups, iii) sampled nitrogen inversions, iv) added an energy term to account for aromatic hydrogen bonds (H-bonds), and v) wrote out a maximum of 15 poses. All other parameters were set to their default values.

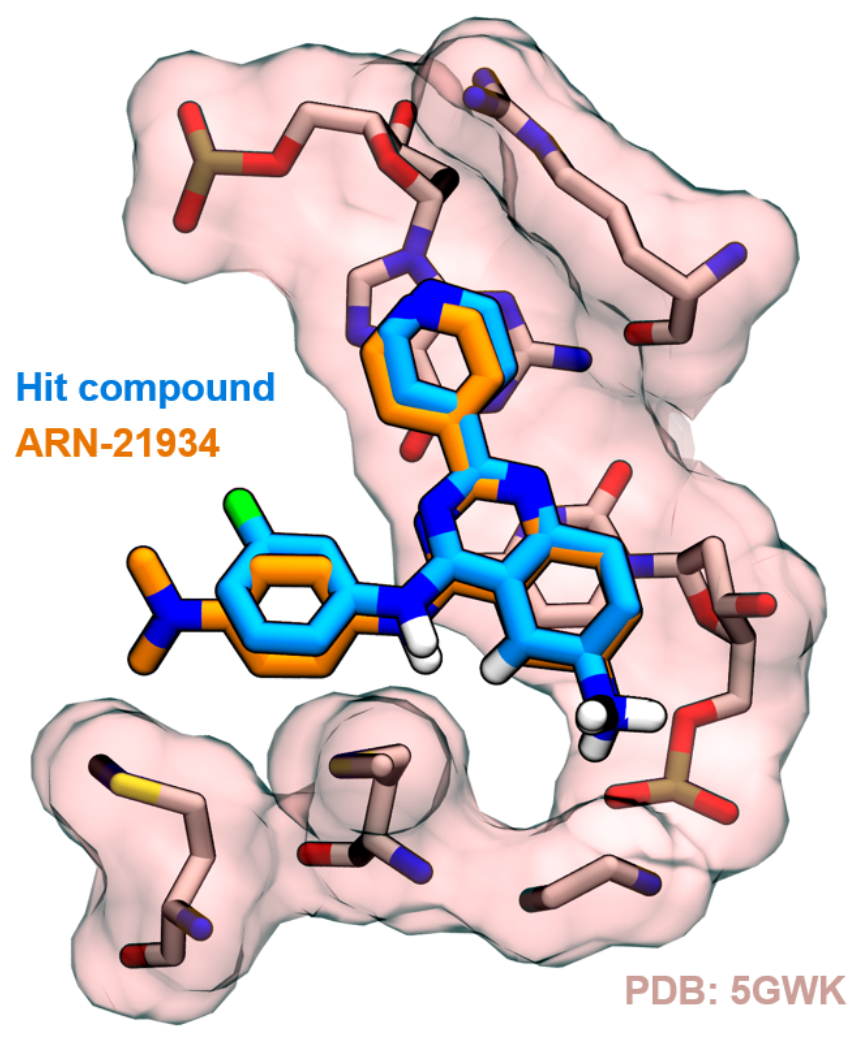

Figure S6. Superposition of the hit compound 1 (blue) and the lead compound ARN-21934 (orange) when bound to the cleaved complex of human topoisomerase Ila. Both molecules display nearly identical binding modes stabilized by m-stacking interactions with nitrogenous bases and an $\mathrm{H}$-bond network with the backbone of the cleaved DNA. The receptor's (i.e., protein and DNA) carbons are shown in light pink. 


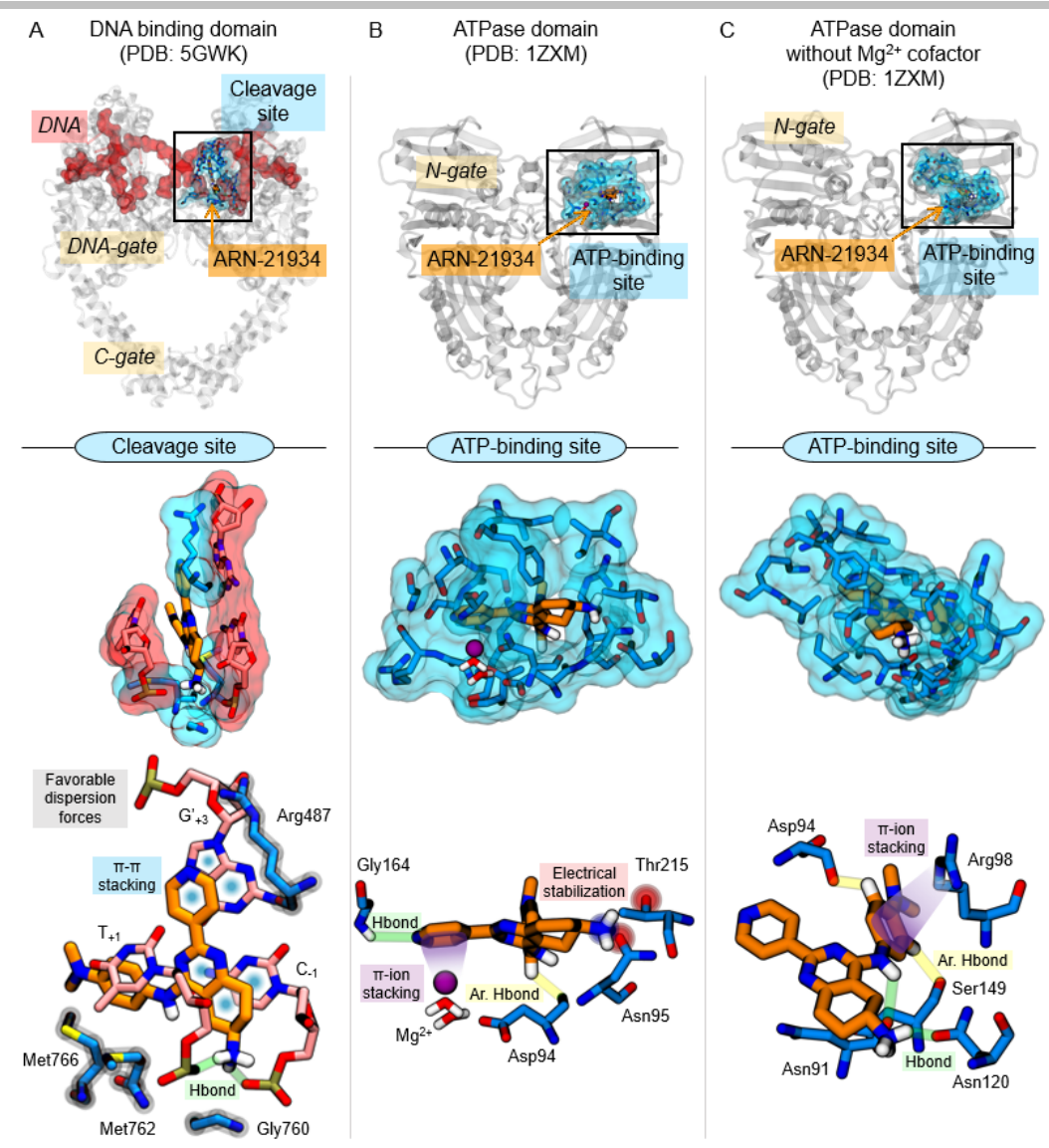

Figure S7. Binding modes from docking calculations for ARN-21034 into topoll. A) The inhibitor bound to the DNA cleaved complex through $\mathrm{H}$-bonds with the backbone of $\mathrm{C}_{-1}$ and $\mathrm{T}_{+1}$ and $\pi$-stacking interactions with the nitrogenous bases of $\mathrm{C}_{-1}$ and $\mathrm{G}_{+3}$. $\mathrm{B}$ ) The inhibitor in the ATP binding site of the ATP gate in the presence of $\mathrm{Mg}$ (II). The binding is stabilized by $\pi$-ion interactions with the metal cofactor, H-bonds with Gly164/Asp94, and electrostatic pairing with Asn95/Thr215. C) The inhibitor in the ATP binding site when the metallic cofactor is absent. In this case, the binding is favored by a $\pi$-ion pairing with Arg98 and $\mathrm{H}$-bonds with Asn91/Asp94/Asn120/Ser149. The protein is colored in cyan, DNA in red, the magnesium cofactor in purple, and ARN-21934 in orange.

(1) Wang, Y. R.; Chen, S. F.; Wu, C. C.; Liao, Y. W.; Lin, T. S.; Liu, K. T.; Chen, Y. S.; Li, T. K.; Chien, T. C.; Chan, N. L. Producing Irreversible Topoisomerase II-Mediated DNA Breaks by Site-Specific Pt(II)-Methionine Coordination Chemistry. Nucleic Acids Res. 2017, 45 (18), 10861-10871. https://doi.org/10.1093/nar/gkx742.

(2) Nitiss, J. L. Targeting DNA Topoisomerase II in Cancer Chemotherapy. https://doi.org/10.1038/nrc2607.

(3) Wei, H.; Ruthenburg, A. J.; Bechis, S. K.; Verdine, G. L. Nucleotide-Dependent Domain Movement in the ATPase Domain of a Human Type IIA DNA Topoisomerase. J. Biol. Chem. 2005, 280 (44), 37041-37047. https://doi.org/10.1074/jbc.M506520200.

(4) Madhavi Sastry, G.; Adzhigirey, M.; Day, T.; Annabhimoju, R.; Sherman, W. Protein and Ligand Preparation: Parameters, Protocols, and Influence on Virtual Screening Enrichments. J. Comput. Aided. Mol. Des. 2013, 27 (3), 221-234. https://doi.org/10.1007/s10822-013-9644-8.

(5) Maestro. Maestro. Schrödinger, LLC: New York, NY 2018.

(6) Jacobson, M. P.; Pincus, D. L.; Rapp, C. S.; Day, T. J. F.; Honig, B.; Shaw, D. E.; Friesner, R. A. A Hierarchical Approach to AllAtom Protein Loop Prediction. Proteins Struct. Funct. Genet. 2004, 55 (2), 351-367. https://doi.org/10.1002/prot.10613.

(7) Olsson, M. H. M.; SØndergaard, C. R.; Rostkowski, M.; Jensen, J. H. PROPKA3: Consistent Treatment of Internal and Surface Residues in Empirical p K a Predictions. J. Chem. Theory Comput. 2011, 7 (2), 525-537. https://doi.org/10.1021/ct100578z.

(8) Harder, E.; Damm, W.; Maple, J.; Wu, C.; Reboul, M.; Xiang, J. Y.; Wang, L.; Lupyan, D.; Dahlgren, M. K.; Knight, J. L.; Kaus, J. W.; Cerutti, D. S.; Krilov, G.; Jorgensen, W. L.; Abel, R.; Friesner, R. A. OPLS3: A Force Field Providing Broad Coverage of Drug-like Small Molecules and Proteins. J. Chem. Theory Comput. 2016, 12 (1), 281-296. https://doi.org/10.1021/acs.jctc.5b00864.

(9) Greenwood, J. R.; Calkins, D.; Sullivan, A. P.; Shelley, J. C. Towards the Comprehensive, Rapid, and Accurate Prediction of the Favorable Tautomeric States of Drug-like Molecules in Aqueous Solution. Journal of Computer-Aided Molecular Design. June 2010, pp 591-604. https://doi.org/10.1007/s10822-010-9349-1. 
(10) Friesner, R. A.; Banks, J. L.; Murphy, R. B.; Halgren, T. A.; Klicic, J. J.; Mainz, D. T.; Repasky, M. P.; Knoll, E. H.; Shelley, M.; Perry, J. K.; Shaw, D. E.; Francis, P.; Shenkin, P. S. Glide: A New Approach for Rapid, Accurate Docking and Scoring. 1. Method and Assessment of Docking Accuracy. J. Med. Chem. 2004, 47 (7), 1739-1749. https://doi.org/10.1021/jm0306430.

(11) Halgren, T. A.; Murphy, R. B.; Friesner, R. A.; Beard, H. S.; Frye, L. L.; Pollard, W. T.; Banks, J. L. Glide: A New Approach for Rapid, Accurate Docking and Scoring. 2. Enrichment Factors in Database Screening. J. Med. Chem. 2004, 47 (7), $1750-1759$. https://doi.org/10.1021/jm030644s.

(12) Friesner, R. A.; Murphy, R. B.; Repasky, M. P.; Frye, L. L.; Greenwood, J. R.; Halgren, T. A.; Sanschagrin, P. C.; Mainz, D. T. Extra Precision Glide: Docking and Scoring Incorporating a Model of Hydrophobic Enclosure for Protein-Ligand Complexes. J. Med. Chem. 2006, 49 (21), 6177-6196. https://doi.org/10.1021/jm051256o. 


\section{S7. In vitro physicochemical and metabolic stability assay}

\section{A. Aqueous kinetic solubility assay.}

The aqueous kinetic solubility was determined from a $10 \mathrm{mM}$ DMSO stock solution of test compound in Phosphate Buffered Saline (PBS) at $\mathrm{pH}$ 7.4. The study was performed by incubation of an aliquot of $10 \mathrm{mM}$ DMSO stock solution in PBS (pH 7.4) at a target concentration of $250 \mu \mathrm{M}(2.5 \% \mathrm{DMSO})$. The incubation was carried out under shaking at $25^{\circ} \mathrm{C}$ for $24 \mathrm{~h}$ followed by centrifugation at $21,100 \times \mathrm{g}$ for $30 \mathrm{~min}$. The supernatant was further diluted (4:1) with $\mathrm{CH}_{3} \mathrm{CN}$ and analyzed by UPLC/MS for the quantification of dissolved compound (in $\mu \mathrm{M}$ ) by UV at a specific wavelength $(215 \mathrm{~nm}$ ). The aqueous kinetic solubility (in $\mu \mathrm{M})$ was calculated by dividing the peak area of the dissolved test compound (supernatant) by the peak area of the test compound in the reference $\left(250 \mu \mathrm{M}\right.$ in $\left.\mathrm{CH}_{3} \mathrm{CN}\right)$ and further multiplied by the target concentration and dilution factor. The UPLC/MS analyses were performed on a Waters ACQUITY UPLC/MS system consisting of a single quadrupole detector (SQD) Mass Spectrometer (MS) equipped with an Electrospray lonization (ESI) interface and a Photodiode Array Detector (PDA). The PDA range was 210-400 nm. ESI in positive mode was used in the mass scan range 100-650 Da. The analyses were run on an ACQUITY UPLC BEH C18 column (50x2.1 mm ID, particle size $1.7 \mu \mathrm{m})$ with a VanGuard BEH C18 pre-column (5x2.1 mm ID, particle size $1.7 \mu \mathrm{m})$, using $10 \mathrm{mM} \mathrm{NH} \mathrm{H}_{4} \mathrm{OAc}$ in $\mathrm{H}_{2} \mathrm{O}$ at $\mathrm{pH} 5$ adjusted with $\mathrm{AcOH}(\mathrm{A})$ and $10 \mathrm{mM} \mathrm{NH}_{4} \mathrm{OAc}$ in $\mathrm{ACN}-\mathrm{H}_{2} \mathrm{O}(95: 5)$ at $\mathrm{pH} 5$ (B) as mobile phase. Values are reported as mean values of $\geq 2$ experiments performed.

\section{B. In vitro mouse plasma stability study.}

Freshly prepared $10 \mathrm{mM}$ DMSO stock solution of test compound was diluted 50 -fold with $\mathrm{DMSO}-\mathrm{H}_{2} \mathrm{O}(1: 1)$ and incubated at $37^{\circ} \mathrm{C}$ for $2 \mathrm{~h}$ with mouse plasma added $5 \% \mathrm{DMSO}$ (pre-heated at $37^{\circ} \mathrm{C}$ for $10 \mathrm{~min}$ ). The final concentration was $2 \mu \mathrm{M}$. At each time point $(0,5$, $15,30,60,120 \mathrm{~min}$ ), $50 \mu \mathrm{L}$ of incubation mixture was diluted with $150 \mu \mathrm{L}$ of cold $\mathrm{CH}_{3} \mathrm{CN}$ spiked with $200 \mathrm{nM}$ of internal standard, followed by centrifugation at $3,300 \times \mathrm{g}$ for $20 \mathrm{~min}$. The supernatant was further diluted with $\mathrm{H}_{2} \mathrm{O}(1: 1)$ for analysis. The concentration of test compound was quantified by LC/MS-MS on a Waters ACQUITY UPLC/MS TQD system consisting of a TQD (triple quadrupole detector) MS equipped with an ESI interface. The analyses were run on an ACQUITY UPLC BEH C18 (50 x $2.1 \mathrm{~mm}$ ID, particle size $1.7 \mu \mathrm{m})$ with a VanGuard BEH C18 pre-column $(5 \times 2.1 \mathrm{~mm} \mathrm{ID}$, particle size $1.7 \mu \mathrm{m})$ at $40^{\circ} \mathrm{C}$. For each compound the appropriate mobile phase was chosen. ESI was applied in positive mode. Compound-dependent parameters as MRM transitions and collision energy were developed for each compound. The percentage of test compound remaining at each time point relative to $t=0$ was calculated by the response factor on the basis of the internal standard peak area. The percentage of test compound versus time was plotted and fitted by GraphPad Prism (GraphPad Software, Version 5 for Windows, CA, USA, www.graphpad.com) to estimate the compounds half-life $\left(t_{1} / 2\right)$ which was reported as mean value along with the standard deviationof at least two independent experiments, performed in two technical replicates.

\section{In vitro mouse microsomal stability study.}

Freshly prepared $10 \mathrm{mM}$ DMSO stock solution of test compound was pre-incubated at $37^{\circ} \mathrm{C}$ for 15 min with mouse liver microsomes added $0.1 \mathrm{M}$ Tris- $\mathrm{HCl}$ buffer $(\mathrm{pH} 7.4)$ with $10 \% \mathrm{DMSO}$. The final concentration was $4.6 \mu \mathrm{M}$. After pre-incubation, the cofactors (NADPH, $\mathrm{G} 6 \mathrm{P}, \mathrm{G} 6 \mathrm{PDH}$ and $\mathrm{MgCl}_{2}$ pre-dissolved in $0.1 \mathrm{M}$ Tris- $\mathrm{HCl}$ ) were added to the incubation mixture and the incubation was continued at $37^{\circ} \mathrm{C}$ for $1 \mathrm{~h}$. At each time point $(0,5,15,30,60 \mathrm{~min}), 30 \mu \mathrm{L}$ of incubation mixture was diluted with $200 \mu \mathrm{L}$ of cold $\mathrm{CH}_{3} \mathrm{CN}$ spiked with $200 \mathrm{nM}$ of internal standard, followed by centrifugation at 3,300 x g for $15 \mathrm{~min}$. The supernatant was further diluted with $\mathrm{H}_{2} \mathrm{O}(1: 1)$ for analysis. The concentration of test compound was quantified by LC/MS-MS on a Waters ACQUITY UPLC/MS TQD system consisting of a TQD (triple quadrupole detector) MS equipped with an ESI interface. The analyses were run on an ACQUITY UPLC BEH C18 (50 x $2.1 \mathrm{~mm}$ ID, particle size $1.7 \mu \mathrm{m})$ with a VanGuard BEH C18 pre-column (5 x $2.1 \mathrm{~mm}$ ID, particle size $1.7 \mu \mathrm{m})$ at $40{ }^{\circ} \mathrm{C}$. For each compound the appropriate mobile phase was chosen. ESI was applied in positive mode. Compound-dependent parameters as MRM transitions and collision energy were developed for each compound. The percentage of test compound remaining at each time point relative to $t=0$ was calculated by the response factor on the basis of the internal standard peak area. The percentage of test compound versus time was plotted and fitted by GraphPad Prism (GraphPad Software, Version 5 for Windows, CA, USA, www.graphpad.com) 
to estimate the compounds half-life $(\mathrm{t} / \mathrm{t} / 2)$ which was reported as mean value along with the standard deviation of at least two independent experiments, performed in two technical replicates.

\section{Accurate Mass Measurements}

Accurate mass measurements were performed on a Waters Synapt G2 Q-ToF Mass Spectrometer equipped with an Electrospray Ionization interface and coupled to a Waters ACQUITY UPLC. Leucine Enkephalin $(2 \mathrm{ng} / \mathrm{mL})$ was used as lock mass reference compound for spectral recalibration. The analyses were run on an ACQUITY UPLC BEH C18 column (50x2.1mmID, particle size $1.7 \mu \mathrm{m})$, using $\mathrm{H} 2 \mathrm{O}+0.1 \% \mathrm{HCOOH}(\mathrm{A})$ and $\mathrm{CH} 3 \mathrm{CN}+0.1 \% \mathrm{HCOOH}$ as mobile phase.

Table S4. In vitro physicochemical and metabolic stability assays.

\begin{tabular}{llllll}
\hline Compound & 1 & 5 & 10 & 11 & 14 \\
\hline Kinetic aqueous solubility $(\mu \mathrm{M})$ & $126 \pm 8$ & $240 \pm 13$ & $>250$ & $>250$ & $>250$ \\
Mouse plasma stability $(\mathrm{t} 1 / 2 \mathrm{~min})$ & $>120$ & $>120$ & $>120$ & $>120$ & $>120$ \\
Mouse micros. stability $\left(\mathrm{t} 1 \frac{1}{2} \mathrm{~min}\right)$ & $>60$ & n.a. & n.a. & n.a. & $>60$ \\
\hline
\end{tabular}

n.a. data not available 


\section{S8. Off target Activity performed at Eurofin (Safety47TM Panel)}

Results: Test Compound(s)

\begin{tabular}{|c|c|c|c|c|}
\hline \multirow{2}{*}{$\begin{array}{l}\text { DiscoverX Gene } \\
\text { Symbol }\end{array}$} & \multirow{2}{*}{ Assay Mode } & \multicolumn{3}{|c|}{ ARN21934 } \\
\hline & & \multicolumn{3}{|c|}{$\begin{array}{c}2 \mu \mathrm{M} \\
\text { \% Response }\end{array}$} \\
\hline GPCRs & & Roplicate 1 & Replicate 2 & Average \\
\hline ADORA2A & Agonist & 0.0 & 0.0 & 0.0 \\
\hline ADORA2A & Antagonist & 0.0 & 0.0 & 0.0 \\
\hline ADRATA & Agonist & 0.0 & 0.0 & 0.0 \\
\hline ADRA1A & Antagonist & 0.0 & 0.0 & 0.0 \\
\hline ADRA2A & Agonist & 5.7 & 4.9 & 5.3 \\
\hline ADRA2A & Antagonist & 0.0 & 0.0 & 0.0 \\
\hline ADRB1 & Agonist & 0.0 & 3.0 & 1.5 \\
\hline ADRB1 & Antagonist & 0.0 & 0.0 & 0.0 \\
\hline ADRB2 & Agonist & 1.5 & 0.0 & 0.8 \\
\hline ADRB2 & Antagonist & 0.0 & 0.0 & 0.0 \\
\hline AVPR1A & Agonist & 0.0 & 1.9 & 1.0 \\
\hline AVPR1A & Antagonist & 0.0 & 0.0 & 0.0 \\
\hline CCKAR & Agonist & 0.0 & 0.0 & 0.0 \\
\hline CCKAR & Antagonist & 0.0 & 0.0 & 0.0 \\
\hline CHRMI & Agonist & 0.3 & 0.1 & 0.2 \\
\hline CHRM1 & Antagonist & 0.0 & 0.0 & 0.0 \\
\hline CHRM2 & Agonist & 2.6 & 0.0 & 1.3 \\
\hline CHRM2 & Antagonist & 0.0 & 0.0 & 0.0 \\
\hline CHRM3 & Agonist & 0.0 & 0.2 & 0.1 \\
\hline CHRM3 & Antagonist & 0.0 & 0.0 & 0.0 \\
\hline CNR1 & Agonist & 3.2 & 0.0 & 1.6 \\
\hline CNR1 & Antagonist & 15.4 & 0.0 & 7.7 \\
\hline CNR2 & Agonist & 6.2 & 9.6 & 7.9 \\
\hline CNR2 & Antagonist & 10.1 & 0.0 & 5.0 \\
\hline DRD1 & Agonist & 1.0 & 0.2 & 0.6 \\
\hline DRD1 & Antagonist & 3.4 & 0.0 & 1.7 \\
\hline DRD2S & Agonist & 0.0 & 0.0 & 0.0 \\
\hline DRD2S & Antagonist & 1.7 & 0.0 & 0.8 \\
\hline EDNRA & Agonist & 0.0 & 0.8 & 0.4 \\
\hline EDNRA & Antagonist & 0.0 & 0.0 & 0.0 \\
\hline HRH1 & Agonist & 0.0 & 0.0 & 0.0 \\
\hline HRH1 & Antagonist & 0.0 & 0.0 & 0.0 \\
\hline HRH2 & Agonist & 0.0 & 0.2 & 0.1 \\
\hline HRH2 & Antagonist & 3.4 & 0.0 & 1.7 \\
\hline HTRTA & Agonist & 1.5 & 0.0 & 0.8 \\
\hline HTR1A & Antagonist & 18.2 & 10.4 & 14.3 \\
\hline HTR1B & Agonist & 0.0 & 0.0 & 0.0 \\
\hline HTR1B & Antagonist & 0.0 & 0.0 & 0.0 \\
\hline HTR2A & Agonist & 0.0 & 0.0 & 0.0 \\
\hline HTR2A & Antagonist & 0.0 & 0.0 & 0.0 \\
\hline HTR2B & Agonist & 0.3 & 0.0 & 0.1 \\
\hline HTR2B & Antagonist & 0.0 & 0.0 & 0.0 \\
\hline OPRD1 & Agonist & 0.0 & 0.2 & 0.1 \\
\hline OPRD1 & Antagonist & 0.0 & 0.0 & 0.0 \\
\hline OPRK1 & Agonist & 0.0 & 2.0 & 1.0 \\
\hline OPRK1 & Antagonist & 0.0 & 3.9 & 2.0 \\
\hline OPRM1 & Agonist & 2.2 & 4.2 & 3.2 \\
\hline OPRM1 & Antagonist & 0.0 & 0.0 & 0.0 \\
\hline
\end{tabular}

Results: Test Compound(s) (cont.)

\begin{tabular}{|c|c|c|c|c|}
\hline \multirow{3}{*}{$\begin{array}{l}\text { DiscoverX Gene } \\
\text { Symbol }\end{array}$} & \multirow{3}{*}{ Assay Mode } & \multicolumn{3}{|c|}{ ARN21934 } \\
\hline & & \multicolumn{3}{|c|}{$2 \mu \mathrm{M}$} \\
\hline & & \multicolumn{3}{|c|}{ \% Response } \\
\hline \multicolumn{2}{|c|}{ Nuclear Hormone Receptors } & Replicate 1 & Replicate 2 & Average \\
\hline AR & Agonist & 0.2 & 0.0 & 0.1 \\
\hline AR & Antagonist & 0.0 & 0.0 & 0.0 \\
\hline $\mathrm{GR}$ & Agonist & 0.2 & 0.0 & 0.1 \\
\hline GR & Antagonist & 0.0 & 0.0 & 0.0 \\
\hline \multicolumn{2}{|c|}{ Transporters } & $\begin{array}{l}\text { Replicate } 1 \\
\end{array}$ & Replicate 2 & Average \\
\hline DAT & Blocker & 3.2 & 0.0 & 1.6 \\
\hline NET & Blocker & 0.0 & 0.0 & 0.0 \\
\hline SERT & Blocker & 0.9 & 3.6 & 2.2 \\
\hline \multicolumn{2}{|c|}{ Ion Channels } & Replicato 1 & Replicate 2 & Average \\
\hline CAV1.2 & Blocker & 0.0 & 0.0 & 0.0 \\
\hline GABAA & Opener & 0.0 & 0.0 & 0.0 \\
\hline GABAA & Blocker & 0.0 & 0.0 & 0.0 \\
\hline hERG & Blocker & 5.5 & 5.1 & 5.3 \\
\hline HTR3A & Opener & 0.0 & 0.0 & 0.0 \\
\hline HTR3A & Blocker & 0.0 & 7.6 & 3.8 \\
\hline KvLQT1/minK & Opener & 0.0 & 0.0 & 0.0 \\
\hline KvLQT1/mink & Blocker & 0.0 & 5.5 & 2.7 \\
\hline nAChR(a4/b2) & Opener & 0.0 & 0.0 & 0.0 \\
\hline $\mathrm{nAChR(a4/b2)}$ & Blocker & 0.0 & 0.0 & 0.0 \\
\hline NAV1.5 & Blocker & 4.3 & 0.0 & 2.1 \\
\hline NMDAR (1A2B) & Opener & 0.0 & 0.0 & 0.0 \\
\hline NMDAR (1A2B) & Blocker & 0.0 & 0.0 & 0.0 \\
\hline \multicolumn{2}{|c|}{ Non-Kinase Enzymes } & \begin{tabular}{l|} 
Replicate 1 \\
\end{tabular} & Replicate 2 & Average \\
\hline AChE & Inhibitor & 7.2 & 0.0 & 3.6 \\
\hline $\operatorname{cox} 1$ & Inhibitor & 100.0 & 100.0 & 100.0 \\
\hline $\cos 2$ & Inhibitor[ & 34.2 & 35.9 & 35.1 \\
\hline MAOA & Inhibitor & 8.9 & 11.0 & 10.0 \\
\hline PDE $3 A$ & Inhibitor & 0.0 & 0.0 & 0.0 \\
\hline PDE4D2 & Inhibitor & 0.0 & 0.0 & 0.0 \\
\hline Kinases & & Replicato 1 & Replicato 2 & Average \\
\hline INSR & Inhibitor & 6.4 & 26.8 & 16.6 \\
\hline LCK & Inhibitor & 1.5 & 7.5 & 4.5 \\
\hline ROCK1 & Inhibitor & 36.2 & 21.2 & 28.7 \\
\hline VEGFR2 & Inhibitor & 0.0 & 3.9 & 2.0 \\
\hline
\end{tabular}

\begin{tabular}{c}
$\begin{array}{c}\text { \% Response Legend } \\
x>95 \%\end{array}$ \\
\hline $95 \% \leq x<90 \%$ \\
\hline $90 \% \leq x<80 \%$ \\
\hline $80 \% \leq x<70 \%$ \\
$70 \% \leq x<50 \%$ \\
\hline$x<50 \%$ \\
\hline
\end{tabular}

No relevant activity vs all the unwanted targets (NOTE no activity vs the hERG channel), in this pane; the $\mathrm{IC}_{50}$ against $\mathrm{Cox}-1$ has been measured and reported below.

Figure 2: Summary of Percent Response for compound(s) tested in Safety47 Panel

Results: Test Compound(s)

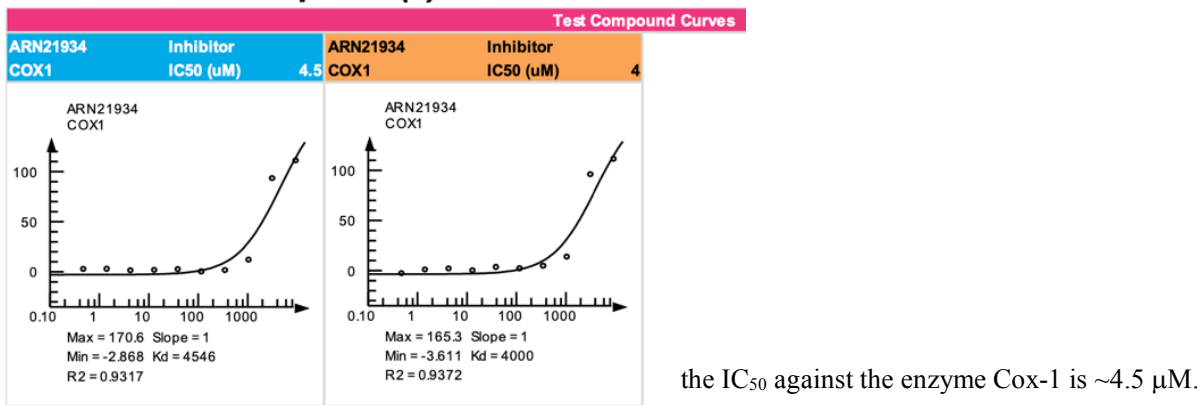

\section{Results: Summary Table}

\begin{tabular}{|c|c|c|c|c|c|c|c|c|c|c|c|c|c|}
\hline Compound Name & Target Class & Assay Name & Mode & Assay Target & ResultType & ValuePrefix & RC50(uM) & Hill & Curve Bottom & Curve Top & MaxResponse & Compound Type \\
\hline ARN21934 & Non-Kinase Enzymes & Enzymatic & Inhibitor & COX1 & IC50 & & 4.5 & 1 & -2.8685 & 170.55 & 109.91 & Test \\
\hline ARN21934 & Non-Kinase Enzymes & Enzymatic & Inhibitor & COX1 & IC50 & & 4 & 1 & -3.611 & 165.29 & 110.23 & Test \\
\hline Indomethacin & Non-Kinase Enzymes & Enzymatic & Inhibitor & COX1 & IC50 & & 0.051 & 1.0 & -6.3 & 105.7 & 102.4 & Control \\
\hline
\end{tabular}




\section{S9. Pharmacokinetic studies}

C57B6/J male mice, 8 weeks old were used (Charles River, Calco). All procedures were performed in accordance with the Ethical Guidelines of European Communities Council (Directive 2010/63/EU of 22 September 2010) and accepted by the Italian Ministry of Health. All efforts were made to minimize animal suffering and to use the minimal number of animals required to produce reliable results, according to the "3Rs rules". Animals were group-housed in ventilated cages and had free access to food and water. They were maintained under a 12-hour light/dark cycle (lights on at $8: 00 \mathrm{am}$ ) at controlled temperature $\left(21^{\circ} \mathrm{C} \pm 1^{\circ} \mathrm{C}\right)$ and relative humidity $(55 \% \pm 10 \%)$.

The compound was administered by a single intraperitoneal injection (i.p.) at $10 \mathrm{mg} / \mathrm{kg}$ dose. Vehicle was: PEG400/Tween $80 / \mathrm{Saline}$ solution (10/10/80 \% in volume respectively). Three animals per dose were treated. Blood samples at $0,15,30,60,120,240$, and 360 min after administration were collected. Plasma was separated from blood by centrifugation for 15 min at $3500 \mathrm{rpm}$ a $4^{\circ} \mathrm{C}$, collected in a eppendorf tube and frozen $\left(-80^{\circ} \mathrm{C}\right)$. Brain samples were homogenized in RIPA buffer $(150 \mathrm{mM} \mathrm{NaCl}, 1.0 \%$ Triton X-100, 0.5\% sodium deoxycholate, $0.1 \%$ sodium dodecyl sulfate, $50 \mathrm{mM}$ Tris, $\mathrm{pH} 8.0$ )and were then split in two aliquots kept at $-80^{\circ} \mathrm{C}$ until analysis. An aliquot was used for compound brain level evaluations, following the same procedure described below for plasma samples. The second aliquot was kept for determination of protein concentration by BCA assay. Control animals treated with vehicle only were also included in the experimental protocol.

Plasma samples were centrifuged at $21.100 \mathrm{~g}$ for $15 \mathrm{~min}$ at $4^{\circ} \mathrm{C}$. A $50 \mu \mathrm{l}$ aliquot was transferred into a 96 -Deep Well plate and $150 \mu \mathrm{l}$ of extraction solution was added. The extraction solution was consisting of cold $\mathrm{CH}_{3} \mathrm{CN}$ spiked with $200 \mathrm{nM}$ of internal standard. The plate was centrifuged at $21.100 \mathrm{~g}$ for $15 \mathrm{~min}$ at $4^{\circ} \mathrm{C}$. $80 \mu \mathrm{l}$ of supernatant was then transferred into a 96-Deep Well plate and $80 \mu \mathrm{l}$ of $\mathrm{H}_{2} \mathrm{O}$ was added. A reference standard of the compound was spiked in naïve mouse plasma to prepare a calibration curve over a $1 \mathrm{nM}-10 \mu \mathrm{M}$ range. Three quality control samples were prepared by spiking the compound in blank mouse plasma to the final concentrations of 20 , 200 and 2000nM. Calibrators and quality controls were extracted with the same extraction solution used for the plasma samples. The samples were analysed on a Waters ACQUITY UPLC/MS TQD system (Waters Inc. Milford, USA) consisting of a TQD (Triple Quadrupole Detector) Mass Spectrometer equipped with an Electrospray lonization interface and a Photodiode Array e $\lambda$ Detector. The analyses were run on an ACQUITY UPLC BEH C18 $(50 \times 2.1 \mathrm{mmID}$, particle size $1.7 \mu \mathrm{m})$ with a VanGuard BEH C18 pre-column $(5 \times 2.1 \mathrm{mmID}$, particle size $1.7 \mu \mathrm{m})$ at $40^{\circ} \mathrm{C} .0 .1 \% \mathrm{HCOOH}$ in $\mathrm{H}_{2} \mathrm{O}(\mathrm{A})$ and $0.1 \% \mathrm{HCOOH}$ in $\mathrm{CH}_{3} \mathrm{CN}(\mathrm{B})$ were used as mobile phase with a linear gradient from 50 to $100 \% \mathrm{~B}$ in $2 \mathrm{~min}$. with the flow rate set to $0.5 \mathrm{~mL} / \mathrm{min}$. Electrospray ionization was applied in positive mode. Plasma levels of the parent compound was quantified by monitoring the MRM peak areas.

\section{Pharmacokinetic measurements}

Plasma and homogenized brain samples were centrifuged at $21.100 \mathrm{xg}$ for $20 \mathrm{~min}$ at $4^{\circ} \mathrm{C}$. An aliquot of each sample was extracted (1:3) with cold $\mathrm{CH}_{3} \mathrm{CN}$ containing 200nM of ARN21646 as internal standard being a close analogue of compound 14 (ARN21934). A calibration curve was prepared in both blank mouse plasma and in centrifugated naïve brain homogenate over a $1 \mathrm{nM}-10 \mu \mathrm{M}$ range. Three quality control samples were prepared by spiking the parent compound in both blank mouse plasma and centrifugated naïve brain homogenate to 20,200 and $2000 \mathrm{nM}$ as final concentrations. The calibrators and quality control samples were extracted (1:3) with the same extraction solution as the plasma and brain samples. The plasma and brain samples, calibrators and quality control samples were centrifuged at $3.270 \times \mathrm{g}$ for $15 \mathrm{~min}$ at $4^{\circ} \mathrm{C}$. The supernatants were further diluted (1:1) with $\mathrm{H}_{2} \mathrm{O}+0.1 \% \mathrm{HCOOH}+0.1 \%$ Heptafluorobutyric acid, and analyzed by LC/MS-MS on a Waters ACQUITY UPLC/MS TQD system consisting of a Triple Quadrupole Detector (TQD) Mass Spectrometer equipped with an Electrospray lonization interface and a Photodiode Array e $\lambda$ Detector. Electrospray ionization was applied in positive mode. Compound-dependent parameters as MRM transitions and collision energy were developed for the parent compound and the internal standard. The analyses were run on an ACQUITY UPLC BEH C18 (100x2.1 mmID, particle size $1.7 \mu \mathrm{m})$ with a VanGuard BEH C18 pre-column $(5 \times 2.1 \mathrm{mmID}$, particle size $1.7 \mu \mathrm{m})$ at $45^{\circ} \mathrm{C}$, using $\mathrm{H}_{2} \mathrm{O}+0.1 \% \mathrm{HCOOH}+$ $0.1 \% 0.1 \%$ Heptafluorobutyric acid $(\mathrm{A})$ and $\mathrm{CH}_{3} \mathrm{CN}+0.1 \% \mathrm{HCOOH}+0.1 \%$ Heptafluorobutyric acid $(\mathrm{B})$ as mobile phase at $0.5 \mathrm{~mL} / \mathrm{min}$. A linear gradient was applied starting at 5\%B with an initial hold for $1 \mathrm{~min}$, then 5-100 \% B in $4.5 \mathrm{~min}$, followed by a hold for 0.5 min at $100 \%$ B. All samples (plasma and brain samples, calibrators and quality controls) were quantified by MRM peak area response factor in order to determine the levels of the parent compound in both plasma and brain. The plasma concentrations and total amount of 
compound in brain versus time were plotted and the profiles were fitted using PK Solutions Excel Application (Summit Research Service, USA) in order to determine the pharmacokinetic parameters.

Table S5. Pharmacokinetic parameters. Study in mouse plasma. Strain: C57B6/J. Way of administration: I.P. Dose: $10 \mathrm{mg} / \mathrm{Kg}$

\begin{tabular}{llllll}
\hline Parameter & Value & Unit & Parameter & Value & Unit \\
\hline Cmax (obs) & 0.68 & $\mu \mathrm{g} / \mathrm{mL}$ & $\mathrm{t} 1 / 2$ (calc) & 149 & $\min$ \\
Tmax (obs) & 15 & $\min$ & VD (calc) & 24.9 & $\mathrm{~L} / \mathrm{kg}$ \\
AUC (calc) & 73.1 & $\mu \mathrm{g}-\mathrm{min} / \mathrm{mL}$ & $\mathrm{CL}$ (calc) & 0.12 & $\mathrm{~L} / \mathrm{min} / \mathrm{kg}$ \\
\hline
\end{tabular}

(obs) observed. (calc) calculated

\section{A. Plasma PK profile}

Table S6. Pharmacokinetic study in mouse plasma. Strain: C57B6/J. Route of administration: I.P. Dose: $10 \mathrm{mg} / \mathrm{Kg}$

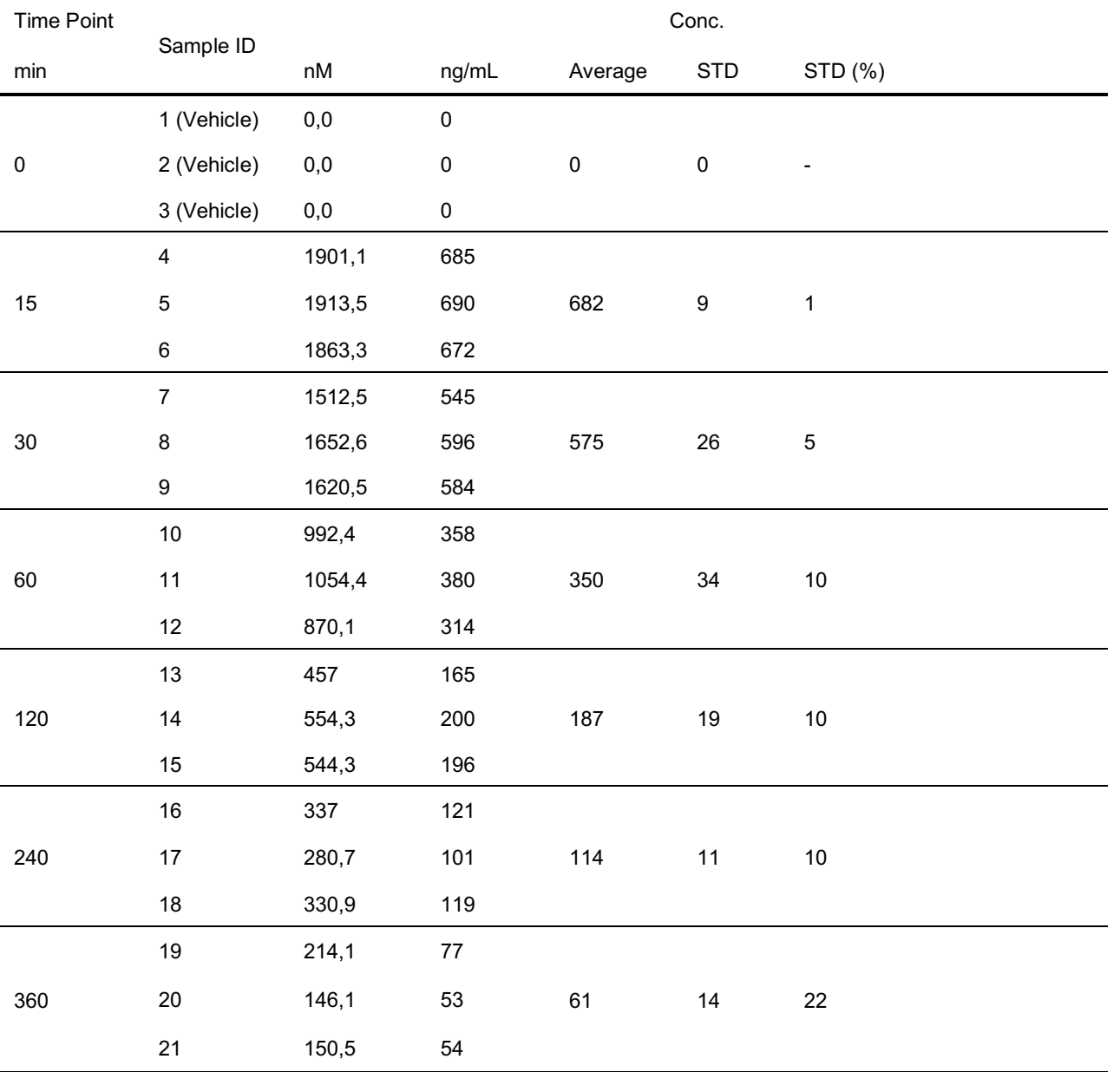




\section{Plasma}

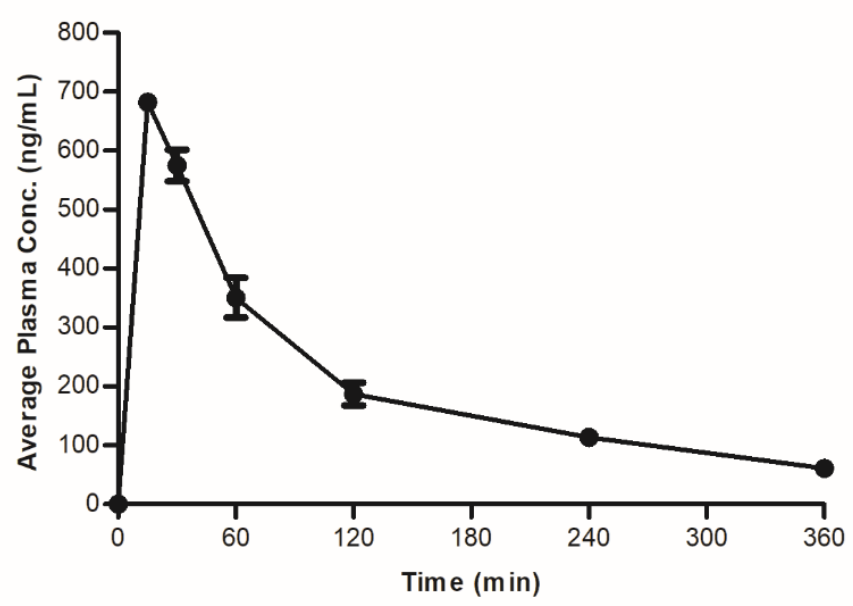

Figure S8. Pharmacokinetic profile of compound 14 (ARN21934) in mouse plasma. Strain: C57B6/J. Route of administration: I.P. Dose: $10 \mathrm{mg} / \mathrm{Kg}$

\section{B. Brain profile}

Table S7. Pharmacokinetic study in mouse Brain. Strain: C57B6/J. Route of administration: I.P. Dose: 10 $\mathrm{mg} / \mathrm{Kg}$

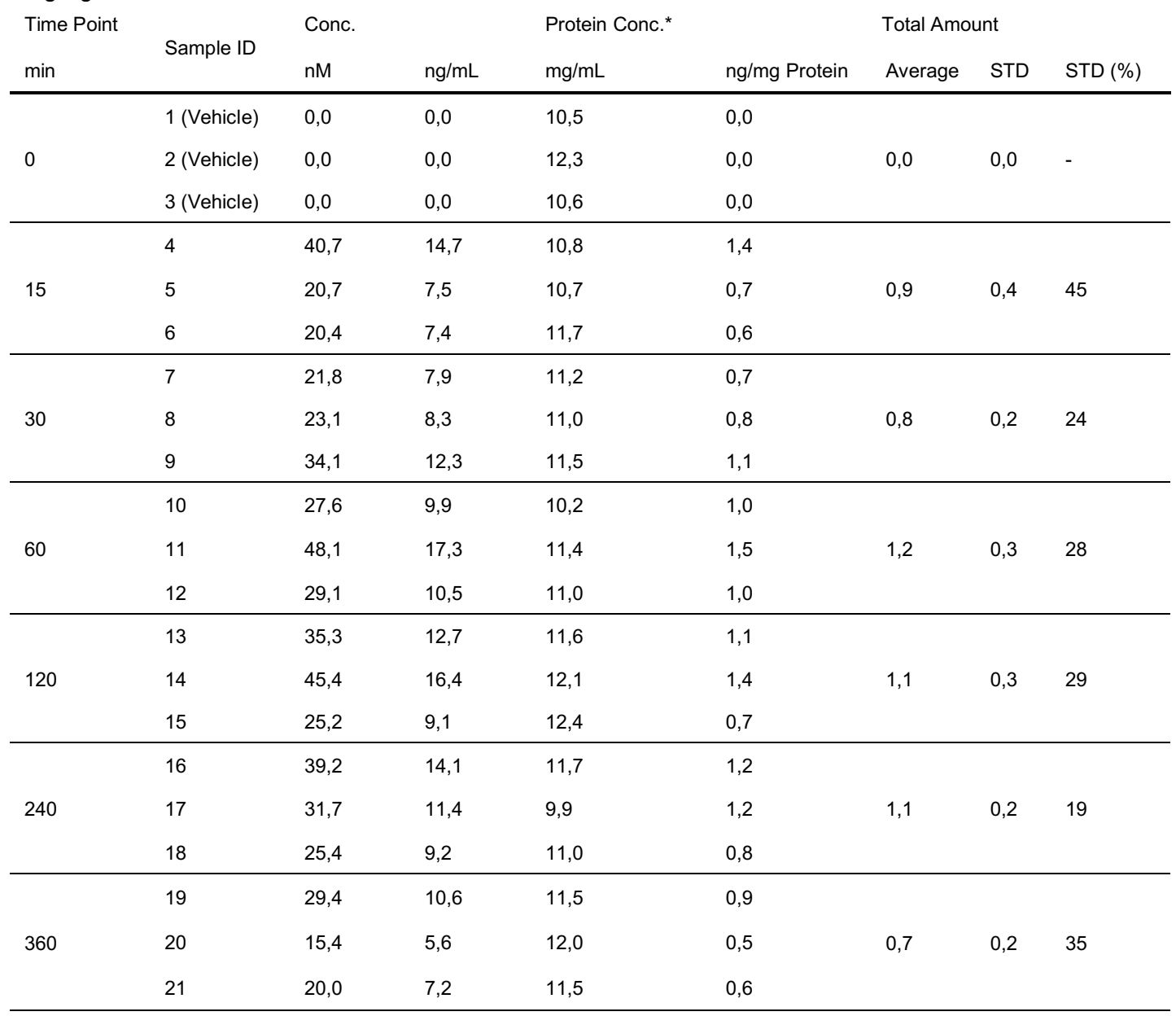

*Normalized by Protein Conc. 
P. $(10 \mathrm{mg} / \mathrm{Kg})$

Brain

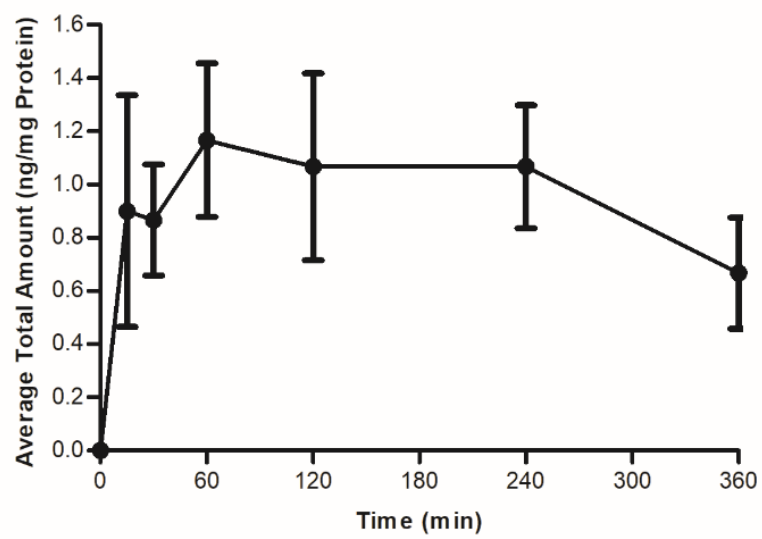

Figure S9 Pharmacokinetic profile of compound 14 (ARN21934) in mouse barin. Strain: C57B6/J. Route of administration: I.P. Dose: $10 \mathrm{mg} / \mathrm{Kg}$ 